\title{
COMBINING ECOLOGICAL AND MORAL DISENGAGEMENT \\ THEORIES: THE IMPACT OF INDIVIDUAL AND SCHOOL-LEVEL \\ PERCEPTIONS ON SELF-REPORTS OF BULLYING, VICTIMIZATION, AND WITNESSING
}

by

Christine Polihronis

(B.A. Child Studies and Psychology, Brock University, 2009)

A thesis submitted to the Faculty of Graduate and Postdoctoral Affairs in partial fulfillment of the requirements for the degree of

Master of Arts

in

Psychology

Carleton University

Ottawa, Canada

C2012 Christine Polihronis 
Library and Archives

Canada

Published Heritage

Branch

395 Wellington Street

Ottawa ON K1A ON4

Canada
Bibliothèque et

Archives Canada

Direction du

Patrimoine de l'édition

395 , rue Wellington

Ottawa ON K1A ON4

Canada
Your file Votre référence

ISBN: 978-0-494-87776-0

Our file Notre référence

ISBN: $978-0-494-87776-0$

\section{NOTICE:}

The author has granted a nonexclusive license allowing Library and Archives Canada to reproduce, publish, archive, preserve, conserve, communicate to the public by telecommunication or on the Internet, loan, distrbute and sell theses worldwide, for commercial or noncommercial purposes, in microform, paper, electronic and/or any other formats.

The author retains copyright ownership and moral rights in this thesis. Neither the thesis nor substantial extracts from it may be printed or otherwise reproduced without the author's permission.
AVIS:

L'auteur a accordé une licence non exclusive permettant à la Bibliothèque et Archives Canada de reproduire, publier, archiver, sauvegarder, conserver, transmettre au public par télécommunication ou par l'Internet, prêter, distribuer et vendre des thèses partout dans le monde, à des fins commerciales ou autres, sur support microforme, papier, électronique et/ou autres formats.

L'auteur conserve la propriété du droit d'auteur et des droits moraux qui protege cette thèse. $\mathrm{Ni}$ la thèse ni des extraits substantiels de celle-ci ne doivent être imprimés ou autrement reproduits sans son autorisation.
In compliance with the Canadian Privacy Act some supporting forms may have been removed from this thesis.

While these forms may be included in the document page count, their removal does not represent any loss of content from the thesis.
Conformément à la loi canadienne sur la protection de la vie privée, quelques formulaires secondaires ont été enlevés de cette thèse.

Bien que ces formulaires aient inclus dans la pagination, il n'y aura aucun contenu manquant. 


\begin{abstract}
Empirical studies in the bullying field have not addressed the merging theories of moral disengagement and ecological systems theory, in order to determine the risk factors associated with bullying involvement. The purpose of this study was to examine how both individual-level variables and school level factors contribute to involvement in bullying, victimization, and bystanding. Participants included 16,879 students from grade 4 - 12 across 114 schools from Southern Ontario. Students completed an online school responsibility survey containing measures of bullying involvement, school safety, adult availability, moral disengagement, and moral engagement. Prevalence rates indicated that the majority of students were witnesses of bullying, with self-reports of bullying and victimization involvement less commonly reported. The majority of variability in bullying, victimization and bystanding was accounted for by individual differences in sex, age, moral disengagement, moral engagement, adult availability, and feeling unsafe at school. Bully perpetrators were likely to score high in moral disengagement and low in moral engagement, whereas victims and bystanders were high in both moral engagement and moral disengagement. Collective perceptions of feeling unsafe at school was the only school-level variable to predict to individual involvement in bullying, victimization, and witnessing. Implications highlight the need for studying the different contexts in which children develop, as well as tailoring bullying intervention to individual schools, rather than using a one-size-fits-all approach.
\end{abstract}

Keywords: bullying as a group process, adolescence, moral disengagement, HLM, victimization, bystanders, school climate 


\section{Acknowledgements}

I would like to sincerely thank a number of people for their generous time and effort in helping complete several aspects of this project. Thank you to my thesis supervisor, Dr. Tina Daniels, for her helpful comments and suggestions when revising the document, and for her endless support with this project for the past two years. I would like to express my gratitude to Dr. Tracy Vaillancourt, for providing the dataset, and also for taking the time out of her busy schedule to attend my prospectus defense and to go over the HLM analyses. I would like to thank my committee members, Dr. Adelle Forth, Dr. Shelley Brown, and Dr. Tullio Caputo for all of their invaluable suggestions and helpful feedback during this process. I would also like to thank and acknowledge my colleagues, Danielle Quigley, Kailey Patterson, Kat Magner, and Tim Trant for the helpful feedback and support during the early morning lab meetings. Last but certainly not least, I would like to thank my friends and my parents, Angelo and Betsy Polihronis, for their words of support and help with reading over the document. 


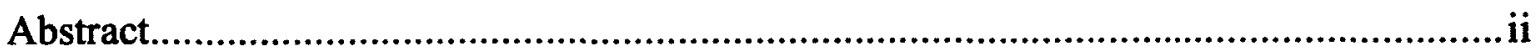

Acknowledgements .................................................................................................ii

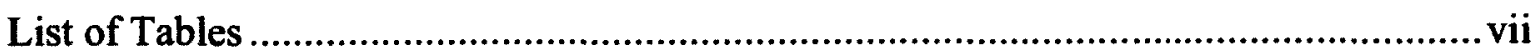

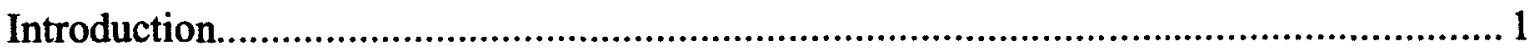

Bullying Involvement: A Serious Relationship Problem ............................................... 3

Psychosocial effects of bullying...................................................................... 3

Definition and forms of bullying................................................................. 5

Prevalence Rates of Bullying and Victimization ..........................................................6

Current issues in the field of prevalence estimation.............................................

Bullying as a Group Process ................................................................................. 13

Bullying involvement and sex differences.................................................... 15

Bullying involvement and grade differences. .............................................. 17

When Good People Do Bad Things: Moral Disengagement.......................................... 19

Mechanisms of moral disengagement. ..........................................................20

Moral disengagement and bullying involvement. ...........................................22

Measuring moral disengagement in childhood. .............................................25

Moral disengagement and the social context. ..............................................2

Ecological Factors that Predict to Bullying Involvement ...........................................28

School-level factors leading to bullying involvement......................................... 30

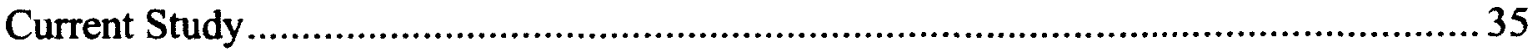

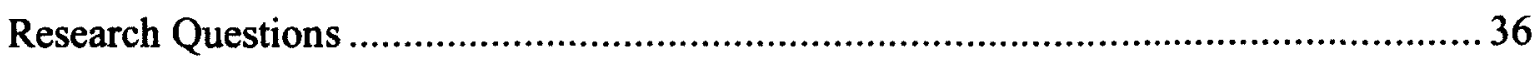

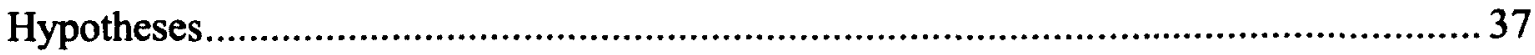




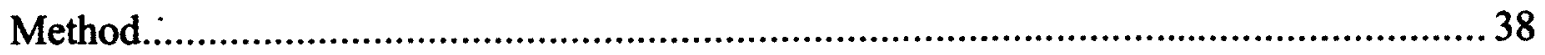

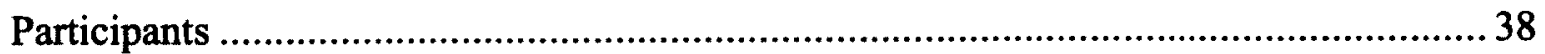

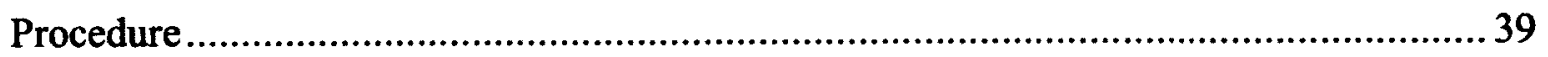

Measures

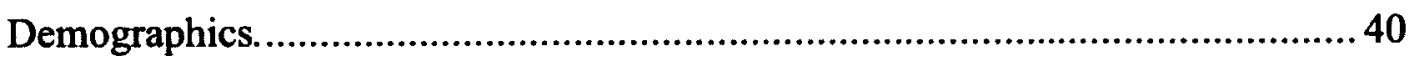

Involvement in bullying, victimization, and bystanding. ............................... 40

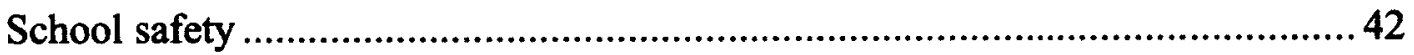

Adult availability and involvement. ............................................................... 43

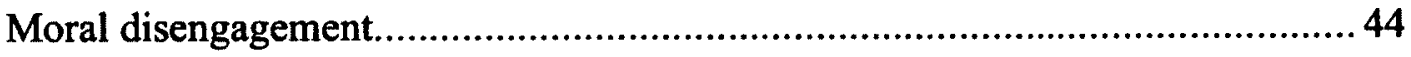

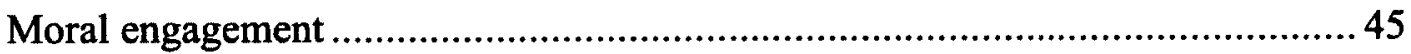

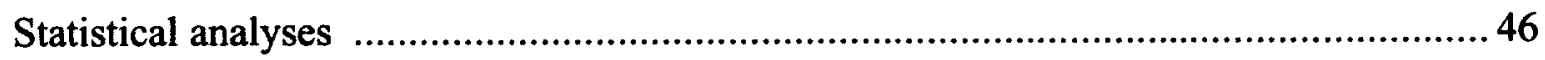

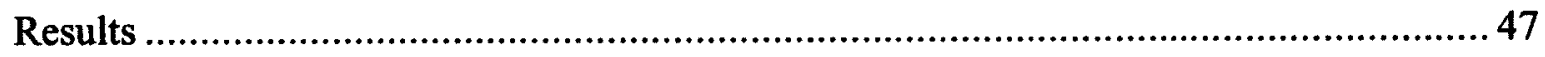

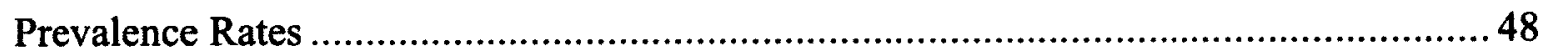

Overall bullying involvement....................................................................... 48

Physical, verbal and social bullying involvement...........................................52

Prevalence rates for feeling unsafe at school. .......................................................64 64

Mean Differences in Independent Variables by Sex and Grade .....................................66

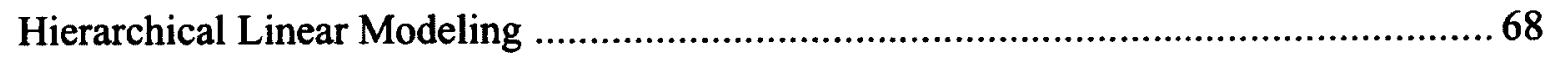

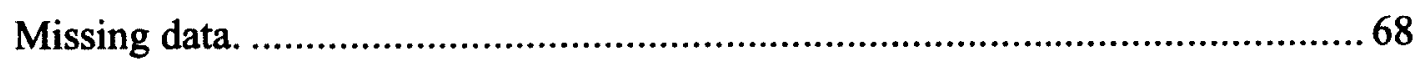

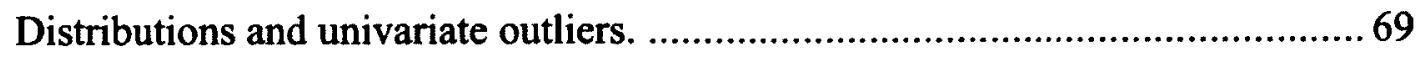

Assumptions of linearity and normality. .........................................................69

Power in multi-level studies....................................................................... 70

Correlations at Level-1 and Level-2 ............................................................. 71 
Bullying, Victimization and Witnessing Models ..................................................... 74

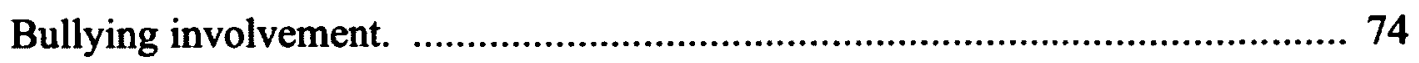

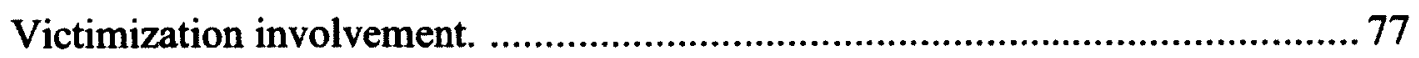

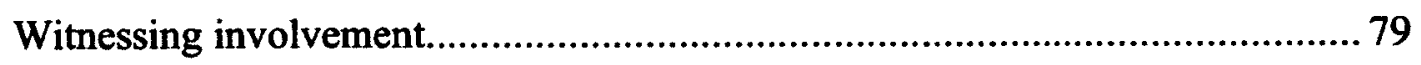

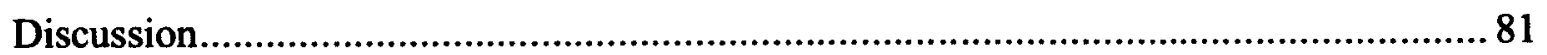

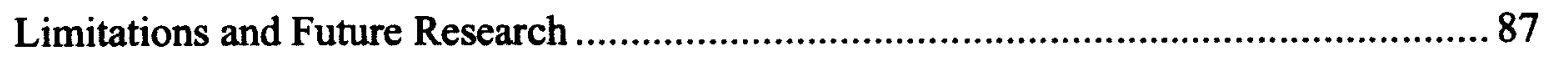

Implications for Educational Professionals and Policy Development ..............................91

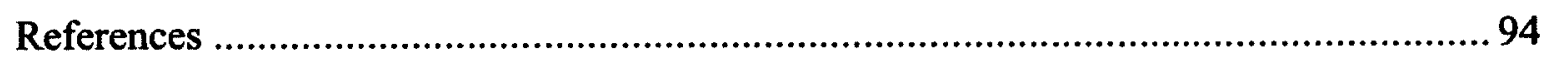

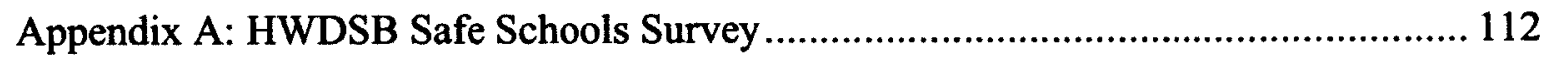




\section{List of Tables}

Table 1. Overall Percentage of Bullying Involvement For Boys and Girls 50

Table 2. Overall Percentage of Bullying Involvement For Primary and Secondary School

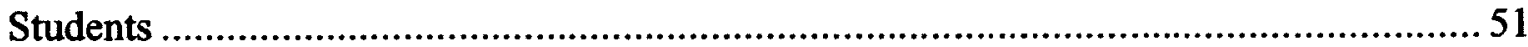

Table 3. Percentage of Physical, Verbal, and Social Bullying Involvement.................. 53

Table 4. Percentage of Bullying Involvement for Boys and Girls.......................... 55

Table 5. Sex Differences in the Percentage of Physical, Verbal, and Social Bullying.... 56

Table 6. Sex Differences in the Percentage of Physical, Verbal, and Social

Victimization

Table 7. Sex Differences in the Percentage of Physical, Verbal, and Social

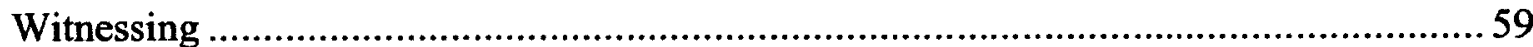

Table 8. Percentage of Bullying Involvement For Primary and Secondary Students....... 60

Table 9. Grade Differences in the Percentage of Physical, Verbal, and Social Bullying . 62

Table 10. Grade Differences in the Percentage of Physical, Verbal, and Social

Victimization

Table 11. Grade Differences in the Percentage of Physical, Verbal, and Social

Witnessing 65

Table 12. HLM Descriptives For Bullying Involvement ................................... 72

Table 13. Correlation Matrices for Variables at Level-1 and Level-2 .......................... 73

Table 14. Effects of Individual-Level and School-Level Variables on Bullying ........... 75

Table 15. Effects of Individual-Level and School-Level Variables on Victimization .... 78

Table 16. Effects of Individual-Level and School-Level Variables on Witnessing 80 
Combining Ecological and Moral Disengagement Theories: The Impact of Individual and School-Level Perceptions on Self-Reports of Bullying, Victimization, and Witnessing School administrators strive to make schools both safe and positive while promoting healthy learning environments that encourage academic and social growth for all students. The school is a predominant social setting in which students gather daily. Despite the good intentions school personnel have to ensure the safety of students, children's mental health may be compromised from experiencing bullying on a daily basis (Olweus, 1978; Rigby, 2003). Bullying is defined as an intentionally committed act that is repeated over time designed to harm a person, and involves a clear power differential between the perpetrator and victim, where the victim has difficulty defending him or herself (Olweus, 1994; 2003; 2010). The World Health Organization reported that Canada ranked a bleak $26^{\text {th }}$ out of 35 countries for bullying problems and $27^{\text {th }}$ out of 35 for victimization (Craig \& Harel, 2004). Compared worldwide, European countries rates of bullying and victimization were notably lower than that of North America, whereas Canadian and American rates of bullying were similarly high. Canada has lagged behind the rest of the world in acknowledging that bullying is a serious problem, which can lead to a number of social emotional and health problems for children and youth, and to tragic and devastating consequences of youth suicide.

The media has highlighted reports of bullying at school throughout the past decade. These news releases have depicted the deplorable behaviours that students can inflict on one another, and the devastating repercussions that occur as a result of school bullying. For example, 14 year-old Reena Virk from Victoria B. C. was burned with cigarettes, beaten horrifically, and left for dead by a group of her so-called "friends" (Godfrey, 2005). Similarly, Dawn Marie Westley from Mission, B.C. and Phoebe Prince from Massachusetts ("Sticks, 
stones and bullies," 2005; Hughes, 2011) were also targets of school bullying by their peers. Both victims of bullying could not handle the daily torment by their peers and eventually committed suicide.

Recent policy developments from the Ontario Ministry of Education view bullying as a serious issue, where bullying intervention and prevention programs are currently mandated in every school within Ontario to promote and ensure the safety of all students (Ontario Ministry of Education, 2011). Despite this effort by the Ontario Ministry of Education, recent suicides reported in the media within Ontario have highlighted the fact that bullying in schools remains a complex problem. Although anti-bullying programs were mandated to be in effect, eleven yearold Mitchell Wilson from Pickering Ontario ("Bully in suicide," 2011) committed suicide before testifying against his attackers, and 15 year-old Jamie Hubley from Ottawa ("Gay Ottawa teen," 2011) committed suicide to escape his long-lasting battle with bullying that continued to plague him even after switching schools. The stories of victims of bullying ending in tragedy are countless, suggesting that the mechanism of bullying and the interrelationships between bullies, victims, and the larger peer group must be further understood theoretically before it can be effectively addressed. When a better theoretical understanding of the role that the school community plays in the development of bullying is gained, more effective school based interventions will better be designed and evaluated.

The primary goal of this study was to better understand the social factors that support bullying behaviour, by combining social-ecological theory and Bandura's theory of moral disengagement. In this paper, I first acknowledge the harmful psychosocial effects of bullying. Next, bulling is defined, and the four different forms of bullying (i.e. physical, social, verbal and cyber) are described. Current prevalence rates in the field of bullying are reviewed, and current 
issues in the field regarding self-report measures of bullying are discussed. Afterwards, a review on how the peer audience plays a vital role in either contributing to or curbing bullying behaviour is provided. The theory of moral disengagement is applied to aid in understanding bullying and bystanding behavior (Bandura, 1999; 2002). Using an ecological lens, an explanation is given for how bullying is manifested, and how the social contexts contribute to these behaviours (Espelage \& Swearer, 2009; 2010; Swearer \& Espelage, 2004; 2011). Finally, these theories are combined to provide an understanding of the individual and school level risk factors associated with bullying, victimization, and bystanding within the larger school environment. In order to provide a context within which to situate this study, the following review describes and integrates current research in the area of bullying, moral disengagement, and social-ecological theory.

\section{Bullying Involvement: A Serious Relationship Problem}

Psychosocial effects of bullying. Bullying is a profound relationship problem (Craig \& Pepler, 2007; Pepler, Craig, \& O'Connell, 2011) that can result in poor psychosocial health issues for victims and bully perpetrators. Researchers have shown that victims of bullying are likely to have experienced maladjustment outcomes, such as loneliness, depression and even suicidal ideation (Crick \& Grotpeter, 1996; Peter, Roberts, \& Buzdugan, 2008; van der Wal, de Wit, \& Hirasing, 2003). Victims and those who both participated in bullying and were victimized were more likely to have low academic achievement, and felt like they did not belong at school (Glew, Fan, Katon, Rivara, \& Kernic, 2005). A Canadian study examining suicidal ideation in a sample of adolescents ages 12 to 15 showed that adolescents who were bullied at home or school within the past 12 months were 1.6 times more likely to have suicidal thoughts in comparison to adolescents who did not experience bullying (Peter et al., 2008). 
Victims of bullying have also been found to report more academic problems, such as low school attendance and low academic achievement (Beran \& Li, 2007; Juvoven, Nishina, \& Graham, 2000; Kochenderfer \& Ladd, 1996).

Victims of bullying are not the only participants who are psychologically affected, both perpetrators and witnesses of bullying are affected as well. Children who frequently bully others have also been found to have poor psychosocial health, resulting in such outcomes as delinquency (Olweus, 1993; van der Wal et al., 2003), depression (Bjorqvist et al, 1992; Kaltiala-Herino et al., 1999; Slee, 1995) and even suicidal ideation (Kaltiala-Herino, Rimplela, Marttunen, Rimpela, \& Rantanen, 1999; Peter et al., 2008; van der Wal, et al, 2003). Of most interest in the current study are the effects on those children who seemingly only stand and watch. Bystanders, otherwise known as participants who frequently witness bullying, are at a greater risk for deteriorated psychosocial functioning, clinical traumatic symptoms (Flannery, Wester, \& Singer, 2004), feeling insecure (Janoz, Archambault, Pagani, Pascal, Morin, \& Bowen, 2008), and are more likely to abuse drugs and alcohol (Rivers et al., 2009). A Canadian study examining the effects of witnessing frequent physical and verbal forms of violence at school found that students reported feeling more insecure, engaged in more externalizing behaviours, and even disliked school more (Janosz et al., 2008). Further, these bullying experiences have been found to negatively affect interpersonal relationships and compromise academic growth well into adulthood (Espelage \& Holt, 2007; Farrington, 1993; Oliver, Hoover, \& Hazler, 1994; Olweus, 1993; Pepler \& Craig, 2000).

The psychosocial effects of bullying therefore appear not only to directly impact the bully-victim relationship, but interestingly also affect witnesses who are indirectly involved as 
well. In order to effectively study the process of bullying, a definition of this behaviour is central to the current study.

Definition and forms of bullying. Bullying was first described by Olweus (1994) as, "being ... exposed, repeatedly, and over time, to negative actions ... when someone intentionally inflicts injury or discomfort upon another" (p. 27). Additionally, Olweus (1993) made it clear that two people of equal power or strength that fight did not constitute bullying. Over the past 20 years, researchers have come to agree there are three important aspects of bullying that are central to the definition: (a) intentionality, (b) repetition, and (c) power imbalance (Hymel, Schonert-Reichl, Bonanno, Vaillancourt, \& Rocke Henderson, 2005; Olweus, 1993; 1994; 2010; Vaillancourt et al., 2008; Wang, Iannotti, \& Nansel, 2009). This is currently the most commonly used definition by researchers in Canada (Beran \& Tutty, 2002; Trach, Hymel, Waterhouse, \& Neale, 2010; Vaillancourt et al., 2008; Vaillancourt, Brittain, et al., 2010). Although earlier research focused solely on physically aggressive acts that were used to bully others (Olweus, 1993), much attention in recent years has focused on other behaviour that also meets this definition. Four different forms of bullying have currently been identified.

Bullying can take several different forms, varying from direct acts to more covert indirect acts. Physical forms of bullying includes repeated, intentional, physical behaviours such as hitting, kicking or pushing victims. Verbal forms of bullying include hurtful teasing and name-calling (Olweus, 1993). Other forms of bullying, such as indirect, relational, or social acts (e.g., social exclusion, ignoring, or rumour spreading) can be used to socially harm or manipulate a person's relationships (Crick \& Grotpeter, 1996). Social bullying behaviour can include a diverse range of non-verbal behaviour, such as negative facial expressions or body movements (e.g., cold shoulder, eye rolling, hair flip; Galen \& Underwood, 1997). Finally, 
electronic technology such as computers and cell phones can be used to cyber bully. This includes anonymously posting nasty notes, emails, and pictures on-line to intentionally hurt and humiliate victims (Wang et al., 2009).

Many studies using self-report measures to compare the prevalence of cyber bullying to more traditional forms of bullying find cyber-bullying perpetration less commonly reported (Kowalski \& Limber, 2007; Trach et al., 2010; Wang et al., 2009; Vaillancourt, Trinh et al., 2010). Cyber bullying has shown to be conceptually different from more traditional bullying forms in a number of ways. Cyber bullying has been shown to often occur off of school grounds, and in any setting at any time. Measuring repetition over time through self-report may also come with challenges, as cyber bullying can be facilitated by people other than the primary initiator (Dooley, Pyzalski, \& Cross, 2009; Kowalski \& Limber, 2007; Wang et al., 2009). In cyber bullying, one act can be spread by others not involved in the social group, leaving the primary perpetrator undetected and not responsible for the repeated actions of the incident.

In conclusion four clear forms of behaviour have been outlined in most studies of bullying; physical, verbal, social, and cyber. A further examination of the studies that have focused on determining the incidence of bullying in school children's lives is warranted.

\section{Prevalence Rates of Bullying and Victimization}

Determining the prevalence of bullying in school children's lives has been an evolving and challenging undertaking as the methodology utilized can result in marked differences in estimates of the problem. Prevalence is defined as the total number of cases at a given time, out of all individuals in a population experiencing the condition (Solberg \& Olweus, 2003). In general, there are two approaches to determining bullying prevalence rates. The Olweus Bullying Questionnaire (1989) has been the most widely used self-report measure to assess 
bullying involvement (O’Connell et al., 1999; Olweus, 2010). The Revised Questionnaire (Olweus, 1996) includes both general and specific questions pertaining to bullying and victimization involvement. One way to determine prevalence is to ask "How often have you been bullied (victimized)?" The second is to provide a list of specific bullying behaviour (e.g., How often have you been hit?; How often have you been left out on purpose?) and the child is asked to identify which behaviours they have experienced (Trach et al., 2010; Vaillancourt, Trinh et al., 2010; Wang et al., 2009). The strengths and limitations of the current methods of studying prevalence will be reviewed.

Current issues in the field of prevalence estimation. Estimating accurate prevalence rates of bullying are difficult for a number of reasons. Espelage and Swearer (2003) report that prevalence rates of bullying vary depending on the definition of bullying used and the researchers methodology. Although researchers have attempted to establish a consistent bullying prevalence measurement (Solberg \& Olweus, 2010; Vaillancourt, Trinh et al., 2010), a consensus regarding prevalence measurement has not been reached. Four factors that have been found to vary among studies include: (a) reference time frame to indicate bullying involvement (e.g. past year, month, week), (b) informant source (e.g., self-report, peer nominations, teacher nominations), (c) measurement approach (e.g. including a definition, overall term, or behavioural descriptors) and (d) using the frequency of behaviour ("once only in the past three months" to "2 to 3 times a month").

The most common forms of informants in bullying include self-reports of the behaviour and peer nominations of bullies and victims (Olweus, 2010). Solberg \& Olweus (2003) argue that peer nominations are not suited towards prevalence estimation due to less precise measurements for behaviours that are covert and indirect. Reports of behaviour in peer- 
nominations are also dependent upon the connection that one peer has with others in the social group (Olweus, 2010). Although self-reports may come with a number of shortcomings such as lapse in auto-biographical memory, positive illusory bias, or social desirable responding (Gresham, MacMillan, Bocian, Ward, \& Forness, 1998; Ladd \& Kochenderfer-Ladd, 2002), it is unlikely that victims of bullying will forget these highly personally significant events (Bovaird, 2010). The Olweus Bully/Victim Questionnaire is therefore the most widely accepted and established self-report measurement of bullying (Espelage \& Swearer, 2003; Olweus, 2010; Solberg \& Olweus, 2003; Vaillancourt, Trinh et al., 2010). Solberg and Olweus (2003) state that simple self-report measurements of bullying that include (a) only one item, (b) provide a defined frequency of measurement, and (c) utilize a specified time period are better able to accurately measure bullying prevalence over time, rather than using a compilation of bullying questions. Measuring bullying and victimization prevalence rates can be rather difficult since there are no concrete standards of measurement.

A common and inclusive cut-off score that has been used by researchers consists of "only once or twice" or more to determine involvement in bullying and victimization (Lee, Cornell, \& Cole, 2006; Leff, Freedman, Macevoy, \& Power; 2011; Wang et al., 2009). Vaillancourt, Trinh et al. (2010) reported using a cut off score of "once only in the past three months", which has been found to accurately classify those involved and not involved in bullying using a Canadian sample. This reference period has been consistently used among other large-scale bullying reports conducted by the World Health Organization (Currie et al., 2004) and the United Nations (Pinheiro, 2006). Other researchers have included more restrictive cut off scores by using " 2 to 3 times per month" (Solberg \& Olweus, 2003). According to Cook, Kirk, Guerra, and Kim (2010), and Olweus (2010) the appropriate reference 
period is unclear, as there is no gold standard when choosing a reference period. Although reference periods regarding bullying measurement have been unclear in past research, it is important to follow standards that have shown to accurately measure prevalence, especially in Canadian samples. Bullying prevalence rates have been found to differ, by researchers using varying methodologies to measure bullying over time.

Prevalence and general bullying behaviour. The extent to which students are asked about the four forms of behaviour as victims, witnesses, and also perpetrators of bullying have an impact on the prevalence rates reported by children. The most cited study that utilizes the general bullying questions is by Nansel et al. (2001), which asked children how often they have been bullied (victimized) over the school term. The authors found that $29 \%$ of middle school children from the United States reported experiencing bullying or victimization at least once over the school term. To be more specific, $10.6 \%$ of children reported being victimized, $13 \%$ reported bullying others, and $6.3 \%$ reported engaging in both bullying and victimization at least once over the school term. In a larger and more widespread sample of 5,000 Canadian elementary and middle school children, the prevalence rate of children reporting being frequently victimized were somewhat higher. Thirty-eight percent reported being victimized once or twice, and $15 \%$ of children reported being bullied more than once or twice. Twentynine percent of children reported bullying others once or twice, and $6 \%$ of children reported bullying others more than once or twice (O'Connell et al., 1997). In conclusion, when children were asked about whether they were bullied or not, about $10-15 \%$ identified themselves as having been victimized more than once or twice. In contrast when children were asked if they had experienced particular bullying behaviours, these numbers climbed considerably. 
Prevalence rate estimation by including a definition and behaviour. Using forms of bullying rather than including a general measure, as well as including a definition was found to accurately measure prevalence rates of bullying. Vaillancourt, Trinh et al. (2010) compared bullying and victimization prevalence rates using the two Olweus questions examining victimization (e.g., "How often have you been bullied?") and bullying (e.g., "How often have you bullied others at school?") to four behavioural descriptors of physical (e.g., hitting, shoving, kicking, spitting, or beating up others), verbal (e.g., name calling, mocking, hurtful teasing, verbally threatening someone), social (e.g., excluding others from a group, gossiping, spreading rumours) and cyber bullying behaviour (e.g., send computer or email messages or pictures to hurt someone's feelings or make them feel bad). The researchers found that the Olweus questions correctly identified up to $55 \%$ of those involved in bullying and victimization, whereas $90 \%$ of those uninvolved in bullying were correctly identified. The overall prevalence rates of bullying and victimization within the past three months were underestimated at $37.6 \%$ and $31.5 \%$, respectively. By using the behavioural descriptors to measure prevalence, $48.9 \%$ reported bullying others and $63.1 \%$ reported being victimized within the past three months. Since the questions posed by Olweus were vague in comparison to the behavioural descriptors, researchers posed that prevalence rates are often underestimated due to students primarily reporting on more direct forms of physical and verbal bullying, and are less likely to report about instances of social and cyber bullying (Vaillancourt, Trinh et al., 2010).

In addition to the importance of behavioural descriptors, providing a definition of bullying to children is also important in measuring prevalence rates. Vaillancourt et al. (2008) found that $92 \%$ of children mentioned general negative behaviour when defining a bully, and failed to recognize the three important aspects central to the definition of bullying as suggested 
by researchers. A meta-analysis conducted by Cook et al. (2010) has pointed to the importance of including behavioural descriptors and bullying definitions to account for the variability in bullying prevalence rates. Eighty-two studies conducted between 1999 and 2006 were compared, and $74 \%$ used self-report methods to measure bullying, whereas $16 \%$ used peer nominations, and $10 \%$ used teacher reports. Forty-six percent of studies included a definition of bullying, and $54 \%$ used behavioural descriptors. The studies that included a definition of bullying or bullying labels had higher weighted average prevalence rates for bullying than behaviour with aggressive descriptors that did not use the word bullying. Therefore, including specific characteristics of bullying (e.g. physical, social, verbal) and including a bullying definition can accurately estimate prevalence rates.

In conclusion, these studies point to the importance of searching for a definition of bullying and bullying behaviors that children can easily conceptualize. Taking into consideration that children often associate bullying with negative behavior, researchers must include definitions of bullying and forms of bullying behavior in order to accurately measure bullying prevalence over time. The extent to which students have been asked about the forms of bullying behaviour as perpetrators and as victims of bullying have shown to impact bullying prevalence rates reported by children.

Prevalence rate estimation for bullying involvement. The best prevalence rates estimates of bullying involvement at the current time are those that provide bullying definitions to students, and additionally include the four forms of bullying. By using behavioural descriptors of bullying, most research examining prevalence rates among Canadian and American youth have found forms of verbal and social bullying and victimization to be the most commonly reported (Trach et al., 2010; Vaillancourt, Trinh et al., 2010; Wang et al., 2009). 
Canadian researchers (Vaillancourt, Trinh et al., 2010) examined prevalence rates of 16,799 students from grades 4-12 in either perpetrating or becoming victimized by providing a definition to children, and by asking about the four forms of bullying. By combining the behavioural descriptors, the authors found that $63 \%$ of students reported being bullied and $49 \%$ of students were victimized within the past three moths. Social and verbal bullying and victimization were more commonly reported. Of those 16,799 students, $31.4 \%$ were bullied physically, $50.8 \%$ were bullied verbally, $37.2 \%$ were bullied socially, and $12.4 \%$ were cyber bullied. Furthermore, $19.4 \%$ of students reported bullying others physically, $36.3 \%$ reported bullying others verbally, $28.8 \%$ reported bullying others socially, and $9.7 \%$ reported bullying others electronically.

Similar prevalence rates of social and verbal bullying and victimization were reported by Trach et al. (2010). The authors found that among 9,116 students from grades $4-12,25 \%$ of students reported being victimized physically, $41 \%$ were victimized verbally, $36 \%$ were victimized socially, and $8 \%$ reported cyber victimization. Of children who report bullying perpetration once or a few times: $17 \%$ reported physically bullying others, $37 \%$ verbally bullied others, $29 \%$ socially bullied others, and $6 \%$ cyber bullied others. Wang et al. (2009) reported in a sample of 7,508 students in grades 6-10 that $13.3 \%$ physically bullied others at least once in the past two months, $37.4 \%$ reported verbally bullying others, $27.2 \%$ socially bullied others, and 8.3\% electronically bullied others (Wang et al., 2009). Victimization rates in the last two months included $12.8 \%$ physical victimization, $36.5 \%$ verbal victimization, $41 \%$ social victimization, and $9.8 \%$ electronic forms of victimization.

In conclusion, the most representative prevalence rates are achieved by asking a single question about bullying experience, accompanied by a definition of bullying and including a list 
of specific behaviours. Researchers who have utilized the behavioural questions to measure bullying prevalence have obtained higher prevalence rate estimates (Trach et al., 2010; Wang et al., 2009), which importantly reflect a wider range of bullying experiences at school.

Bullying prevalence rates to date have focused only on victims and perpetrators. This is a dated approach to understanding this phenomenon. Recent research suggests that there is usually a large number of other children present when bullying occurs (Craig \& Pepler, 1997; O'Connell et al., 1999; Trach et al., 2010). To further understand bullying behaviour and how it operates within the peer group, a more sophisticated view of bullying must be adopted that looks at the bystander's influence on this behaviour.

\section{Bullying as a Group Process}

Bullying is situated within a social context involving a triadic relationship between perpetrators of bullying, the victim, and most notably the bystanders who witness the behaviour. Research has suggested that this triadic relationship of bullying be examined theoretically to include the indirect role of bystanders. For example, research by Twemlow, Fonagy and Sacco (2010) stress the importance of including not only the direct role of bullies, but also the indirect role played by the bystander in encouraging bullying. The inclusion of indirect encouragement provides an understanding of how bullying is enforced and even encouraged through avoidance or non-intervention by the group. This points to the importance of examining how the wider audience can contribute to or suppress bullying.

It has been well documented in the psychology literature that the larger a group is in an emergency situation, the less likely individuals are to help or intervene. Early work by Latane and Darley (1968) coined the term bystander effect to explain why individuals do not intervene in emergency situations when other people are present. Research by Latane and Darley (1970) 
has found that individual's who witnessed an emergency situation as a member of a group were less likely to intervene than when witnessing the emergency situation alone. This lack of action was attributed to not perceiving the situation as serious enough to intervene and thus participants conformed to the passive behaviour of others in the group. According to Latane and Nida (1981) the bystander must notice the event, interpret it as an emergency, feel personally responsible for dealing with it, and possess the necessary skills and resources to act. The bystander effect is an important consideration in understanding bullying situations, especially since research indicates that when bystanders fail to intervene on behalf of a victim, this implicitly encourages the perpetrator to continue their negative behavior. The bullying process is not a simple dyadic relationship between two people, and is a more complex interrelationship than was once thought.

Among observational studies in Toronto schoolyards, bullying was found to commonly occur within a group context. Bullying is an exciting and physically stimulating event (Olweus, 1991) which attracts children. Up to $81-85 \%$ of bystanders were found to be aware of the incident and to reinforce the bullying behaviour in some way (Craig \& Pepler, 1997, O'Connell, Pepler \& Craig, 1999). Twenty-one percent of students reported actively joining in with the bully to abuse the victim, , while $54 \%$ passively watched and did nothing (Craig \& Pepler, 1997; O'Connell et al., 1999). Self-report data has been found to support the observational data. Rivers et al. (2009) found that of 2,002 students aged 12-16 years old, the majority (63\%) reported being witnesses of bullying. In a recent Canadian study, up to $68 \%$ of children reported witnessing bullying on a regular basis (Trach et al., 2010). Research in England has also found that $66 \%$ of students have witnessed bullying at their school (Smith \& Shu, 2000). 
Although the time frame of these studies differ (i.e. including the whole school term versus a more recent time frame) the majority of students are witnesses in bullying situations.

Besides passively watching, bystanders can take on more active roles such as defending the victim. This pro-social action can have a significant effect in preventing the bullying from escalating further. Observational research has shown that when bystanders stand up for the victim, the bullying incident almost always stops within 10 seconds of intervention (Hawkins, Pepler, \& Craig, 2001). When bystanders remain passive during a bullying episode and do not intervene on behalf of the victim, this passive reaction may lead to a cognitive reappraisal resulting in a justification that the victim was responsible and to blame for this behaviour (Cowie, 2000; Gini, Albeiro, Benelli, \& Altoe, 2008). Therefore, encouraging the bystander to intervene by taking on a more active role is an important factor in preventing bullying situations from escalating.

To account for these explanations in the forms of bullying and bystanding behaviour (i.e. assisting, reinforcing, and defending), it is integral to examine the individual differences among children, such as sex and grade level that are associated with bullying involvement. Once an understanding is gained about the individual differences associated with bullying involvement, we can also explore how bullying involvement occurs within the wider school environment.

Bullying involvement and sex differences. There have been relatively few conflicting results in the literature pertaining to sex and involvement in bullying and victimization. Boys have been found to be perpetrators of bullying (Beran \& Tutty, 2002; Bosworth, Espelage, \& Simon; 1999; Gendron, Williams, Guerra, 2011; Goldbaum, Craig, Pepler, \& Connolly, 2007; Vaillancourt, Brittain et al., 2010) more so than girls. Boys also report being targets of bullying more so than girls (Espelage \& Holt, 2001; Vaillancourt et al., 2008), although girls report being 
victimized more often when bullying forms include more social and verbal behaviours (Vaillancourt, Trinh et al., 2010). Although participation in bullying behaviours and being bullied has been documented especially for boys (Hymel et al. 2005), perhaps this is a function of using an overall measurement of bullying.

When the four forms of bullying were examined, findings for bullying perpetration and victimization differed by sex. Boys were more involved in physical forms of bullying such as hitting, and verbal forms such as saying mean things to others (Beran \& Tutty, 2002; Wang et al., 2009). When bullying was examined by including social and cyber means, girls were more likely to be involved in more sophisticated relational forms of bullying (Vaillancourt, Trinh et al., 2010; Wang et al., 2009). Boys also report more physical victimization, whereas girls report more social of victimization (Jeffery, Miller, \& Linn, 2001). Other studies have not found any significant differences between sex and self reported bullying behaviour (Obermann, $2011 \mathrm{a}$ ). Therefore, it seems that boys are more likely to engage in and support direct forms of bullying, where as girls are more likely to use covert forms of bullying to attack their victim.

Sex differences among bystanders have been less frequently examined, especially pertaining to witnesses of bullying. Observational studies by Craig and Pepler (1997) have shown that boys are more likely to be witnesses and defenders in bullying situations in comparison to girls. In peer nominated studies and self-report studies, girls have been found to be rated as outsiders by peers and rate themselves as witnesses of bullying who passively watch or do not respond to the incident (Rivers et al., 2009; Salmivalli et al., 1996; 1999). When it comes to intervention behaviour on behalf of the bystander, girls have shown to react on behalf of the victim when they witness bullying (Oh \& Hazler, 2009; Gini, Pozzoli, Borghi, \& Franzoni, 2008). Similarly, Gini et al. (2008) found that girls endorsed defending behaviours, 
while assistive and passive bullying behaviours were not endorsed. Boys on the other hand, were more likely to endorse behaviors that assisted the bully (Gini et al., 2008). Overall, girls were more likely to witness bullying more often, but were also likely to feel morally responsible and act on behalf of the victim, while boys were more likely to endorse attitudes that support bullying. Although sex differences have been found to exist, these differences do not provide the whole story when examining instances of bullying, victimization, and bystanding. These behaviours are based upon differing developmental trajectories, in which bullying, victimization, and bystanding behaviour are likely to vary as a child is developing throughout the school years.

Bullying involvement and grade differences. Bullying among children and adolescents is seen as a developmental process, with physical forms of bullying decreasing with age, and more sophisticated forms of bullying such as social bullying that require social manipulation increasing with age (Crick \& Grotpeter, 1996; Craig \& Pepler, 1997). Comparing among grade levels rather than using age has been a commonly used method to examine the developmental process involved in bullying. A consistent finding in the literature has shown that elementary school students reported higher frequencies of victimization in comparison to older grades (Bradshaw, Sawyer, \& O'Brennan, 2009; Olweus, 1994; Wang et al., 2009). Goldbaum et al. (2007) found that bullying perpetration tends to increase at the middle school level, and then drops considerably as children are established within their social context. Individuals are less likely to use bullying behaviour at the end of secondary school, with higher reports of these behaviours at the transition between middle and secondary school (Nansel et al., 2001; Pepler, Craig, \& O’Connell, 2011). Studies examining very limited grade levels (e.g., only middle or secondary levels) are inadequate in explaining the developmental differences in 
bullying and victimization that occur with increasing age. By comparing children in both elementary and secondary school, a more comprehensive understanding of children's behavior related to bullying involvement will be gained.

Active intervention by bystanders has been consistently shown to decline in secondary school by using observational, peer report, and self-report methods (O'Connell et al., 2009; Pozzoli \& Gini, 2007; Trach et al., 2010). In a Canadian study by O'Connell et al. (1997), children were less likely to offer support to victims of bullying as they became older. A similar finding is reported by Rigby ad Slee (1992), such that children become less concerned and less empathic for victims with increasing age. Trach et al. (2010) found that elementary students were more likely to engage in direct and positive intervention strategies that were recommended by adults, such as telling the bully to stop, helping the victim, and talking to an adult at school. Secondary school students were more likely to passively or aggressively respond to bullying situations, suggesting increased disengagement from these situations. Although moral disengagement was not explicitly measured in this study to explain the passive responses for bystanders, a focus of this study was to determine if increased levels of moral disengagement led to witnessing bullying among primary and secondary school students.

In conclusion, bullying research has tended to focus solely on individual factors and the larger peer group. It was therefore necessary to develop a modern integrated approach to understand how the peer group is actively or passively involved in bullying, and how bullying can be explained by individual characteristics such as sex and grade level. The bullying process however is not only due to a function of individual differences and as a result of the peer group. A large body of literature exists that considers the role of the environment in supporting bullying attitudes, which has yet to be reviewed. Understanding the psychological processes 
children undergo while engage in or witnessing bullying within the school environment is a particularly important consideration in this study since it has not extensively been explored.

\section{When Good People do Bad Things: Moral Disengagement}

In order to better understand how children can harm others physically or psychologically it was important to look for a theory of behaviour that could be applied to bullying. Sociocognitive theories such as Bandura's hold promise. Bandura was highly interested in how the moral thoughts of adults who participated in or witnessed military conduct could justify using these hurtful behaviours. He coined the term moral disengagement to describe this phenomenon.

Moral disengagement is a process by which people are able to commit harmful acts towards others by means of socio-cognitive justifications in every day life (Bandura, 1999; 2002). Within Bandura's theory of moral agency, Bandura proposed a dual mechanism involved in moral disengagement. This dual mechanism known as moral engagement also explains how individuals can adopt moral standards that reflect an invested interest in the welfare of others, and instill a sense of community (Bandura, 1999). Moral disengagement is also dependent upon social situations, where the social conditions that people are exposed to may lead ordinary people to engage in extraordinarily cruel behaviour (Bandura, 1990). Bandura $(1990 ; 1999 ; 2002)$ explained that an incongruent gap exists when social pressures to act inhumanely go against one's personal moral standards, and therefore justifications are made to close this gap. In order to fully understand human behaviour, four mechanisms of moral disengagement have been identified by Bandura $(1990 ; 1999)$ that are important in explaining why individuals who engage in or witness harmful behaviours do not actively intervene. 
More recently researchers have been interested in whether Bandura's social cognitive theory of moral disengagement could ultimately explain anti-social behaviours (Hyde, Shaw, \& Moilanen, 2010), conduct problems (South \& Wood, 2006), and children's involvement in bullying (Gini, 2006; Hymel et al., 2005; Menesini et al., 2003; Obermann, 2011a).

Researchers have been interested in determining the link between immoral attitudes and behaviour in bullying situations (Gasser \& Keller, 2009; Gini, 2006; Hymel, Schonert-Reichl, Bonanno, Vaillancourt, \& Rocke Henderson, 2010). In order to apply Bandura's theory to bullying, the four moral disengagement mechanisms will be reviewed.

Mechanisms of moral disengagement. Bandura (1999) proposed four ways in which individuals can excuse themselves for engaging in behaviour that is morally wrong. These four mechanisms of moral disengagement include (a) restructuring behaviour so they are not interpreted as morally wrong, (b) obscuring one's role so that harm caused to others is minimized, (c) disregarding injurious consequences as a function of one's actions, and (d) blaming and devaluating victims so as to be justified in treating them unfairly (Bandura, 1990; 1999).

The first mechanism works by justifying the harmful behaviour itself, in terms of cognitive restructuring. During this process, harmful behaviours are misconstrued to seem personally justified and morally acceptable (Bandura, 2002). Cognitive restructuring involves three mechanisms - moral justification (e.g., restructuring harmful behaviour as serving a moral or social purpose), euphemistic labeling (e.g., misconstruing the negativity of acts through language), and advantageous comparison (e.g., comparing a negative act to a more serious one, in order to make the act seem less harmful). The second mechanism involves justifications regarding injurious effects towards the victim. These mechanisms work by minimizing the 
perpetrators responsibility and therefore diminishing the effect of harmful consequences involved. The third mechanism involves a link between ones behaviour and the detrimental effects incurred. Displacement of responsibility and diffusion of responsibility are justified by perpetrators as becoming less responsible for the immoral behaviours. Finally, mechanisms that reduce personal identification related to the victim, such as dehumanization and attribution of blame, facilitate in treating victims unjustly (Bandura, 2002). Therefore, those who engage in bullying perpetration are willing to justify the victims as deserving of bullying behaviour.

These mechanisms may operate in combination with one another, strengthening the effect of moral or immoral behaviour. For example, people are likely to behave more harshly against others when diffusion of responsibility and dehumanization are combined (Bandura, 1990). There is a dual nature of moral agency that explains how people can commit either immoral behaviours by moral disengagement justifications, or pro-social acts by ways of moral engagement. This combination of mechanisms is also relevant to engaging in morally responsible behaviour. For example, individuals who project humanization as well as feel personally responsible are less likely to behave in a reprehensible manner (Bandura, 1990). This may ultimately explain why certain individuals feel it is their personal responsibility to defend victims in bullying situations.

Bandura $(1990 ; 1999 ; 2002)$ notes that the process by which people disengage is gradual, strengthening approval to commit small tolerable injustices without feeling guilt. Over time, individuals are less likely to feel guilt due to repeated performances of small harmful acts that are tolerable. These harmful behaviours that re-occur are able to be endured and can lead to decreased levels of discomfort, and to more harmful behaviours which can be performed without much distress over time. According to Bandura (1999), 
High moral disengagers are less troubled by anticipatory feelings of guilt over injurious conduct, are less pro-social, and prone to ruminate about perceived grievances and vengeful retaliation all of which are conducive to aggressive and antisocial conduct. The higher the moral disengagement and the weaker the perceived self-efficacy to resist peer pressure for transgressive activities, the heavier the involvement in antisocial conduct ( $p$. 206).

The implications of high levels of moral disengagement protect the self from negative feelings of shame or guilt, which usually follow from engaging in immoral behaviours (Bandura, 2002; Bandura, Caprara, Barbaranelli, Pastorelli, \& Regalia, 2001). Therefore, individuals who commit intentional immoral behaviours over time may not find it particularly stressful or guilty when a victim is harmed, due to cognitive justifications that their behaviour is appropriate.

The types of cognitive restructuring that Bandura studied in adults seems to lend itself well to study the thought processes related to engaging in bullying behaviour in childhood. Recent studies have been interested in whether moral disengagement can explain justifications and behaviours in bullying situations (Hymel et al., 2005; Hymel et al., 2010; Gini, 2006;

Obermann, 2011b). A review of these studies will be conducted, highlighting how bullies and bystanders are more likely to use moral disengagement mechanisms.

Moral disengagement and bullying involvement. Research has suggested that children use moral disengagement strategies. Bullying has been considered to be a moral issue, with children being able to disengage from feeling guilty in order to bully others (Hymel et al., 2010). Early work by Bandura, Barbanelli, Caprara, \& Pastorelli (1996) examined moral justifications among an Italian sample of school aged children. They found that boys who were 
aggressive had higher moral disengagement scores, provided more moral justification for their actions, used euphemistic language, minimized the injurious effects, and dehumanized the victim by attributing blame to the target.

Recent research by Gini, Pozzoli, \& Hauser (2011) have discovered that bullies do not have a deficit in moral understanding as was previously thought. Bullies have been found to be socially skilled manipulators, who better understand the mental states and intentions of others in order to harm their victims (Gini, 2006). The distinction lies in their ability to disengage their moral conscience from any feeling involved with moral compassion that is evident when harming an individual (Gini et al., 2008). Therefore, those who bully know their behaviour is indeed harmful and wrong, however, the ability to disengage from feeling emotional guilt and responsibility for bullying allows these harmful actions to be justified.

Researchers have consistently found that moral disengagement attitudes are related to direct engagement in bullying situations (Menesini et al., 2003; Hymel et al., 2005; Gini et al., 2006). For example, Menesini, Fonzi, Ortega, Costabile, \& Lo Feudo (2003) found that children who were peer nominated as bullies and were able to put themselves in the role of the bullies showed higher level of moral disengagement than children nominated as victims and those who were not involved. Although this study examined moral disengagement utilizing hypothetical bullying scenarios and peer nominations, there have been numerous studies that also find a link between direct engagement in bullying and high levels of moral disengagement by using selfreport methodologies.

Hymel et al. (2005) examined justifications attitudes and beliefs among 494 North American secondary students (grades 8-10) who reported experiences with bullying, victimizing and being included in the bully-victim role within Western Canada. Results showed that moral 
disengagement attitudes explained $38 \%$ of the variance in self-reports of bullying, and levels of moral disengagement varied as a function of the child's bullying and victimization status. Overall, children who were perpetrators of bullying had the highest levels of moral disengagement, whereas victims had the lowest levels of moral disengagement. Experiencing both bullying and victimization was found to act as a buffer from the justifications that can be made in moral disengagement. This study was the first to examine moral disengagement using a self-report methodology of bullying-specific justifications using the Moral Disengagement Scale. However, there is still much to know about how moral disengagement operates among the larger peer group.

The recent literature examining moral disengagement among the peer group points to the importance of considering how the peer group can justify bullying attitudes as well as behaviours in bullying situations. Craig and Pepler (1997) suggested that those who witness bullying but do not intervene experience a degree of cognitive dissonance resulting from a discrepancy in their behavioral intentions to intervene, and their actual actions of remaining uninvolved. Research conducted by Gini (2006) found that among 204 elementary school children, those who engaged in participatory bullying behaviour as bullies, reinforcers, and assistants of the bully had higher levels of moral disengagement than victims and outsiders. Defenders and outsiders on the other hand, had the lowest levels of moral disengagement. Overall, the literature shows that direct engagement in bullying behaviour is linked to justification by moral disengagement, whereas the experience of victimization and defending acts as a buffer towards disengaging emotions. Furthermore, the term outsiders describes those who witness bullying, as the participants are outside of the situation. Despite a link found 
among the bully-victim continuum related to moral disengagement, there has been little research conducted in the field examining how moral disengagement impacts the role of the bystander.

Only one study to date (Obermann, 2011b) has examined differences in moral disengagement mechanisms among bystander roles using self and peer reports. Obermann (2011b) found that among 660 school children in grades six and seven, unconcerned bystanders (e.g., students who do not intervene and just watched the bullying incident) showed higher levels of moral disengagement than guilty bystanders (e.g., those who did not intervene, but felt personally responsible to intervene) and defenders (i.e. felt personally responsible to intervene). Furthermore, outsiders who were not aware of the bullying situation had higher levels of moral disengagement than defenders. Therefore, it is likely that consistent with Craig and Pepler (1997) witnesses who do not intervene experience some form of moral disengagement in order to avoid personal feelings of responsibility due to inaction in bullying situations.

Taken as a whole, justifications of bullying involvement are highest in individuals whom directly engage in bullying as a bully, assistant or reinforcer, whereas the experience of victimization acts as a buffer from condoning bullying attitudes. In addition, defenders and outsiders had the lowest levels of moral disengagement when compared to those who directly engage in bullying. Examining the dual aspects of moral disengagement and moral engagement among witnesses of bullying points to an explanation of why some bystanders may either feel personally responsible to intervene on behalf of the victim, or why they are justified as to not actively intervene.

Measuring moral disengagement in childhood. Moral disengagement has primarily been measured through self-report methodologies. The original 32-item scale, Mechanisms of Moral Disengagement by Bandura, Caprara, Pastorelli and Regalia (2001) examined the 
mechanisms of moral disengagement using cognitive justifications leading to detrimental activities. These activities included physical conduct, verbal abuse, stealing, property damage, and deceit, in family, peer, and community contexts. This scale examined the endorsement of broad negative acts related to moral disengagement (e.g., "It's alright to beat someone who bad mouths your family" and "Children are not at fault for misbehaving if their parents force them too much") is inappropriate for examining cognitive justifications within peer contexts related to bullying. A more appropriate scale to measure individuals' cognitive justifications specific to bullying situations within the peer context was created by Canadian researchers (Hymel et al., 2005). Items on this scale that related to cognitive justifications in bullying situations included "Some kids get bullied because they deserve it" and "In my group of friends, bullying is okay". Despite both Bandura and Hymel's scales including the four mechanisms of moral disengagement, factor analyses indicate moral disengagement is composed of one dimension (Bandura et al., 1996; Bandura et al., 2001). In addition, the use of moral disengagement items pertaining to bullying situations (Almeida et al., 2010; Gini, 2006; Hymel et al., 2005) also led to one factor. This suggests that the different moral disengagement mechanisms interact with one another to determine cognitive justifications towards general misconduct and in more specific situations related to bullying.

Another issue in the measurement of moral disengagement highlights contrasting differences in the continuous measure of high and low moral disengagement. Do low moral disengagement scores reflect that an individual is highly morally engaged? Bandura et al. (2001) reported that a high value on the Mechanisms of Moral Disengagement scale reflected high moral disengagement whereas a low score on the scale pertained to high moral engagement. Moral disengagement mechanisms related to bullying which were measured by 
Hymel et al. (2005), and Obermann (2011b) determined that high scores of moral disengagement in bullying situations reflected higher endorsement of bullying behaviours, whereas low moral disengagement scores indicated a low endorsement of moral disengagement attitudes. Moral disengagement and moral engagement as different constructs will be examined in the present study by using measures of moral disengagement and moral engagement specific to bullying situations. Past studies have failed to include the measurement of moral engagement to explain the group process of bullying. The moral disengagement studies that have been reviewed in this paper have primarily examined individual differences in moral disengagement without taking the classroom or school contexts into consideration.

Moral disengagement and the social context. Advances in research on the topic of bullying and moral disengagement have come to focus on not only the individualistic differences in moral disengagement, but also how the larger social context is involved in supporting attitudes and behaviour related to bullying. Only recently have studies been conducted, linking moral disengagement attitudes related to bullying and victimization among classroom and school contexts. Salmivalli \& Voeten (2004) found that among elementary children in fourth to sixth grade, pro-bullying attitudes and norms of the classroom predicted bullying behaviour over and above individual level factors such as sex and age. A strength of this study included the differing participant roles that were taken into consideration along with the social peer group context, rather than only measuring individual level perceptions regarding bullying justification. However Salmivalli and Voeten (2004) mention there are important group level factors other than classroom norms that are related to students' involvement in bullying. Examining how bullying is also allowed among the larger school context is of substitutive value 
when considering that children are nested within classrooms and these classrooms are nested within schools (Field, 2009).

Similarly, Almeida et al., (2010) found that attitudes supporting moral disengagement, and the peer group perception of normative bullying beliefs predicted attitudes in favour of bullying participation. Also, high moral disengagement and low peer group normative beliefs about the defender role predicted more negative attitudes towards defending the victim. Although this study examined attitudes towards bullying and defending as an outcome in older students, there is a need for studies that will expand on this to include how attitudes that justify bullying relate to self-reported bullying behaviour.

Overall, the studies on moral disengagement and bullying involvement to date have primarily examined moral disengagement at the individual level, failing to take into consideration the larger school environment that supports bullying, victimization, and bystander behaviour. Bandura's model of moral agency identifies the importance of the interplay between personal and social-contextual factors. By examining factors of the school climate that allow bullying attitudes and behaviour, these factors provide key information in determining one's role in bullying situations. Therefore, personal attitudes as well as the broader social contexts that support moral disengagement justifications within schools need to be examined in order to predict one's role in bullying, victimization, and witnessing.

\section{Ecological Factors that Predict to Bullying Involvement}

Studies examining the factors related to bullying have found that characteristics of the school impact on levels of bullying and victimization. Physical aspects of the school such as size and ethnic composition (Ma, 2002; Olweus, 1994; Whitney \& Smith, 1993) were not related to bullying involvement. Social-ecological variables such as the child's peer group and 
the social climate of the child's school, have been found to be important factors that contribute to bullying and victimization (Espelage \& Swearer, 2009). In order for schools to intervene effectively in bullying situations, individual and school-level risk factors must be identified to prevent bullying, victimization and bystanding behaviours from being supported within a school environment.

In this study, the processes of bullying, victimization, and bystanding has been explored by using Bandura's theory of moral disengagement. Similar to the arguments proposed by Hymel et al., (2005), and Swearer and Doll (2001), I planned to understand how attitudes and behaviours related to bullying were supported through an ecological perspective, by examining influences of individual, peer group, and school contexts. Furthermore, many hierarchical studies have primarily examined how individual, classroom, and school contexts lead to bullying and victimization involvement (Espelage \& Swearer, 2009; Hymel et al., 2005; Ma, 2002). Since bullying occurs within a social context, it is imperative that both individual and collective attitudes are examined that support bullying within the school context.

A social-ecological framework has been used in numerous studies to describe how the interaction between bullying and victims could be understood within a complex social system (Craig \& Pepler, 1997; Espelage \& Holt, 2001; Espelage \& Swearer, 2009; 2010; Hymel et al., 2005; Swearer \& Doll, 2001; Swearer \& Espelage, 2004; 2011). Both personal traits such as age and sex, and the wider school environment in which children are embedded, have provided a comprehensive understanding of how bullying behaviour is supported. Examining how the wider school environment influences one's bullying attitudes and involvement is of interest to determine in the current study since it has not been explored. 
Social-ecological systems theory has been extended to research in the bullying field, examining how the individual child's bullying behaviour is influenced by the family, peer group, classroom, school, and the wider community (Espelage \& Holt, 2001; Espelage \& Swearer, 2009; 2010; Hymel et al., 2005; Swearer \& Doll, 2001; Swearer \& Espelage, 2004; 2011). A study by Lee (2011) found that all levels of the ecological system influenced bullying behaviour at the middle school level, with individual traits having the most influence on bullying behaviour. Lee (2011) found that children who perceived their community and peer groups as collective were more likely to perceive their school climate as positive, were less likely to hold supportive attitudes towards bullying, and were less likely to bully others. Although Lee's ecological model has strengths in examining the many contexts in which children develop, this model is limited in that it does not account for how moral disengagement mechanisms are supported by the wider social environment to explain bullying behaviour. In order to gain a better understanding of how school environments encourage and tolerate bullying behaviour, the social and psychological features of a negative school climate must be examined further.

School-level factors leading to bullying involvement. There has been a great deal of research to date focusing on how individual personality characteristics, family, and peer influences (Alsaker \& Gutzwiller-Helfenfinger, 2010; Pellegrini \& van Ryzin, 2004; Pozzolli \& Gini, 2007; Swearer, Collins, Radcliff, \& Wang, 2004) lead to bullying involvement. Factors that relate to the social context of bullying, such as school-level factors are also important when examining bullying, victimization and bystanding from an ecological perspective. An understanding of the involvement of both adults and peers as bystanders on the attitudes of the 
school climate provides information about how bullying attitudes and behaviours are tolerated within the school environment.

School Climate. New research on bullying is presently focused on the explanation of context, including school climate to predict involvement in bullying and victimization. In recent literature, a negative school climate is often a factor that contributes to bullying and victimization at the school level (Espelage \& Swearer, 2009; Kasen, Berenson, Cohen, \& Johnson, 2004; Lee, 2000).

A recent study by Gendron, Williams and Guerra (2011) examined the interaction between individual and school level factors such as school climate that were predictive of bullying perpetration over one year. At the school level, normative beliefs that were supportive of bullying (Gendron et al., 2011; Werner \& Nixon, 2005), as well as negative perceptions of school climate were shown to predict bullying perpetration over time (Gendron et al., 2011). This study suggested that school climates characterized by an atmosphere of accepting bullying attitudes increases the likelihood of engaging in bullying behaviour. Eliot, Cornell, Gregory, and Fan (2010) found that collective school-level perceptions of a positive school climate led to more willingness to seek help for bullying and violent behaviours. Positive school climate in this instance included perceptions of adult support and caring at school, which influenced students' willingness to seek help in bullying situations from adults.

These studies showed that negative perceptions of school climate influenced the approval of normative beliefs that supported bullying, as well as the approval of actual harmful bullying behaviour. When school climate was perceived as positive, this resulted in a climate that was characterized by obtaining support and intervention in bullying situations. An 
important aspect across all studies pertaining to school climate included the supportive role of adults.

Adult availability and support. A consistent finding across the literature suggests that decreased adult supervision and support within school settings has been found to exacerbate problems of bullying. Parents are critical socializing agents that can act as positive role models for children and adolescents throughout a child's life. This impact is often long lasting, providing examples of support and guidance of healthy relationships and behaviour. Espelage et al. (2000) displayed the importance of positive adult behaviour and bullying behaviour in childhood. Among 588 middle school children from the United States, children were less likely to bully others when parents handled conflicts using non-violent strategies. Similarly, Kasen et al. (2004) shows that parental support has been found to decrease bullying. For example, maternal warmth and support was associated with a decline in bullying related behaviours and internalizing problems, whereas relationships that consisted of harsh punishment by parents was associated with increased aggression and externalizing problems in children (Kasen et al., 2004). This shows the important role that parents can play in teaching children about social relationships.

Parents are not the only adults involved in curbing bullying behaviours and providing support to children in school. Teacher support, when available, has also been shown to counteract and prevent negative effects of bullying in schools (Demeray \& Malecki, 2011; Malecki \& Demeray, 2004). Research by Olweus (1994) has found that increased teacher awareness and involvement in bullying situations leads to decreased rates of bullying. Smith \& Shu (2000) show that increased adult supervision on the playground and adults who intervene in bullying are likely to reduce the number of bullying incidents. Likewise, Vaillancourt, Brittain 
et al. (2010) also highlight the importance of adult supervision and students' feelings of safety. Students reported feeling unsafe and vulnerable in areas within schools in which adult support was not easily available. Although students did report victimization in the classroom, these reports of bullying may have been undetected by teachers.

In observational studies, teachers have been found to intervene on behalf of victims in only $4 \%$ of episodes (Craig \& Pepler, 1994). A discrepancy has been found in the literature such that $71 \%$ of teachers reported usually intervening in bullying, whereas $25 \%$ of children usually say teachers intervene. This discrepancy in the literature shows just how covert behaviours are, and how unaware teachers are of bullying problems due to their hidden nature. Yet another reason for lack of intervention is due to teachers being unsure as to how to respond to more sophisticated types of social bullying due to inadequate training (Boulton, 1997), or not perceiving covert forms of bullying as serious in comparison to physical forms (Craig, Henderson, \& Murphy, 2000). Despite school personnel assuming the role of responsibility for intervening in bullying and ensuring the safety of students at school, the majority of teachers are unaware of its occurrence, which makes intervention in bullying situations quite challenging.

The implications of school personnel dismissing bullying as not serious sends a message to victims that they are likely to internalize that bullying behaviours are tolerated when these behaviours are indirectly supported by teachers (Hoover \& Hazler, 1994). However, when these behaviours are not tolerated by school personnel by intervening when aware of bullying situations, this adult support can ultimately change the school culture as a whole to become less tolerant of bullying (Holt \& Keyes, 2004). Overall, the role of social support from adults within the school system can impact children's social relationships and create a more positive school environment. 
The ecological contexts of family, peer group, school, and the wider community have been examined by Espelage and Swearer (2009) to determine if school community factors predicted bullying and victimization behaviour over and above individual, parental, and peer level factors. Greater alcohol and drug use, depressed and suicidal feelings, and low levels of caring from parents predicted bullying perpetration whereas suicidal and depressed feelings, negative peer influence and low parental caring predicted victimization. In addition to examining the individual factors leading to bullying involvement, the school climate accounted for an additional $50 \%$ of the explained variance in bullying perpetration and $51 \%$ of the variance in victimization.

Overall, positive school climate has shown to act as a buffer from bullying perpetration and victimization when parental caring was low. Furthermore, positive school climate acted as a buffer for bullying perpetration when peer influences were negative. Although $50 \%$ of the variance in bullying and $51 \%$ of the variance in victimization were explained by school climate factors, this study used an 8-item general measure of school climate examining perceptions of good education and adult caring and respect in an educational setting.

Measurement of school climate. General measures of school climate have been primarily used as a common methodology to examine the relationship between school climate and bullying (Eliot, Cornell, Gregory, \& Fan, 2010; Espelage \& Swearer, 2009; Gendron,; Nansel et al., 2001; Wei, Williams, Chen, \& Chang, 2010; Williams, \& Guerra, 2011). General measures of school climate often vary in the components that characterize the school environment, such as including adult support and caring (Eliot et al. 2010; Kasen, Berenson, Cohen, \& Johnson, 2004; Wei et al., 2010) adult involvement and teen drinking (Nansel et al. 2001), and school environments that are composed of an academic, social, and personal focus 
(Kasen et al., 2004). There have been no studies to date that have used bullying-specific measures of school climate to measure a climate composed of adult support, general safety, and attitudes that allow bullying behaviour to occur at school.

Measuring students' perceptions of a school climate that is composed of student, school personnel, and parental attitudes that allow bullying behaviour to occur is of particular interest in this study. Rather than using a general measure of school climate, of particular interest is to measure factors of school climate that include adult support and attitudes that allow bullying to be maintained within a school environment. To date, the only research that has been conducted involving school climate has only examined school-level risk factors predicting bullying and victimization involvement (Espelage \& Swearer, 2009). This paper builds on previous studies, by exploring the impact of students' collective perceptions of school climate on witnessing bullying behaviour, which indirectly allows bullying to be maintained and allowed within the school environment.

\section{Current Study}

The purpose of this study was to determine if a disengaged school climate contributed over and above individual attitudes to predict bullying perpetration, victimization, and bystander behaviour. Recent research has come to show the link between cognitive justifications of moral disengagement and individual experiences of bullying and victimization (Hymel et al., 2005). Previous investigations of Bandura's theory of moral disengagement explaining bullying and victimization have failed to include individual and school-level justifications simultaneously using a multi-level structure. There has not been any research conducted to date examining the individual and collective impact of moral disengagement mechanisms of bystanders who witness bullying at school. Research conducted by Hymel et al. (2005) was extended by 
including bystanders, recognizing that bullying occurs as a group phenomenon within a social context.

Despite studies linking moral disengagement mechanisms and bullying behaviour, no studies to date have included measuring the dual nature of this mechanism as proposed by Bandura $(1990 ; 1999 ; 2002)$. Therefore, it is important to examine not only the justifications as to why people commit immoral behaviours or do nothing when they witness bullying, but also how moral engagement promotes pro-social behaviour.

Within the literature examining school climate (e.g. Espelage \& Swearer, 2009; Gendron et al., 2011), the construct has been primarily measured through general positive measures of climate, such as examining individual perceptions of adult support and respect in the school environment. Researchers have yet to examine school climate by using quantitative measures that include the collective attitudes of students and adults at school regarding the tolerance of bullying involvement. This will be the first study to date to examine individual and school-level perceptions of bullying involvement by using quantitative measures pertaining to specific bullying situations using Hierarchical Linear Modeling.

Research Questions. Five questions that aim to be answered from this study are asked These questions include:

1) What are the current prevalence rates among overall bullying, victimization and witnessing for children and adolescents aged 8-20? Do sex and grade level differences exist in current prevalence rates among overall bullying, victimization, and witnessing? 
2) What are the current prevalence rates for physical, verbal and social bullying, victimization and bystanding? Do sex and grade level differences exist in current physical, verbal, and social bullying prevalence rates?

3) Are there sex and grade level differences in adult availability, moral engagement, moral disengagement, and feelings of being unsafe at school?

4) To what extent do school level factors contribute to the explained variability in bullying, victimization, and witnessing over and above individual level factors?

Hypotheses. Of present interest was to determine which individual and school-level variables were associated with participation in bullying, victimization, and bystanding. In addition, the collective contribution of moral disengagement, moral engagement, school safety, and adult availability predicted to involvement of bullying, victimization and byststanding are important to consider over and above the contribution of individual perceptions.

Based on the literature reviewed in this study regarding individual characteristics, moral justifications, and the school climate regarding bullying behaviour, it was hypothesized that individual factors related to bullying perpetration included boys who were younger, with high moral disengagement, low moral engagement, low adult availability, and more likely to feel unsafe at school. Research by Hymel et al. (2005) indicated that the experience of victimization buffered against feelings of moral disengagement. Espelage, Mebane, and Adams (2004) also noted that victims have high levels of empathy and caring behaviours. Therefore, hypotheses at the individual level for victims regarding moral disengagement and moral engagement were reversed. Individual level-factors that were hypothesized to predict victimization included being a younger boy, with low moral disengagement, high moral engagement, low school 
safety, and low adult availability. Based on the literature involving the individual characteristics, moral justifications, and school climate factors related to witnessing bullying, it was hypothesized that girls who were older, high in moral disengagement, low in moral engagement, low in adult availability, and perceived their schools as less safe were more likely to be witnesses of bullying.

I explored whether schools that were characterized by environments that allowed bullying to occur also had students who are more likely to engage in bullying, victimization, and witnessing. Based on Bandura's social-cognitive theory of moral agency, it was hypothesized that school climates characterized by collective perceptions of high moral disengagement, low moral engagement, increased feelings of being unsafe at school, low adult availability and at the primary grade level will predict to more individual reports of bullying, victimization, and bystanding behaviour.

Finally, it was of interest to determine how much of the variance in bullying, victimization, and bystanding was accounted for by both individual level factors and school level factors. From hierarchical studies conducted on bullying involvement (Espelage \& Swearer, 2009) and finding approximately $50 \%$ of the variance in bullying and $51 \%$ of the variance in victimization at the school level, it was hypothesized that collective perceptions at the school level of high levels of moral disengagement, low moral engagement, low adult availability and low school safety, as well as primary grade level will account for more of the variance in explaining bullying, victimization, and bystanding than individual level factors.

\section{Method}

\section{Participants}


This study was based upon an archival dataset funded by a CURA grant awarded by the Social Science and Humanities Research Council of Canada to McMaster University. The data was completely anonymous and any identifying information was removed from the dataset prior to receiving access. The data was collected in 2005 and included a sample of 16,879 students with 8,226 girls (48.7\%) and 8,653 boys (51.3\%) from grades 4-12. Students from 114 schools within one school district were invited to participate. School size ranged from 1-1224 students $(M=311, S D=296.32)$, and students were sampled from a region in Southern Ontario. The mean age of the sample was $12.54(S D=2.47)$, ranging from 8-20 years old. Equal proportions of students were represented from 8-17 years old, with less than $3 \%$ of the sample over 16 years of age. Students were grouped by grade level: primary (4-8) and secondary (9-12). The number of students grouped into grade levels included $12,179(72.1 \%)$ students at the primary level and $4,700(27.8 \%)$ students at the secondary level.

The ethnicity of this sample was primarily Caucasian (54\%), but $16.5 \%$ of racial minorities were also represented in this sample. Racial minorities included $5.3 \%$ Asian, $3.8 \%$ Black, 3.6\% South Asian, 2\% Aboriginal, 1.8\% other. Twenty-nine percent did not report their race/ethnicity. The 2006 Census (Statistics Canada, 2006) reported similar population results for the same region in Southern Ontario, with a $12.3 \%$ reported visible minority population. The following racial minorities were represented in the 2006 Southern Ontario region population: $2.9 \%$ South Asian, 1.0\% Southeast Asian, 1.7\% Chinese, 2.4\% Black, 0.7\% Filipino, and 1.0\% Latin American. This value was strictly used for descriptive analyses and was not included in subsequent analyses.

\section{Procedure}


Elementary and secondary school students were invited to complete an online questionnaire during class time that included questions about bullying involvement, feeling safe at school, moral engagement, moral disengagement, and adult availability; see Appendix. Supervision during the online survey occurred in the schools computer lab, and was conducted by classroom teachers for elementary school students and homeroom teachers for secondary school students. Data collection occurred within a one-month period in the months of January for elementary school students and February for secondary school students.

\section{Measures}

The Safe Schools Survey is an online self-report questionnaire assessing general and specific relations to involvement with bullying, victimization and bystanding behaviour. This self-report survey also measures children's perceptions of safety at school, perceptions of adult availability and involvement in bullying situations, as well as attitudes that support the endorsement of moral disengagement and engagement mechanisms.

Demographics. Descriptive questions included that of sex, grade level, and age. Sex was dummy coded as 0 (boys) and 1 (girls). Grade was also dummy coded as 0 (primary level) and 1 (secondary level). Age was included as a continuous variable.

Involvement in bullying, victimization, and bystanding. Self-reported involvement in bullying, victimization and bystanding behaviour was measured by using an adapted version of the Olweus Bully/Victim Questionnaire (BVQ; Solberg \& Olweus, 2003). For the purposes of data collection and research questions, the BVQ was adapted by adding the bystander role as well as additional questions regarding forms of bullying. One item was used to measure general bullying ("How often have you been bullied in the past three months?") and victimization ("How often have you been victimized in the past three months?"). The revised BVQ is a well- 
validated and reliable measure of self-reported involvement in bullying and victimization (Beran, 2006; Vaillancourt, Trinh et al., 2010). Past research has shown evidence of convergent validity, with moderate to high correlations found between teacher perceptions of children's proactive aggression and bullying items on the BVQ (Beran, 2006).

Prior to the BVQ questions asking about bullying involvement, a definition of bullying was provided to the students taking the questionnaire (Whitney \& Smith, 1993):

We say a student is being bullied when another student, or group of students say nasty and unpleasant things to him or her. It is also bullying when a student is hit, kicked, threatened, or locked inside a room, sent nasty notes, when people don't talk to him or her and things like that. These things may take place frequently, and it is difficult for the student being bullied to defend him/herself. It is also bullying when a student is teased repeatedly in a negative way. But it is not bullying when students of the same strength quarrel or fight (p. 7).

After the definition of bullying was provided, participants were asked to report their involvement in receiving, participating in, or witnessing physical, verbal, social and cyber bullying. Being bullied, and bullying others using the four forms of bullying have been used by Vaillancourt, Brittain and colleagues (2010), and by Wang and colleagues (2009). Each form of bullying was measured by asking about the prevalence of frequency in engaging in the following behaviour. Examples of each of the four forms of bullying were provided to all students prior to filling out the questionnaire. The four forms of bullying were included in the following order: physical bullying (e.g., hits, shoves, kicks, spits, or beats up on others); verbal bullying (e.g., name calling, mocking, hurtful teasing, threatening someone, etc.); social bullying (e.g., excluding others form the group, gossiping or spreading rumors about others, 
setting up others to look foolish, making sure other persons don't associate with that person), and cyber bullying (e.g., using the computer, or email messages, or pictures to hurt some one's feelings, make someone feel bad, threaten someone, etc.). Despite the cyber bullying item being included in the questionnaire, it was not included in any composites or statistical analyses.

All questions pertaining to involvement with bullying were measured on a 5-point response scale. These response scales included 0 (not at all in the past three months), 1 (once only in the past three months), 2 (a few times in the past three months), 3 (every week in the past three months), and 4 (many times a week in the past three months). Higher scores indicated that students reported engaging in these behaviours more frequently.

Bullying, victimization, and bystander composite score. The victim composite score was calculated by averaging across the three forms of physical, verbal, and social victimization. The victimization composite was highly correlated with the Olweus victimization measure, $r=$ $.68, p<.001$, which indicated good concurrent validity. Chronbach's alpha for the victimization composite scale including physical, verbal, and social victimization was good, $a=.76$.

The bullying composite score averaged across physical, verbal and social bullying measures. This composite score was correlated with the Olweus bullying measure, $r=.60, p$ $<.001$ which indicated good concurrent validity. Chronbach's alpha for the bullying scale including physical, verbal, and social bullying involvement was good, $a=.78$.

The bystander composite score was composed of witnessing physical, verbal, and social bullying. There was no measure in this study to compare validity against the bystander composite. Chronbach's alpha for the bystander composite scale was excellent, $a=.87$.

School safety. Student safety in schools was measured by the statement "During the past 3 months, I have felt safe at this school" (See item 1). Vaillancourt, Britain et al. (2010) 
measured school safety on a 5-point scale, with 1 (all of the time), 2 (most of the time), 3 (some of the time), 4 (rarely), and 5 (never). Higher scores on this item indicated increased feelings of being unsafe at school. According to Olweus (2010) and Solberg and Olweus (2003), using a single item to measure a construct rather than a composite score is preferred and suggested as the method of choice for prevalence estimation. Composite scores are considered to be more abstract, and choosing cut off scores can be deemed rather difficult. Using a single item to assess a construct can assist the researcher in choosing an easily identifiable cut off point, and can be reproduced by other researchers to compare across studies more easily (Solberg \& Olweus, 2003). For prevalence estimation, a single measure relating to school safety, as well as types of physical, verbal, and social bullying behaviour were included.

Adult availability and involvement. Seven items measuring perceived adult availability and involvement in providing assistance in bullying situations were adapted from the original Olweus questionnaire, and additional questions were created by experts in the bullying field; see items $11-13,15-19$. Therefore, this scale is considered to have good face validity. The extent to which students perceived adults as available or involved in handling bullying situations included the following seven items: How often has your mother or father talked with you about bullying?; How often do teachers put a stop to it when a student is being bullied at this school?; How often does the Principal/Vice Principal try to stop it when a student is being bullied at this school; How often can you find an adult at this school when you need help?; How often do you think teachers in this school talk with students in class about bullying?; How often do you think teachers in this school talk to students about being a bystander (witness) to bullying?; and, How often do teachers address conflict resolution during lessons in this school? The extent of adult availability and involvement was measured on a uni- 
dimensional 4-point scale with 0 (Never), 1 (Sometimes), 2 (Often), and 3 (Very often). Higher scores indicate higher levels of perceived availability and involvement from adults and teachers in handling bullying. Chronbach's alpha for adult availability was good, $a=.80$.

Moral disengagement. The moral disengagement scale examines childrens' and adolescents' rationalizations and justifications for bullying behaviour. Moral disengagement attitudes towards bullying were adapted from a self-report measure created by Hymel et al. (2005). According to S. Hymel (personal communication, October 14, 2011), Canadian experts in the bullying field created the items that were best suited for measuring moral disengagement and the scale was created post hoc. A scale was comprised of seven items that were included in Hymel et al., (2005) which were chosen as the most applicable in measuring moral disengagement in bullying situations. The original scale utilized 18 items, 13 of which loaded on a single factor of moral disengagement (Hymel et al., 2005), and has been reported to have high internal consistency, $a=.81$. This scale has also been used by Almeida et al. (2010) in a more age diverse sample of 292 students, 10-18 years-old from Portugal, retaining 15 items on all questions asked by Hymel et al. (2005) on a single factor with a higher internal consistency of .86 . Similar high internal consistency values were reported for the original 32 item unidimensional Mechanisms of Moral Disengagement scale by Bandura et al. (2001) at .85 .

For the purposes of this study, seven items that loaded highly on a uni-dimensional scale by Hymel et al. (2005) were used; items 20-21, 23-25, 27, 30; which referred to using justifications of moral disengagement in bullying situations. These seven items included: It's okay to call some students nasty names; Students who get picked on a lot usually deserve it; It's okay to join in when someone you don't like is being bullied; Bullying is just a normal part of being a student; Getting bullied helps to make students tougher; In my group of friends, 
bullying is okay; and, If you're angry with someone, its okay to keep them out of your group of friends. A 4-point scale was used to measure the likelihood of endorsing moral disengagement attitudes: 0 (Strongly disagree), 1 (Disagree), 2 (Agree), and 3 (Strongly Agree). Higher scores indicated higher endorsement of moral disengagement attitudes related to bullying situations. In this study, the seven items on the moral disengagement composite revealed good internal consistency, $a=.86$.

Moral engagement. The moral engagement scale was used to measure pro-social moral justifications pertaining to empathic responses related to bullying. Eight items referring to moral engagement were adapted from the measure by Hymel et al. (2005), and were also created by Canadian bullying experts apriori for the purposes of the original data collection (S. Hymel, personal communication, October 14,2011 ). The following items on the survey include questions pertaining to moral engagement; $22,26,28-29,31-34$. The eight items pertaining to moral engagement in bullying situations included: Students who are bullied feel sad about it; It is my responsibility to do something to help when I see bullying; Students who join in bullying are just as bad as the bully; I'm upset when another student is being bullied; It's best to avoid repeating stories about others, if you don't know what is true; It's okay to like students who get bullied; Students who get bullied are just as good as other students; and Students should be punished for teasing. Similar to the four point attitude scale that was used by Hymel et al. (2005), the response scale for moral engagement included the following: 0 (Strongly disagree), 1 (Disagree), 2 (Agree), and 3 (Strongly Agree). Higher scores indicate higher endorsement of moral engagement attitudes towards bullying reflecting empathy and moral responsibility. Chronbach's alpha examining internal consistency between items for moral engagement was good, $a=.78$. 


\section{Statistical Analyses}

Current prevalence. In this study, we examined overall and specific prevalence rates of bullying, victimization and bystanding. A number of chi-square tests of independence were conducted to examine the proportional differences in bullying involvement by sex and grade. Four 2 (sex) $\times 2$ (grade level) ANOVA's for were used to examine the differences in mean levels of adult availability, moral disengagement, moral engagement, and school safety by sex and grade level.

Hierarchical linear modeling. Hierarchical Linear Modeling (HLM) is a statistical technique which takes the hierarchy within social contexts into consideration. HLM analyses were conducted to include the nesting of children within their school context, and to examine the variability in bullying, victimization, and bystanding involvement that is accounted for at the individual and school levels. HLM has been used in studies concerning the individual and collective level factors either at the classroom level or the school level in predicting bullying perpetration and victimization (Espelage \& Swearer, 2009; Sapouna, 2010). Individual level variables are typically categorized as level 1 variables, whereas school-level variables are classified as a grouping variable at level 2. Therefore, HLM is appropriate in describing hierarchical relationships between our individual student variables at level 1 , as well as collective school level variables at level 2 .

For the HLM analyses, data were analyzed within a two-level hierarchical design, as students (Level-1) were nested within schools (Level-2). MLWin 2.10 (Rasbash, Charlton et al., 2009) software was used to generate three hierarchical linear models (HLM) investigating the effects of individual and school level factors on three continuous outcomes of bullying, victimization and bystanding. For each dependent variable (i.e. bullying, victimization, and 
bystanding), a two-level hierarchical linear model was built in three steps: examining the null model, entering group centered predictors at Level-1, and finally entering mean aggregated predictors at Level-2. The first step was to create a basic null model, excluding all predictors to partition the variance into between (school level) and within (student level) variance. The second step involved adding Level-1 variables of sex, age, adult availability/involvement, moral engagement, moral disengagement, and feeling unsafe at school to determine the proportion of variance accounted for at the individual level. Age was entered as a control variable at Level-1. All variables at level-1 (with the exception of sex and grade) were centred on the grand mean. The last step included variables at Level-2 to determine the additional proportion of between school variance accounted for by adding school level factors, while controlling for significant individual-level variables. Measures of moral disengagement, moral engagement, adult availability and school safety were aggregated by averaging scores at the school level to determine school-level perceptions of condoning bullying. Mean aggregations of individual level data is accepted by Rowan et al. (1991), and is a common method in the bullying literature when using school-level data at Level-2 (Espelage, Holt, \& Henkel, 2003; Espelage \& Swearer, 2009; Sapouna et al., 2010). Before conducting HLM analyses, preliminary results regarding prevalence rates and mean differences were reported.

\section{Results}

Three main analyses regarding the hypotheses of interest were conducted using the following analyses. First, prevalence rates were calculated to determine the overall rates of involvement in bullying, victimization and witnessing, as well as to examine the three forms of bullying (e.g., physical, verbal, and social) for the whole sample, and by sex and grade. Next, mean level differences were calculated to examine the independent predictors of adult 
availability, moral engagement, moral disengagement, and safety at school by sex and grade. Finally, Hierarchical Linear Modeling was used to account for the individual and school level variability in bullying involvement. Prior to conducting analyses, the data were checked for errors, missing values, and to ensure that all scores were within the plausible range. All chisquare and ANOVA statistics were calculated with missing values included in the distribution.

\section{Prevalence Rates}

Overall bullying involvement. Prevalence rates of bullying involvement were examined by calculating the percentage of involvement over the number of students in the total sample. Involvement in all forms of bullying at any rate were reported in subsequent analyses. In an attempt to accurately measure prevalence rates of bullying, a reference standard score of "only once in the past three months" was used for bullying involvement across all forms of bullying. This cut-off score has been previously used by the World Health Organization (Currie et al., 2004), as well as in Canadian studies (Trach et al., 2010; Vaillancourt, Trinh et al., 2010). In addition, this cut off score has shown to accurately detect cases of bullying (Vaillancourt, Trinh et al., 2010).

A composite score was created to examine overall prevalence of bullying, victimization, and bystanding. Any involvement of any form or frequency of bullying was coded as 1 (involved), with separate composites created for bullies, victims, and bystanders. When combined into a composite score, $47.9 \%(n=8,083)$ of students reported bullying others, $62 \%$ $(n=10,462)$ reported being victimized, and $73.3 \%(n=12,273)$ reported witnessing bullying within the past three months. Chi-square tests of independence were conducted on the number of children who reported overall bullying, victimization and witnessing across all forms by sex and grade. 
Table 1 illustrates chi-square values and percentages between boys and girls for bullying, victimization, and bystanding. A Yates correction for continuity was reported for all chi-square analyses involving sex or grade level due to a 2 (not involved versus involved) $\times 2$ (boys versus girls) design. This correction compensates for the overestimate of the chi-square value when using a $2 \times 2$ design (Pallant, 2010). Three chi-square tests for independence indicated statistically significant associations between sex and bullying involvement, victimization, and bystanding, respectively. A larger percentage of girls reported bullying others, were victimized, and also witnessed bullying behaviour in comparison to boys. According to effect size criteria by Cohen (1992), the effect size for bullying prevalence in the current study was close to .10 , which was considered to be small. The overall bullying and victimization percentages should be interpreted with caution. The differences in bullying perpetration and victimization between boys and girls were around $4 \%$ and $7 \%$, respectively. The difference in percentages between boys and girls for witnessing was above $10 \%$.

An additional chi-square test of independence was conducted to determine the association between grade level and overall bullying, victimization, and bystanding. Table 2 displays the overall rates of bullying involvement by grade level. A chi-square test for independence indicated no statistically significant association between grade and bullying involvement, indicating that both primary and secondary school students reported equal involvement in bullying perpetration. Two chi-square tests for independence indicated statistically significant associations between grade for victimization and bystanding. Overall, a larger percentage of primary students reported being victimized than secondary school students, 
Table 1

Overall Percentage of Bullying Involvement For Boys and Girls

\begin{tabular}{|c|c|c|c|c|c|}
\hline & $\begin{array}{c}\text { Not } \\
\text { involved }\end{array}$ & Involved & $\begin{array}{c}\text { Percentage } \\
\text { involved }\end{array}$ & Chi square & $\begin{array}{c}\text { Effect size } \\
\text { Phi }\end{array}$ \\
\hline \multicolumn{6}{|l|}{${ }^{\mathrm{a}}$ Bullying } \\
\hline${ }^{\mathrm{a}}$ Boys & $\begin{array}{c}4,654 \\
(4,509.3)\end{array}$ & $\begin{array}{c}3,999 \\
(4,143.7)\end{array}$ & 46.2 & $19.91^{* *}$ & $0.03^{* *}$ \\
\hline${ }^{\mathrm{a}}$ Girls & $\begin{array}{c}4,142 \\
(4,286.7) \\
\end{array}$ & $\begin{array}{c}4,084 \\
(3,939.3) \\
\end{array}$ & 49.6 & & \\
\hline Total & 8,796 & 8,083 & 47.9 & & \\
\hline \multicolumn{6}{|l|}{${ }^{\mathrm{b}}$ Victimization } \\
\hline${ }^{\mathrm{b} B o y s}$ & $\begin{array}{c}3,578 \\
(3,289.7)\end{array}$ & $\begin{array}{c}5,075 \\
(5,363.3)\end{array}$ & 58.7 & $83.37^{* *}$ & $0.07^{* *}$ \\
\hline${ }^{\mathrm{b}}$ Girls & $\begin{array}{c}2,839 \\
(3,127.3) \\
\end{array}$ & $\begin{array}{c}5,387 \\
(5,098.7) \\
\end{array}$ & 65.5 & & \\
\hline Total & 6,417 & 10,462 & 62.0 & & \\
\hline \multicolumn{6}{|l|}{${ }^{c}$ Bystanding } \\
\hline${ }^{\mathrm{c}}$ Boys & $\begin{array}{c}2,724 \\
(2,290)\end{array}$ & $\begin{array}{c}5,855 \\
(6,289)\end{array}$ & 68.2 & $229.57^{* *}$ & $0.12^{* *}$ \\
\hline${ }^{\circ}$ Girls & $\begin{array}{c}1,745 \\
(2,179)\end{array}$ & $\begin{array}{c}6,418 \\
(5,984) \\
\end{array}$ & 78.6 & & \\
\hline Total & 4,469 & 12,273 & 73.3 & & \\
\hline
\end{tabular}

Note. Expected values are in parentheses.

${ }^{a, b}$ Boys, $n=8,653 ;{ }^{a, b}$ Girls, $n=8,226 ;{ }^{a, b} \mathrm{~N}=16,879$.

${ }^{\mathrm{c}}$ Boys, $\mathrm{n}=8,579 ;{ }^{\mathrm{c}}$ Girls, $\mathrm{n}=8,163{ }^{\mathrm{c}} \mathrm{N}=16,742$. 
Table 2

Overall Percentage of Bullying Involvement For Primary and Secondary School Students

\begin{tabular}{|c|c|c|c|c|c|}
\hline & $\begin{array}{c}\text { Not } \\
\text { involved }\end{array}$ & Involved & $\begin{array}{l}\text { Percentage } \\
\text { involved }\end{array}$ & Chi Square & $\begin{array}{c}\text { Effect Size } \\
\text { Phi }\end{array}$ \\
\hline \multicolumn{6}{|l|}{ Bullying } \\
\hline${ }^{\mathrm{a}}$ Primary & $\begin{array}{c}6,330 \\
(6,346.7)\end{array}$ & $\begin{array}{c}5,849 \\
(5,832.3)\end{array}$ & 48.4 & 0.31 & -0.004 \\
\hline${ }^{a}$ Secondary & $\begin{array}{c}2,466 \\
(2,449.3) \\
\end{array}$ & $\begin{array}{c}2,234 \\
(2,250.7) \\
\end{array}$ & 47.7 & & \\
\hline Total & 8,796 & 8,083 & 47.9 & & \\
\hline \multicolumn{6}{|l|}{${ }^{\mathrm{b}}$ Victimzation } \\
\hline${ }^{b}$ Primary & $\begin{array}{c}4,207 \\
(4,630.2)\end{array}$ & $\begin{array}{c}7,972 \\
(7,548.8)\end{array}$ & 66.1 & $223.56^{* *}$ & $-0.12 * *$ \\
\hline${ }^{\mathrm{b}}$ Secondary & $\begin{array}{c}2,210 \\
(1,786.8)\end{array}$ & $\begin{array}{c}2,490 \\
(2,913.2)\end{array}$ & 53.2 & & \\
\hline Total & 6,417 & 10,462 & 62.0 & & \\
\hline \multicolumn{6}{|l|}{${ }^{\mathrm{c}}$ Bystanding } \\
\hline${ }^{c}$ Primary & $\begin{array}{c}3,412 \\
(3,219.2)\end{array}$ & $\begin{array}{c}8,648 \\
(8,840.8)\end{array}$ & 71.0 & $56.02 * *$ & $0.06^{* *}$ \\
\hline${ }^{\mathrm{c}}$ Secondary & $\begin{array}{c}1,057 \\
(1,249.8)\end{array}$ & $\begin{array}{c}3,625 \\
(3,432.2)\end{array}$ & 77.1 & & \\
\hline Total & 4,469 & 12,273 & 73.3 & & \\
\hline
\end{tabular}

Note. Expected values are in parentheses. Percentages are between grade.

${ }^{\mathrm{a}, \mathrm{b}}$ Primary, $\mathrm{n}=12,179 ;{ }^{\mathrm{a}, \mathrm{b}}$ Secondary, $\mathrm{n}=4,700 ;{ }^{\mathrm{a}, \mathrm{b}} \mathrm{N}=16,879$.

${ }^{c}$ Primary, $n=12,060 ;{ }^{c}$ Secondary, $n=4,682 ;{ }^{c} \mathrm{~N}=16,742$. 
and a larger percentage of secondary school students reported witnessing bullying in comparison to primary school students. Effect sizes of approximately .10 or lower were reported according to the effect size criteria by Cohen (1992). Although significant associations between sex and grade were found for victimization and bystanding, these effects were considered to be small. The difference in percentage between primary and secondary school students for bystanding was around $6 \%$, and therefore must be interpreted with caution. The difference in percentage between primary and secondary school students for victimization was above $10 \%$.

Physical, verbal, and social bullying involvement. Secondary analyses were conducted to examine the prevalence of physical, verbal, and social involvement in bullying, victimization, and witnessing. Table 3 examines the percentage of the three forms of bullying involvement for the total sample. The majority of students $(63-80 \%)$ reported no involvement at all as a perpetrator of bullying, $49-68 \%$ reported no involvement at all as a victim, and 36$44 \%$ reported no involvement as a witness. The majority of students (55-63\%) reported having witnessed physical, verbal, and social forms of bullying at least once over the duration of three months, whereas approximately $31-50 \%$ reported being victimized, and $20-36 \%$ reported bullying others at least once. Total involvement in verbal bullying, victimization and bystanding was reported most often, with total involvement as a bully perpetrator, victim and bystander ranging from $36-63 \%$. Engagement in physical forms of bullying, and victimization occurred less often, ranging from $20-60 \%$. Extreme bullying perpetration, victimization, and bystanding of every week or more occurred less frequently. Approximately $5 \%$ of students reported frequent bullying others every week or more, $10 \%$ reported being victimized every 
Table 3

Percentage of Physical, Verbal, and Social Bullying Involvement

\begin{tabular}{|c|c|c|c|}
\hline Status & Bullying & Victimization & Bystanding \\
\hline \multicolumn{4}{|l|}{ Physical } \\
\hline Not at all & 80.5 & 68.5 & 39.9 \\
\hline Once & 10.8 & 14.5 & 16.2 \\
\hline Few Times & 5.9 & 12.2 & 28.7 \\
\hline Every Week & 0.8 & 1.8 & 6.5 \\
\hline Many Times a Week & 2.0 & 3.0 & 8.7 \\
\hline Total Involvement & 19.5 & 31.5 & 60.1 \\
\hline \multicolumn{4}{|l|}{ Verbal } \\
\hline Not at all & 63.6 & 49.2 & 36.8 \\
\hline Once & 19.2 & 19.7 & 14.9 \\
\hline Few Times & 12.7 & 20.7 & 26.0 \\
\hline Every Week & 1.5 & 3.9 & 9.4 \\
\hline Many Times a Week & 3.0 & 6.4 & 12.7 \\
\hline Total Involvement & 36.4 & 50.8 & 63.0 \\
\hline \multicolumn{4}{|l|}{ Social } \\
\hline Not at all & 71.1 & 62.7 & 44.4 \\
\hline Once & 15.8 & 17.8 & 15.6 \\
\hline Few Times & 9.5 & 13.8 & 23.4 \\
\hline Every Week & 1.3 & 2.0 & 6.4 \\
\hline Many Times a Week & 2.3 & 3.6 & 9.1 \\
\hline Total Involvement & 28.9 & 37.2 & 55.5 \\
\hline
\end{tabular}


week or more, and $20 \%$ witnessed bullying every week or more.

The percentages of bullying involvement were examined separately for sex to determine the percentage of boys and girls involved in the three forms of bullying, victimization, and witnessing. Table 4 displays the percentage of boys and girls involved in bullying within the past three months. Overall, the majority of boys and girls were not involved in bullying perpetration at all. As bullying behaviour became more extreme in frequency, reported involvement in bullying, victimization, and witnessing was reported less often. Verbal bullying involvement was the most commonly reported form of bullying by both boys and girls, and physical bullying involvement was the least commonly reported. Finally, girls and boys reported witnessing social and verbal bullying more often than physical bullying.

Differences in the frequency of bullying between boys and girls were examined by chisquare tests for independence. Since the current sample was relatively large in size, a Bonferroni corrected alpha level of .006 was used (.05/9) to avoid making a Type 1 error. Table 5 displays the percentages and chi-square values for bullying perpetration between boys and girls. Two chi-square tests of independence indicated statistically significant associations between physical and social bullying perpetration and sex. A larger percentage of boys reported physically bullying others in comparison to girls, whereas a larger percentage of girls reported socially bullying others in comparison to boys. Similar percentages of boys and girls reported engaging in verbal bullying perpetration. Effect sizes were considered to be small. The differences in the percentages of physical and social bullying perpetration between boys and girls were close to $10 \%$.

Three chi-square tests of independence were conducted to determine the association for victimization involvement by sex. Table 6 displays the chi-square values and percentages for 
Table 4

Percentage of Bullying Involvement for Boys and Girls

\begin{tabular}{lcccccc}
\hline Bullying Form & \multicolumn{2}{c}{ Bullying } & \multicolumn{2}{c}{ Victimization } & \multicolumn{2}{c}{ Bystanding } \\
\cline { 2 - 7 } & Boys & Girls & Boys & Girls & Boys & Girls \\
\hline Physical & & & & & & \\
Not at all & 75.8 & 85.4 & 64.4 & 72.8 & 42.6 & 37.1 \\
Once & 12.8 & 8.7 & 15.8 & 13.2 & 14.8 & 17.7 \\
Few Times & 7.4 & 4.3 & 13.3 & 11.0 & 26.5 & 31.0 \\
Every Week & 1.0 & 0.5 & 2.4 & 1.1 & 6.4 & 6.7 \\
Many Times a Week & 2.9 & 1.0 & 4.1 & 1.9 & 9.7 & 7.5 \\
& & & & & & \\
Total Involvement & 24.2 & 14.6 & 35.6 & 27.2 & 57.4 & 62.9 \\
\hline Verbal & & & & & & \\
Not at all & & & & & & \\
Once & 63.6 & 63.6 & 51.7 & 46.5 & 41.6 & 31.8 \\
Few Times & 17.8 & 20.7 & 18.0 & 21.5 & 14.0 & 15.9 \\
Every Week & 12.9 & 12.6 & 18.7 & 22.9 & 23.0 & 29.1 \\
Many Times a Week & 1.7 & 1.3 & 4.2 & 3.6 & 8.8 & 10.3 \\
Total Involvement & 4.0 & 1.9 & 7.4 & 5.5 & 12.6 & 12.9 \\
& 36.4 & 36.4 & 48.3 & 53.5 & 58.4 & 68.2 \\
\hline Social l & & & & & & \\
Not at all & 75.5 & 66.4 & 68.9 & 56.3 & 51.7 & 37.5 \\
Once & 12.9 & 19.0 & 15.0 & 20.7 & 14.7 & 16.9 \\
Few Times & 7.5 & 11.5 & 10.6 & 17.1 & 19.7 & 27.7 \\
Every Week & 1.2 & 1.3 & 1.8 & 2.3 & 5.2 & 8.3 \\
Many Times a Week & 2.8 & 1.8 & 3.7 & 3.5 & 8.7 & 9.6 \\
Total Involvement & 24.4 & 33.6 & 31.1 & 43.8 & 48.3 & 62.5 \\
\hline
\end{tabular}

Note. Boys, $\mathrm{n}=8,653 ;$ Girls, $\mathrm{n}=8,226 ; \mathrm{N}=16,879$.

Social bystanding: Boys, $n=8,579$; Girls, $n=8,163 ; N=16,742$.

Percentages were between sex. Total involvement included any frequency of involvement from "once only in the past three months" to "many times a week." 
Table 5

Sex Differences in the Percentage of Physical, Verbal, and Social Bullying

\begin{tabular}{|c|c|c|c|c|c|}
\hline $\begin{array}{l}\text { Bullying } \\
\text { form }\end{array}$ & $\begin{array}{c}\text { Not } \\
\text { involved }\end{array}$ & Involved & $\begin{array}{c}\text { Percentage } \\
\text { involved }\end{array}$ & Chi Square & $\begin{array}{c}\text { Effect size } \\
\text { Phi }\end{array}$ \\
\hline \multicolumn{6}{|l|}{${ }^{a}$ Physical } \\
\hline${ }^{\mathrm{a}}$ Boys & $\begin{array}{c}6,558 \\
(6,961.8)\end{array}$ & $\begin{array}{c}2,095 \\
(1,619.2)\end{array}$ & 24.2 & $245.24 * *$ & $-0.12 * *$ \\
\hline${ }^{\mathrm{a}}$ Girls & $\begin{array}{c}7,022 \\
(6,618.2)\end{array}$ & $\begin{array}{c}1,204 \\
(1,607.8)\end{array}$ & 14.6 & & \\
\hline Total & 13,580 & 3,299 & 19.5 & & \\
\hline \multicolumn{6}{|l|}{${ }^{6}$ Verbal } \\
\hline${ }^{b}$ Boys & $\begin{array}{c}5,503 \\
(5,502.3)\end{array}$ & $\begin{array}{c}3,150 \\
(3,150.7)\end{array}$ & 36.4 & .001 & 0.00 \\
\hline${ }^{\mathrm{b}}$ Girls & $\begin{array}{c}3,230 \\
(5,230.7)\end{array}$ & $\begin{array}{c}2,996 \\
(2,995.3)\end{array}$ & 36.4 & & \\
\hline Total & 10,733 & 6,146 & 36.4 & & \\
\hline \multicolumn{6}{|l|}{ c'Social } \\
\hline cBoys & $\begin{array}{c}6,538 \\
(6,152.3)\end{array}$ & $\begin{array}{c}2,115 \\
(2,500.7)\end{array}$ & 24.4 & $171.24 * *$ & $0.10^{* *}$ \\
\hline${ }^{\circ}$ Girls & $\begin{array}{c}5,463 \\
(5,848.7)\end{array}$ & $\begin{array}{c}2,763 \\
(2,377.3)\end{array}$ & 33.6 & & \\
\hline Total & 12,001 & 4,878 & 28.9 & & \\
\hline
\end{tabular}

Note. Expected values are in parentheses. Percentages are between sex.

a, b Boys, $n=8,653 ;^{\text {a, b }}$ Girls, $n=8,226 ;{ }^{\text {a, }}{ }^{\mathrm{N}} \mathrm{N}=16,879$.

${ }^{c}$ Boys, $n=8,579 ;{ }^{c}$ Girls, $n=8,163 ;{ }^{c} N=16,742$.

** $p<.001$. 
Table 6

Sex Differences in the Percentage of Physical, Verbal, and Social Victimization

\begin{tabular}{|c|c|c|c|c|c|}
\hline $\begin{array}{l}\text { Victimization } \\
\text { form }\end{array}$ & $\begin{array}{c}\text { Not } \\
\text { involved }\end{array}$ & Involved & $\begin{array}{l}\text { Percentage } \\
\text { Involved }\end{array}$ & Chi Square & $\begin{array}{c}\text { Effect size } \\
P h i\end{array}$ \\
\hline \multicolumn{6}{|l|}{${ }^{\mathrm{a}}$ Physical } \\
\hline${ }^{\mathrm{a}}$ Boys & $\begin{array}{c}5,571 \\
(5,924.7)\end{array}$ & $\begin{array}{c}3,082 \\
(2,728,3)\end{array}$ & 35.6 & $137.01^{* *}$ & $-0.09 * *$ \\
\hline${ }^{\mathrm{a}}$ Girls & $\begin{array}{c}5,986 \\
(5,632.3)\end{array}$ & $\begin{array}{c}2,240 \\
(2,593.7)\end{array}$ & 27.2 & & \\
\hline Total & 11,557 & 5,322 & 31.5 & & \\
\hline \multicolumn{6}{|l|}{${ }^{b}$ Verbal } \\
\hline${ }^{b}$ Boys & $\begin{array}{c}4,474 \\
(4,256)\end{array}$ & $\begin{array}{c}4,179 \\
(4,397)\end{array}$ & 48.3 & $44.88^{* *}$ & $0.05^{* *}$ \\
\hline${ }^{\mathrm{b}}$ Girls & $\begin{array}{c}3,828 \\
(4,046)\end{array}$ & $\begin{array}{c}4,398 \\
(4,180)\end{array}$ & 53.5 & & \\
\hline Total & 8,302 & 8,577 & 50.8 & & \\
\hline \multicolumn{6}{|l|}{${ }^{{ }^{c} \text { Social }}$} \\
\hline c Boys & $\begin{array}{c}5,960 \\
(5,427.4)\end{array}$ & $\begin{array}{c}2,693 \\
(3,225.6)\end{array}$ & 31.4 & $287.14^{* *}$ & $0.13^{* *}$ \\
\hline${ }^{\circ}$ Girls & $\begin{array}{c}4,627 \\
(5,159.6)\end{array}$ & $\begin{array}{c}3,599 \\
(3,066.4)\end{array}$ & 44.1 & & \\
\hline Total & 10,587 & 6,292 & 37.2 & & \\
\hline
\end{tabular}

Note. Expected values are in parentheses. Percentages are between sex.

${ }^{a, b}$ Boys, $n=8,653 ;{ }^{a, b}$ Girls, $n=8,226 ;{ }^{a, b} \mathrm{~N}=16,879$.

${ }^{\mathrm{c}}$ Boys, $\mathrm{n}=8,579 ;{ }^{\mathrm{c}}$ Girls, $\mathrm{n}=8,163 ;{ }^{\circ} \mathrm{N}=16,742$.

$* * p<.001$. 
victimization involvement among boys and girls. A larger percentage of boys reported being physically victimized in comparison to girls, whereas a larger percentage of girls reported being verbally and socially victimized in comparison to boys. All effect sizes for victimization were considered to be small (Cohen 1992). Since the statistically significant differences in percentage between boys and girls for physical and verbal victimization were below $10 \%$, these differences must be interpreted with caution. The difference in percentage for social victimization between boy and girls was above $10 \%$.

A chi-square test of independence was conducted to determine the association between witnessing involvement and sex. See Table 7 for chi-square values and percentages for witnessing involvement by sex. Three chi-square tests of independence indicated statistically significant associations between sex and witnessing involvement. A larger percentage of girls reported witnessing physical, verbal, and social bullying in comparison to boys. Effect sizes were either below or slightly above the small effect size criteria by Cohen (1992). The difference in the percentage of witnessing physical bullying between boys and girls was approximately $5 \%$, and should be interpreted with caution. The differences in percentages of witnessing verbal and social bullying between boys and girls were slightly above $10 \%$.

Table 8 displays the percentages of bullying, victimization, and witnessing for primary and secondary school students. Overall, the majority of primary and secondary students were not involved in physical, verbal, or social bullying. When using a more inclusive cut-off of "once only in the past three months", larger percentage of primary and secondary students reported verbally and socially bullying others, as well as being verbally and socially victimized. Physical bullying perpetration, victimization, and witnessing were less commonly reported among students. The majority of primary and secondary students reported witnessing physical 
Table 7

Sex Differences in the Percentage of Physical, Verbal, and Social Witnessing

\begin{tabular}{|c|c|c|c|c|c|}
\hline $\begin{array}{l}\text { Bystanding } \\
\text { form }\end{array}$ & $\begin{array}{c}\text { Not } \\
\text { involved }\end{array}$ & Involved & $\begin{array}{l}\text { Percentage } \\
\text { involved }\end{array}$ & Chi Square & $\begin{array}{c}\text { Effect size } \\
P h i \\
\end{array}$ \\
\hline \multicolumn{6}{|l|}{ Physical } \\
\hline Boys & $\begin{array}{c}3,682 \\
(3,450.1)\end{array}$ & $\begin{array}{c}4,971 \\
(5,202.9)\end{array}$ & 57.4 & $52.95^{* *}$ & $0.06 * *$ \\
\hline Girls & $\begin{array}{c}3,048 \\
(3,279.9)\end{array}$ & $\begin{array}{c}5,178 \\
(4,946.1)\end{array}$ & 62.9 & & \\
\hline Total & 6,730 & 10,149 & 60.1 & & \\
\hline \multicolumn{6}{|l|}{ Verbal } \\
\hline Boys & $\begin{array}{c}3,599 \\
(3,186.6)\end{array}$ & $\begin{array}{c}5,054 \\
(5,466.4)\end{array}$ & 58.4 & $172.91^{* *}$ & $0.10^{* *}$ \\
\hline Girls & $\begin{array}{c}2,617 \\
(3,029.4)\end{array}$ & $\begin{array}{c}5,609 \\
(5,196.6)\end{array}$ & 68.2 & & \\
\hline Total & 6,216 & 10,633 & 63.0 & & \\
\hline \multicolumn{6}{|l|}{ Social } \\
\hline Boys & $\begin{array}{c}4,439 \\
(3,844.2)\end{array}$ & $\begin{array}{c}4,140 \\
(4,734.8)\end{array}$ & 48.3 & $341.42 * *$ & $0.14 * *$ \\
\hline Girls & $\begin{array}{c}3,063 \\
(3,657.8)\end{array}$ & $\begin{array}{c}5,100 \\
(4,505.2)\end{array}$ & 62.5 & & \\
\hline Total & 7,502 & 9,240 & 55.5 & & \\
\hline
\end{tabular}

Note. Expected values are in parentheses.

a,b Boys, $n=8,653 ;$;, $\mathrm{b}$ Girls, $\mathrm{n}=8,226 ;{ }^{\mathrm{a}, \mathrm{b}} \mathrm{N}=16,879$.

${ }^{\mathrm{c}}$ Boys, $\mathrm{n}=8,579 ;{ }^{\mathrm{c}}$ Girls, $\mathrm{n}=8,163 ;{ }^{\mathrm{c}} \mathrm{N}=16,742$.

${ }^{* *} p<.001$. 
INDIVIDUAL AND SCHOOL LEVEL PERCEPTIONS

Table 8

Percentage of Bullying Involvement For Primary and Secondary Students

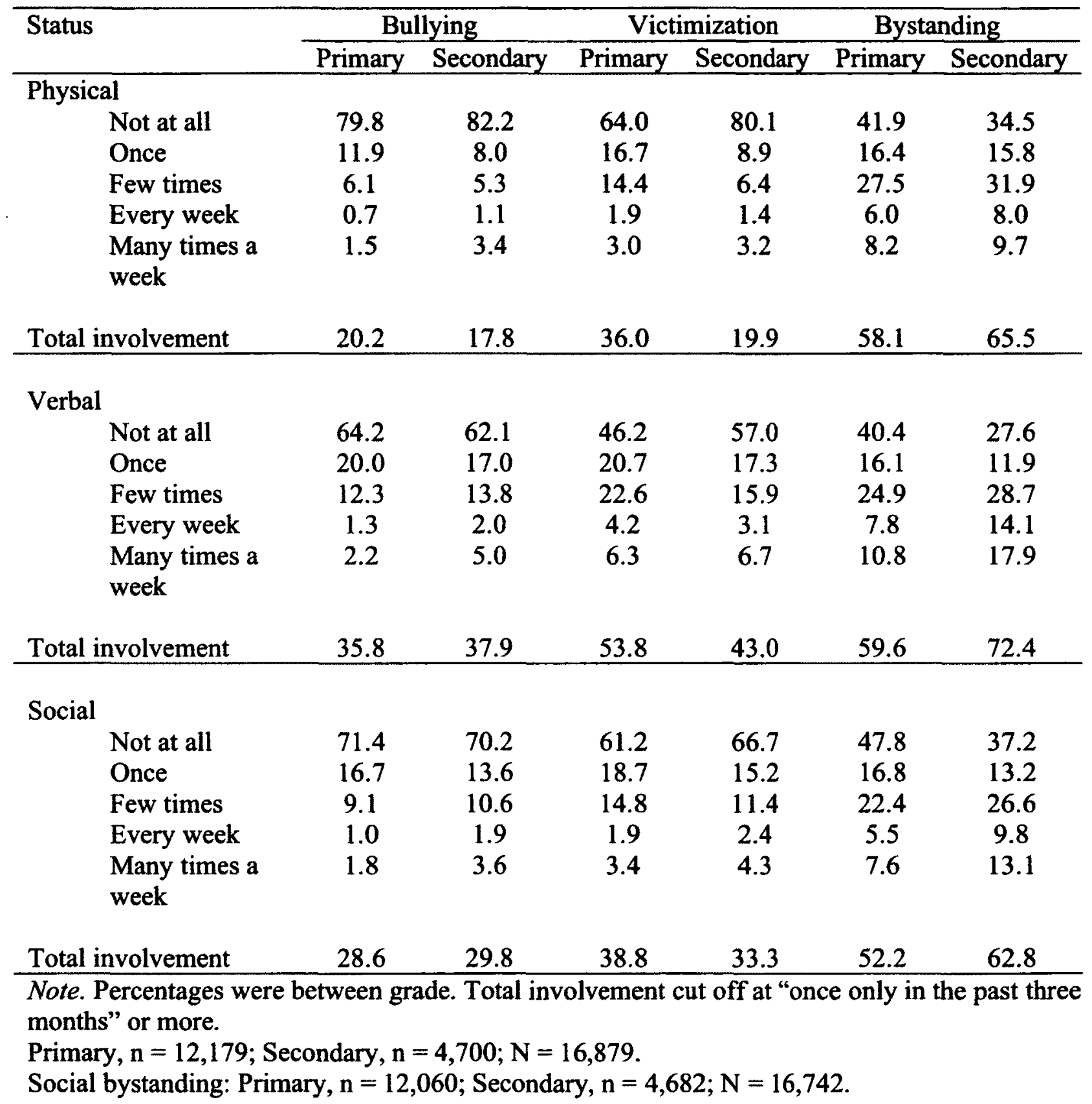


and social bullying behaviour within the past three months. When bullying involvement increased in frequency, prevalence rates dropped considerably. Frequent bullying involvement was measured by using a cut-off of "every week or more", which was an infrequent event that occurred within less than $10 \%$ of the sample. Frequent bullying perpetration for primary and secondary school students was below $5 \%$, whereas frequent victimization for primary and secondary school students was below $10 \%$. Frequent witnessing of bullying was below $30 \%$ for primary and secondary school students.

Three chi-square tests of independence were conducted to determine the associations between bullying perpetration and grade level. Table 9 reveals the chi-square values and percentage of bullying perpetration by grade level. One chi-square test of independence indicated a statistically significant association between physical bullying perpetration and grade. A higher percentage of primary school students reported engaging in physical bullying perpetration compared to secondary students. Equal proportions of primary and secondary school students reported engaging in verbal and social bullying perpetration. The effect sizes that were reported were below the small effect size criteria of 10 by Cohen (1992). The difference in the percentage of physical bullying perpetration for primary and secondary students was below $4 \%$, and should be interpreted with caution.

Three chi-square tests of independence were conducted to determine the associations between victimization involvement for primary and secondary students. Table 10 includes chisquare values and percentages of victimization for primary and secondary school students. Three chi-square tests of independence indicated statistically significant associations between forms of victimization involvement and grade level. A larger percentage of primary students reported being victimized physically, verbally, and socially in comparison to secondary school 
Table 9

Grade Differences in the Percentage of Physical, Verbal, and Social Bullying Perpetration

\begin{tabular}{|c|c|c|c|c|c|}
\hline $\begin{array}{l}\text { Bullying } \\
\text { form }\end{array}$ & $\begin{array}{c}\text { Not } \\
\text { involved }\end{array}$ & Involved & $\begin{array}{l}\text { Percentage } \\
\text { involved }\end{array}$ & Chi Square & $\begin{array}{c}\text { Effect size } \\
\text { Phi }\end{array}$ \\
\hline \multicolumn{6}{|l|}{${ }^{\mathrm{a}}$ Physical } \\
\hline${ }^{\mathrm{a}}$ Primary & $\begin{array}{c}9,717 \\
(9,798.6)\end{array}$ & $\begin{array}{c}2,462 \\
(2,380.4)\end{array}$ & 20.2 & $12.34^{* *}$ & $-0.03 * *$ \\
\hline a Secondary & $\begin{array}{c}3,863 \\
(3,781.4)\end{array}$ & $\begin{array}{c}837 \\
(918.6)\end{array}$ & 17.8 & & \\
\hline Total & 13,580 & 3,299 & 19.5 & & \\
\hline \multicolumn{6}{|l|}{${ }^{\mathrm{b}}$ Verbal } \\
\hline${ }^{\mathbf{b}}$ Primary & $\begin{array}{c}7,813 \\
(7,744.4)\end{array}$ & $\begin{array}{c}4,366 \\
(4,434.6)\end{array}$ & 35.8 & 5.91 & 0.02 \\
\hline 'Secondary & $\begin{array}{c}2,920 \\
(2,988.6)\end{array}$ & $\begin{array}{c}1,780 \\
(1,711.4)\end{array}$ & 37.9 & & \\
\hline Total & 10,733 & 6,146 & 36.4 & & \\
\hline \multicolumn{6}{|l|}{${ }^{\mathrm{c}}$ Social } \\
\hline${ }^{\mathbf{c}}$ Primary & $\begin{array}{c}8,701 \\
(8,659.3)\end{array}$ & $\begin{array}{c}3,478 \\
(3,519.7)\end{array}$ & 28.6 & 2.44 & 0.01 \\
\hline 'Secondary & $\begin{array}{c}3,300 \\
(3,341.7)\end{array}$ & $\begin{array}{c}1,700 \\
(1,358.3)\end{array}$ & 29.8 & & \\
\hline Total & 12,001 & 4,878 & 28.9 & & \\
\hline
\end{tabular}

Note. Expected values are in parentheses. Percentages are between grade.

${ }^{\mathrm{a}, \mathrm{b}}$ Primary, $\mathrm{n}=12,179 ;{ }^{\mathrm{a}, \mathrm{b}}$ Secondary, $\mathrm{n}=4,700 ;{ }^{\mathrm{a}, \mathrm{b}} \mathrm{N}=16,879$.

${ }^{c}$ Primary, $n=12,060 ;{ }^{~}$ Secondary, $n=4,682 ;{ }^{c} N=16,742$.

** $p<.001$. 
Table 10

Grade Differences in the Percentage of Physical, Verbal, and Social Victimization

\begin{tabular}{|c|c|c|c|c|c|}
\hline $\begin{array}{l}\text { Victimization } \\
\text { form }\end{array}$ & $\begin{array}{c}\text { Not } \\
\text { involved }\end{array}$ & Involved & $\begin{array}{l}\text { Percentage } \\
\text { involved }\end{array}$ & Chi Square & $\begin{array}{c}\text { Effect size } \\
P h i\end{array}$ \\
\hline \multicolumn{6}{|l|}{${ }^{\mathrm{a} P h y s i c a l}$} \\
\hline${ }^{a}$ Primary & $\begin{array}{c}7,792 \\
(8338.9)\end{array}$ & $\begin{array}{c}4,387 \\
(3840.1)\end{array}$ & 36.0 & $407.82^{* *}$ & $-0.16^{* *}$ \\
\hline a Secondary & $\begin{array}{c}3,765 \\
(3218.1)\end{array}$ & $\begin{array}{c}935 \\
(1,481.9)\end{array}$ & 19.9 & & \\
\hline \multirow{2}{*}{\multicolumn{6}{|c|}{${ }^{b}$ Verbal }} \\
\hline & & & & & \\
\hline${ }^{\mathrm{b}}$ Primary & $\begin{array}{c}5,624 \\
(5,990.3)\end{array}$ & $\begin{array}{c}6,555 \\
(6,188.7)\end{array}$ & 53.8 & $157.86^{* *}$ & $-0.10^{* *}$ \\
\hline bSecondary & $\begin{array}{c}2,678 \\
(2,311.7)\end{array}$ & $\begin{array}{c}2,022 \\
(2,388.3)\end{array}$ & 43.0 & & \\
\hline Total & 8,302 & 8,577 & 50.8 & & \\
\hline \multicolumn{6}{|l|}{$\begin{array}{l}{ }^{\mathrm{c}} \text { Social } \\
\text { (a) }\end{array}$} \\
\hline${ }^{\circ}$ Primary & $\begin{array}{c}7,454 \\
(7,639.0)\end{array}$ & $\begin{array}{c}4,725 \\
(4,540.0)\end{array}$ & 38.8 & $42.94^{* *}$ & $-0.05^{* *}$ \\
\hline${ }^{\mathrm{c} S}$ Secondary & $\begin{array}{c}3,133 \\
(2,948.0)\end{array}$ & $\begin{array}{c}1,567 \\
(1,752.0)\end{array}$ & 33.3 & & \\
\hline Total & 10,587 & 6,292 & 37.2 & & \\
\hline
\end{tabular}

Note. Expected values are in parentheses. Percentages are between grade.

${ }^{a, b}$ Primary, $n=12,179 ;{ }^{a, b}$ Secondary, $n=4,700 ;{ }^{a, b} \mathrm{~N}=16,879$.

${ }^{\mathrm{c}}$ Primary, $\mathrm{n}=12,060 ;{ }^{\mathrm{c}}$ Secondary, $\mathrm{n}=4,682 ;{ }^{\mathrm{c}} \mathrm{N}=16,742$.

$* * p<.001$. 
students. All effect sizes were considered to be small. The difference in percentage for social victimization between primary and secondary school students was below $5 \%$, which should be interpreted with caution. Differences in the percentage of verbal and physical victimization between primary and secondary students were close to or above $10 \%$.

Three chi-square tests of independence were conducted to determine the association between grade and witnessing involvement. Table 11 displays the percentages and chi-square values for grade and witnessing involvement. Three chi-square tests for independence indicated statistically significant associations for witnessing involvement between primary and secondary students. A larger percentage of secondary students reported witnessing physical, verbal, and social bullying in comparison to primary school students. The effect sizes of the statistically significant chi-square tests were small. The difference in the percentage of witnessing physical bullying for primary and secondary students was close to $7 \%$, which should be interpreted with caution. The differences in percentage of witnessing verbal and social forms of bullying for primary and secondary students were close to or above $10 \%$.

Overall, a larger number of primary school students were likely to report more bullying perpetration through physical forms. More primary students were also likely to report being victimized physically, verbally, and socially. A larger percentage of secondary school students witnessed all forms of bullying behaviour more often. No differences were found for verbal and social bullying perpetration by grade, indicating that similar proportions of primary and secondary school students reported verbally and socially bullying others. Small to smallmedium sized effects around .10 were reported according to Cohen (1992).

Prevalence rates for feeling unsafe at school. Since prevalence rates for bullying, victimization, and bystanding were examined, school safety prevalence was also of interest in 
Table 11

Grade Differences in the Percentage of Physical, Verbal, and Social Bystanding

\begin{tabular}{|c|c|c|c|c|c|}
\hline $\begin{array}{l}\text { Bystanding } \\
\text { form }\end{array}$ & $\begin{array}{c}\text { Not } \\
\text { involved }\end{array}$ & Involved & $\begin{array}{c}\text { Percentage } \\
\text { involved }\end{array}$ & Chi Square & $\begin{array}{c}\text { Effect size } \\
\text { Phi }\end{array}$ \\
\hline \multicolumn{6}{|l|}{${ }^{2}$ Physical } \\
\hline${ }^{\text {a Primary }}$ & $\begin{array}{c}5,107 \\
(4,856)\end{array}$ & $\begin{array}{c}7,072 \\
(7,323)\end{array}$ & 58.1 & $77.17^{* *}$ & $0.07 * *$ \\
\hline${ }^{\text {a Secondary }}$ & $\begin{array}{c}1,623 \\
(1,874)\end{array}$ & $\begin{array}{c}3,077 \\
(2,826)\end{array}$ & 65.5 & & \\
\hline Total & 6,730 & 10,149 & 60.1 & & \\
\hline \multicolumn{6}{|l|}{${ }^{5}$ Verbal } \\
\hline${ }^{\mathrm{b}}$ Primary & $\begin{array}{c}4,920 \\
(4,485.1)\end{array}$ & $\begin{array}{c}7,259 \\
(7,693.9)\end{array}$ & 59.6 & $239.13^{* *}$ & $0.12^{* *}$ \\
\hline${ }^{b}$ Secondary & $\begin{array}{c}1,296 \\
(1,730.9)\end{array}$ & $\begin{array}{c}3,404 \\
(2,969.1)\end{array}$ & 72.4 & & \\
\hline Total & 6,216 & 10,663 & 63.2 & & \\
\hline \multicolumn{6}{|l|}{ c Social } \\
\hline${ }^{\mathrm{c}}$ Primary & $\begin{array}{c}5,759 \\
(5,405)\end{array}$ & $\begin{array}{c}6,301 \\
(6,656)\end{array}$ & 52.2 & $150.65^{* *}$ & $0.10^{* *}$ \\
\hline 'Secondary & $\begin{array}{c}1,743 \\
(2,098)\end{array}$ & $\begin{array}{c}2,939 \\
(2,584)\end{array}$ & 62.8 & & \\
\hline Total & 7,502 & 9,240 & 55.5 & & \\
\hline
\end{tabular}

Note. Expected values are in parentheses. Percentages are between sex.

a,b Primary, $n=12,179 ;{ }^{a, b}$ Secondary, $n=4,700 ;{ }^{a, b} N=16,879$.

${ }^{\mathrm{c}}$ Primary, $\mathrm{n}=12,060 ;{ }^{\mathrm{c}}$ Secondary, $\mathrm{n}=4,682 ;{ }^{\mathrm{c}} \mathrm{N}=16,742$.

** $p<.001$. 
the current study. A total of 8,802 (52.1\%) students reported feeling safe all of the time, 5,621 (33.3\%) most of the time, $1,494(8.9 \%)$ some of the time, 435 (2.6\%) rarely, and $527(3.1 \%)$ never felt safe at school. According to the school safety cut-off scores used by Vaillancourt et al. (2008) in a Canadian sample, combining "never " or "rarely" constituted reports of feeling unsafe at school. In the current sample, 5.7\% (962 students; 672 primary and 290 secondary) reported not feeling safe at school.

\section{Mean differences in Independent Variables by Sex and Grade}

In addition to examining the prevalence rates of bullying, victimization, bystanding and for feeling unsafe at school, mean differences by sex and grade level for adult availability, moral engagement, moral disengagement, and feeling unsafe at school were examined. Four 2 (boys versus girls) $\mathrm{2}$ (primary versus secondary) ANOVA's were conducted to examine the differences in mean levels of moral engagement, moral disengagement, adult availability, and feeling unsafe at school. A Bonferroni adjustment of 0.0125 was used (.05/4).

There were no significant interactions between grade level and sex for moral engagement, $F(1,15481)=4.56, p=.03$, moral disengagement, $F(1,15660)=2.78, p=10$, adult availability, $F(1,15532)=1.64, p=.20$, and feeling unsafe at school, $F(1,16875)=.02, p$ $=.90$. A statistically significant main effect for moral engagement was found for sex, $F(1$, $15481)=22.07, \mathrm{p}<.001$, partial $\eta^{2}=.005$, indicating that girls $(M=2.04 ; S D=.52)$ were more likely to endorse moral engagement mechanisms in comparison to boys $(M=1.97 ; S D=.57)$. Furthermore, a statistically significant main effect for grade was found, $F(1,15481)=58.25, p$ $<.001$, partial $\eta^{2}=.004$, indicating that primary school students were more likely to endorse moral engagement mechanisms $(M=2.03 ; S D=.54)$ in comparison to secondary school students $(M=1.95 ; S D=.56)$. 
Significant main effects for moral disengagement were found for $\operatorname{sex} F(1,15,660)=$ $116.48, p<.001$, partial $\eta^{2}=.007$ and grade level, $F(1,15660)=111.71, p<.001$, partial $\eta^{2}=$ .004. Boys reported higher endorsement of moral disengagement mechanisms $(M=1.01 ; S D=$ $.68)$ than girls $(M=.89 ; S D=.62)$, whereas secondary school students reported higher endorsement of moral disengagement mechanisms $(M=1.044 ; S D=.67)$ than primary students $(M=.91 ; S D=.64)$

A statistically significant main effect for sex, $F(1,15532)=101.68, p<.001$, partial $\eta^{2}=$ .007 , and grade level, $F(1,15532)=1809.99, p<.001$, partial $\eta^{2}=.104$, was found for adult availability. Girls reported higher levels of adult availability $(M=1.38 ; S D .57)$ than boys $(M=$ $1.26 ; S D=.63)$, and primary school students reported more adult availability $(M=1.44 ; S D=$ .58) than secondary school students $(M=1.00 ; S D=55)$. A statistically significant main effect for grade level, $F(1,16875)=8.20, p<.01$, partial $\eta^{2}=.0005$, was found for feeling unsafe at school, such that primary students reported feeling less safe $(M=1.72 ; S D=.95)$ than secondary students $(M=1.67 ; S D=.97)$. No statistically significant main effect for sex was found, $F(1,16875)=4.63, p<.05$, indicating that boys $(M=1.72 ; S D=1.02)$ and girls $(M=$ $1.69 ; S D=.88$ ) felt equally safe.

Overall, mean differences displayed that girls were more likely to support moral engagement mechanisms, less likely to support moral disengagement mechanisms, perceived adults as more available, in comparison to boys. Boys and girls reported equal mean levels of feeling safe at school. Mean differences at the school level showed that secondary students reported less moral engagement, higher moral disengagement, less adult availability, but felt safer at school in comparison to primary school students. These differences must be interpreted 
with caution, since the differences are extremely small according to the effect size criteria below .10 by Cohen (1992).

\section{Hierarchical Linear Modeling}

Prior to conducting data analysis involving HLM, the data were screened according to the checklist by Dedrick et al. (2009) for missing data, outliers, assumptions of normality and linearity at Level-1 and Level-2. All values were checked and found to be within the plausible ranges.

Missing data. A missing value analysis was conducted on the Level-1 independent and dependent variables of interest. For the dependent variables relating to bullying involvement, $137(0.8 \%)$ cases were missing for the social bystanding variable only. No other variables of bullying involvement contained missing values.

Out of 16,879 students, $1,343(8 \%)$ had data missing on our independent variables for adult availability, $1,215(7.2 \%)$ had data missing for moral disengagement, and $1,349(8.3 \%)$ had data missing for moral engagement. Little's MCAR test under the EM estimation method in SPSS was used to test if the pattern of missing values was missing completely at random (MCAR). Data was not missing completely at random, as shown by a significant Little's MCAR test, $\chi^{2}(103)=317.72, p<.001$. This may be in part due to having the remaining part of the survey labelled as optional. Therefore, data that is not missing completely at random can be inferred from this pattern (Tabachnick \& Fidell, 2007).

HLM is able to compensate for data not missing completely at random for Level-1, but is unable to compensate for missing data at Level-2. In HLM, maximum likelihood methods are used to produce accurate parameter estimates for missing values by borrowing information from Level-1 observations (Nezlek, 2008). In this sample, there were no missing values on any of the 
variables at Level-2. Data was therefore entered into the HLM models under the Maximum Likelihood Estimation Method with missing data included at Level-1.

Distributions and univariate outliers. Data were screened for outliers using box-plots, and through estimated residuals at Level-1 and Level-2. All dependent variables examining bullying behaviour were positively skewed and reflected the natural progression of this behaviour within the population. Bullying behaviour and victimization behaviour were positively skewed and outliers were detected through z-scores at the tail end of the distribution. Bullying victimization distributions were extremely positively skewed, and values above 3 for bullying, and 3.67 for victimization were found to be outliers above a z-score of 3.29 (Tabachnick \& Fidell, 2007). All outliers were deemed to be legitimate (i.e. within range and flagged due to skewness of the distribution) and kept in the remaining analyses. These extreme cases of bullying are of interest to developmental researchers, and it would not make theoretical sense to delete them from the analysis.

Assumptions of linearity and normality. The residuals in the multilevel model at Level-1 were screened for outliers and influential observations against each dependent variable of bullying, victimization, and bystanding. The transformation of the criterion variable has been recommended by researchers to improve the violation of residual normality and linearity. A log transformation was considered to improve multivariate normality and linearity of the bullying and victimization dependent variables. Although the variable of bullying and victimization was transformed, the variability at the individual and school level decreased severely to below zero, interfering with the interpretation of the variance at Level- 1 and Level-2. According to Maas and Hox (2004), HLM assumes a large sample size at Level-1, and the influence of nonnormality at Level-1 is less in comparison to non-normality at Level-2. Due to the large sample 
size in this study, less restrictive assumptions of normality and linearity are needed at Level-1, and assumptions of linearity and normality will therefore be examined at Level-2.

To test the model assumptions for normality and linearity, residuals were examined at Level-2, which is suggested by Rasbash, Steele et al. (2009). Examining the standardized residuals plotted against normal scores tested normality, and linearity was examined through the standardized residuals plotted against predicted scores, as suggested by Rasbash, Steele et al. (2009). Residuals at Level-2 met the assumption of linearity, and followed a normal distribution, which were between a standardized value of 2.9 and -2.9. Influence values were below a recommended value of 1 at .32 , and deletion values were below a value of 1 at .8 (Bryk \& Raudenbush, 2002). For victimization, Level-2 residuals met the assumption of linearity, and followed a normal distribution with outlying schools between 2.7 and -2.7 . Influence statistics were below a value of .05 , and the outliers that had leverage scores were below 0.7 . Residuals of the bystander variable at Level-2 met the assumption of linearity, and were between a value of -3.2 and 3.2. Although the influence statistics were below .05 , leverage values were below .012 , and deletion of residuals were between -2.8 and 3.2 . When assumptions of normality are violated at Level-2, sandwich estimators (robust standard errors) are suggested for less restrictive model assumptions (Snijders \& Bosker, 1999). Since distributional assumptions regarding residuals were not violated at Level-2, robust standard errors which are less dependent on the assumption of normality (Maas \& Hox, 2004; 2005) were not used (T. Vaillancourt, personal communication, December 12, 2011).

Power in multi-level studies. In multilevel regression simulation studies regarding low sample size and group size have found to not impact the parameter estimates or variance components at Level-1. At level-2, the group level variance estimates are estimated smaller 
when the numbers of groups are under 100 (Maas \& Hox, 2004; 2005). Furthermore, small group sizes around 50 lead to biased estimates of Level-2 standard errors (Maas \& Hox, 2004). To avoid bias in the variance in a two-level random intercepts model, Clarke and Wheaton (2007) suggest at least 10 observations per group, including at least 100 groups. Six schools in the present study had less than 10 students, and were characterized by wider variability ranges and higher leverage values than schools with more than 10 students. By including these schools in the model, the regression coefficients were slightly larger and the deviance statistics were higher indicating poorer model fit when the schools with 10 pupils remained. Schools with less than 10 pupils were removed from the study since those scores were not representative of the whole school population. In total, 108 schools remained in the analyses. Despite dropping these schools, the group size remained over the suggested size of 100 . As shown in Table 12, the Level-1 and Level-2 means, standard deviations, and range values are summarized.

Correlations at Level-1 and Level-2. Table 13 summarizes the correlation matrices for the variables at Level-1 and Level-2. At Level-1, bullying, victimization, and bystanding were significantly positively correlated with moral disengagement and school safety. Bullying, victimization, and bystanding were also significantly negatively related to adult availability. Bullying and bystanding were significantly negatively related to moral engagement, in that bystanders and bully perpetrators were less likely to endorse moral engagement attitudes. There was no significant relationship found for victimization and moral engagement at Level-1. Bullying and bystanding were significantly positively correlated with age and victimization was negatively correlated with age. Adult availability was significantly positively related to moral engagement and negatively related to moral disengagement. School safety was negatively related to moral engagement and adult availability, indicating a relationship between low 
Table 12

HLM Descriptives For Bullying Involvement

\begin{tabular}{lllcc}
\hline & Mean & SD & Minimum & Maximum \\
\hline $\begin{array}{l}\text { Independent variables } \\
\text { Level 1 }\end{array}$ & & & & \\
(N = 16,858) & & & & \\
$\quad$ Sex $(0=$ boy, 1 = & 0.487 & 0.50 & 0 & 1 \\
girl) $\quad$ Age & 12.54 & 2.47 & 8 & 20 \\
$\quad$ School safety & 1.71 & 0.95 & 1 & 5 \\
$\quad$ Adult availability & 1.32 & 0.60 & 0 & 3 \\
$\quad$ Moral engagement & 2.01 & 0.55 & 0 & 3 \\
$\quad$ Moral disengagement & 0.95 & 0.65 & 0 & 3 \\
\hline Level 2 & & & & \\
(N) 108) & & & & \\
$\quad$ Grade (0 = primary, 1 & 0.28 & 0.45 & 0 & 1 \\
$\quad$ secondary) & 1.40 & 0.28 & 0.82 & 2 \\
$\quad$ Adult availability & 2.04 & 0.24 & 1.81 & 2.37 \\
$\quad$ Moral engagement & 0.94 & 0.31 & 0.57 & 1.19 \\
$\quad$ Moral disengagement & 1.74 & 0.37 & 1.35 & 2.11 \\
$\quad$ School safety & & & & \\
\hline Dependent variables & 0.47 & 0.74 & 0 & 4 \\
Bullying & 0.73 & 0.88 & 0 & 4 \\
Victimization & 1.31 & 1.18 & 0 & 4 \\
Bystanding & & & & \\
\hline
\end{tabular}


INDIVIDUAL AND SCHOOL LEVEL PERCEPTIONS

Table 13

Correlation Matrices for Variables at Level-1 and Level-2

\begin{tabular}{|c|c|c|c|c|c|c|c|c|}
\hline & 1 & 2 & 3 & 4 & 5 & 6 & 7 & 8 \\
\hline \multicolumn{9}{|l|}{ Level-1 Variables } \\
\hline 1. Bullying & - & & & & & & & \\
\hline 2. Victimization & $.45^{* *}$ & - & & & & & & \\
\hline 3. Bystander & $.45^{* *}$ & $.42^{* *}$ & - & & & & & \\
\hline 4. Sex & $-.04 * *$ & .01 & $.08 * *$ & - & & & & \\
\hline 5. Age & $.10^{* *}$ & $-.07^{* *}$ & $.20^{* *}$ & -.01 & - & & & \\
\hline 6. School Safety & $.25^{* *}$ & $.47^{* *}$ & $.21^{* *}$ & $-.02^{*}$ & $.03^{* *}$ & - & & \\
\hline 7. Adult Avail & $-.12 * *$ & $-.04 * *$ & $-.12^{* *}$ & $.09^{* *}$ & $.34^{* *}$ & $-.12 * *$ & - & \\
\hline 8. ME & $-.14^{* *}$ & .01 & $-.04 * *$ & $.07^{* *}$ & $.10^{* *}$ & $-.06 * *$ & $-.13 * *$ & \\
\hline \multirow[t]{2}{*}{ 9. MD } & $.20^{* *}$ & $.06^{* *}$ & $.11^{* *}$ & $-.09 * *$ & $.15^{* *}$ & $.11^{* *}$ & $-.21 * *$ & $-.40 * *$ \\
\hline & 1 & 2 & 3 & 4 & & & & \\
\hline \multicolumn{9}{|l|}{ Level-2 Variables } \\
\hline 1. Grade & - & & & & & & & \\
\hline 2. School Safety & $-.15^{* *}$ & - & & & & & & \\
\hline 3. Adult & $-.81^{* *}$ & $-.03 * *$ & & & & & & \\
\hline 4. $\mathrm{ME}$ & $-.36 * *$ & $-.28^{* *}$ & $.48^{* *}$ & & & & & \\
\hline 5. MD & $.43^{* *}$ & $.17^{* *}$ & $-.58 * *$ & $-.83 * *$ & & & & \\
\hline
\end{tabular}


endorsement of moral engagement attitudes and increased feelings of being unsafe and low adult availability. School safety was positively related to moral disengagement, indicating that increased feeling of being unsafe is related to endorsement of moral disengagement attitudes.

At the school level, collective moral disengagement was negatively related to grade and school safety, whereas collective moral engagement was positively related to grade and school safety. Collective moral engagement was also significantly related to adult availability, whereas collective moral disengagement was significantly negatively correlated with adult availability. Furthermore, collective adult availability was negatively related to low school safety. School level correlations that exceeded .80 included that between moral disengagement and moral engagement, and between grade and adult availability. Therefore, multicollinearity may be an issue for these variables. Moral engagement was included in the final model due to theoretical assumptions that moral engagement and moral disengagement exist as separate dimensions.

\section{Bullying, Victimization and Witnessing Models}

Bullying involvement. A Hierarchical Linear Model was conducted to examine the individual and school level effects for bullying involvement. Table 14 summarizes each model involving all hierarchical levels (null, Level-1, and Level-2) for bullying involvement. The between and within schools variance component is calculated by an Intra-class Correlation Coefficient (ICC). The ICC value is a strength of association or effect size measure (Tabachnick \& Fidell, 2007), examining the ratio of variability between schools at Level-2 to variability within those schools at Level- 1 . The ICC for the null model revealed that approximately $2 \%$ of the variance in bullying is between schools, and $98 \%$ within schools ${ }^{1}$. Although the majority of variance can be accounted for within schools, a significant chi-square value determined that

\footnotetext{
${ }^{1}$ The Intraclass Correlation Coefficient is calculated by the following formula provided by Bryk and Raudenbush (2002): $\rho=\mu_{0}$ unconditional null $/\left(\mu_{0}\right.$ unconditional null $+\varepsilon_{0}$ unconditional null).
} 
Table 14

Effects of Individual-Level and School-Level Variables on Bullying

\begin{tabular}{|c|c|c|c|c|c|c|}
\hline & $\begin{array}{l}\text { Null } \\
\text { Model }\end{array}$ & & $\begin{array}{l}\text { Level-1 } \\
\text { Model }\end{array}$ & & $\begin{array}{l}\text { Level-2 } \\
\text { Model }\end{array}$ & \\
\hline \multicolumn{7}{|l|}{ Level-1 } \\
\hline Constant & $0.452 * * *$ & $(0.012)$ & $0.489 * * *$ & $(0.012)$ & $0.500^{* * *}$ & $(0.016)$ \\
\hline Female & & & -0.015 & $(0.012)$ & -0.015 & $(0.012)$ \\
\hline Age & & & $0.026^{* * *}$ & $(0.003)$ & $0.037^{* * *}$ & $(0.004)$ \\
\hline Adult Availability & & & $-0.048 * * *$ & $(0.011)$ & $-0.053 * * *$ & $(0.011)$ \\
\hline Moral Engagement & & & $-0.077 * * *$ & $(0.012)$ & $-0.077 * * *$ & $(0.012)$ \\
\hline Moral & & & $0.147^{* * *}$ & $(0.010)$ & $0.145^{* * *}$ & $(0.010)$ \\
\hline \multicolumn{7}{|l|}{ Disengagement } \\
\hline School Safety & & & $0.177 * * *$ & $(0.006)$ & $0.176^{* * *}$ & $(0.006)$ \\
\hline \multicolumn{7}{|l|}{ Level-2 } \\
\hline Secondary & & & & & -0.075 & $(0.039)$ \\
\hline Adult Availability & & & & & 0.113 & $(0.069)$ \\
\hline Moral Engagement & & & & & 0.086 & $(0.168)$ \\
\hline Moral & & & & & 0.105 & $(0.126)$ \\
\hline \multicolumn{7}{|l|}{ Disengagement } \\
\hline Safety & & & & & $0.138^{*}$ & $(0.067)$ \\
\hline \multicolumn{7}{|l|}{ Variance } \\
\hline $\begin{array}{l}\text { Between Schools } \\
\left(\mu_{0}\right)\end{array}$ & 0.010 & $(0.002)$ & 0.005 & $(0.001)$ & 0.004 & $(0.001)$ \\
\hline Within Schools $\left(\varepsilon_{0}\right)$ & 0.537 & $(0.006)$ & 0.480 & $(0.006)$ & 0.480 & $(0.006)$ \\
\hline Total Variance & 0.547 & & 0.485 & & 0.484 & \\
\hline$-2 \operatorname{LogL}$ (Deviance) & 37478.68 & & 29298.92 & & 29277.94 & \\
\hline
\end{tabular}

Note. Standard errors are in parentheses.

${ }^{* * *} p<.001, * * p<.01,{ }^{*} p<.05$. 
variation between schools could be explained, $\chi^{2}(1)=147.26, p<.001$. All Level-1 variables were centered around the grand mean. The final model for bullying included:

Bullying $_{\mathrm{ij}}=\beta_{0 \mathrm{j}}$ Constant $+\beta 1_{\mathrm{ij}}$ (Female) $+\beta 2_{\mathrm{ij}}(\mathrm{age})+\beta 3_{\mathrm{ij}}$ (Adult Availability) $+\beta 4_{\mathrm{ij}}$ (Moral Engagement) $+\beta 5_{\mathrm{ij}}$ (Moral Disengagement) $+\beta 6_{\mathrm{ij}}$ (School safety) $+\gamma_{01 \mathrm{j}}$ (Secondary) $+\gamma_{02 \mathrm{j}}$ (Adult Availability) $+\gamma_{03 \mathrm{j}}$ (Moral Disengagement) $+\gamma_{04 \mathrm{j}}($ Safety) $\beta_{0 \mathrm{ij}}=+\gamma_{00}+\mu_{0 \mathrm{j}}+\varepsilon_{0 \mathrm{ij}}$

Significant predictors of bullying at Level-1 included older age, low adult availability, low moral engagement, high moral disengagement, and high perceptions of feeling unsafe at school. Sex was not a significant predictor of individual bullying behaviour. By including these Level-1 predictors in the model, the Level-1 variables explained approximately $11 \%$ of the proportion of variance in bullying $\left(\mathrm{R}_{1}^{2}=.113\right)^{2}$. In the conditional Level-1 model, a one-unit increase in age, moral disengagement, and student safety increased the average levels of bullying by $.03, .15$, and .18 , respectively. In addition, a one-unit increase in moral engagement and adult availability decreased the average levels of bullying by .05 and .08 , respectively. The Level- 2 conditional model including grade, collective perceptions of adult availability, moral engagement, moral disengagement, and feeling unsafe accounted for an additional $9 \%\left(\mathrm{R}_{2}^{2}=.089\right)^{3}$ of the variance between schools for bullying. All predictors at

\footnotetext{
${ }^{2}$ The formula for $\mathrm{R}_{1}^{2}$ was calculated by comparing the variance terms of the Level-1 conditional model to the unconditional null model by using Snijders and Bosker (1999): $\mathbf{R}^{2}{ }_{1}=1$ $-\left[\left(e_{0}\right.\right.$ conditional level-1 $+\mu_{0}$ conditional Level-1 $/\left[\left(\mathrm{e}_{0}\right.\right.$ unconditional null $+\mu_{0}$ unconditional null $]$

${ }^{3}$ The formula for $\mathrm{R}_{2}^{2}$ was calculated by comparing the variance terms of the Level-2 conditional model to the unconditional null model. The harmonic mean is used when the sample sizes are unbalanced (Luke, 2004), and is noted by $n_{\mathrm{H}}$. used in this model was calculated at 77.62. The following formula for calculating the variability accounted for by the level-2 model suggested by Snijders and Bosker (1999): $\mathrm{R}_{2}^{2}=1-\left[\left(\mathrm{e}_{0}\right.\right.$ conditional level-2 $\left./ \mathrm{n}_{\mathrm{H}}\right)+\mu_{0}$ conditional Level-2 $] /$ $\left[\left(\mathrm{e}_{0}\right.\right.$ unconditional null $\left./ \mathrm{n}_{\mathrm{H}}\right)+\mu_{0 \text { unconditional null }]}$
} 
Level-1 remained significant, while collective perceptions of feeling unsafe was the only statistically significant predictor at Level-2. Therefore, the inclusion of the Level-2 variables in the final model decreased the school level error variance by $9 \%$.

Victimization involvement. A hierarchical linear random intercepts model was conducted to examine the individual and school level effect for victimization involvement. Table 15 displays the HLM coefficients for victimization. Approximately $2.7 \%$ of the variance in victimization could be accounted for between schools $(\mathrm{ICC}=.027)$, and $96.3 \%$ within schools. The null hypothesis that average levels victimization was identical between schools was rejected, $\chi^{2}(1)=275.46, p<.001$, indicating that the variance between schools for mean levels of victimization could be accounted for. The final model for victimization included: Victimization $_{\mathrm{ij}}=\beta_{0 \mathrm{j}}$ Constant $+\beta 1_{\mathrm{ij}}($ Female $)+\beta 2_{\mathrm{ij}}($ age $)+\beta 3_{\mathrm{ij}}$ (Adult Availability) $+\beta 4_{\mathrm{ij}}$ (Moral Engagement $)+\beta 5_{i j}$ (Moral Disengagement $)+\beta 6_{i j}$ (School safety $)+\gamma_{01 j}$ (Secondary $)+\gamma_{02 \mathrm{j}}$ (Adult Availability) $+\gamma_{03 \mathrm{j}}$ (Moral Disengagement) $+\gamma_{04 \mathrm{j}}($ Safety) $\beta_{0 \mathrm{ij}}=+\gamma_{00}+\mu_{0 \mathrm{j}}+\varepsilon_{0 \mathrm{ij}}$

In the first model at Level-1, statistically significant predictors of victimization included being a girl, younger age, low adult availability, high moral engagement, high moral disengagement, and perceptions of feeling unsafe at school. The proportion of variance accounted for by the addition of the individual predictors at Level- $1\left(\mathrm{R}_{1}{ }_{1}=.22\right)$ for victimization was $22 \%$. In the conditional Level-1 model, a one-unit increase in sex, moral disengagement, and student safety increased the average levels of bullying by $.03, .03$, and .43 , respectively. In addition, a one-unit increase in age, adult availability, and moral engagement decreased the average levels of bullying by $.01, .03$, and .03 , respectively.

The Level- 2 conditional model including grade, collective perceptions of adult 
Table 15

Effects of Individual-Level and School-Level Variables on Victimization

\begin{tabular}{|c|c|c|c|c|c|c|}
\hline & $\begin{array}{c}\text { Null } \\
\text { Model }\end{array}$ & & $\begin{array}{l}\text { Level-1 } \\
\text { Model }\end{array}$ & & $\begin{array}{c}\text { Level-2 } \\
\text { Model }\end{array}$ & \\
\hline \multicolumn{7}{|l|}{ Level-1 } \\
\hline Constant & $0.766^{* * *}$ & $(0.016)$ & $0.748 * * *$ & $(0.015)$ & $0.762 * * *$ & $(0.020)$ \\
\hline male & & & $0.027^{*}$ & $(0.013)$ & $0.028^{*}$ & $(0.013)$ \\
\hline Age & & & $-0.011 *$ & $(0.004)$ & -0.000 & $(0.005)$ \\
\hline Adult Availability & & & $-0.025^{*}$ & $(0.012)$ & $-0.028 *$ & $(0.012)$ \\
\hline Moral Engagement & & & $-0.034 * *$ & $(0.013)$ & $0.033 * *$ & $(0.013)$ \\
\hline Moral & & & $0.033 * *$ & $(0.011)$ & $0.031 *$ & $(0.011)$ \\
\hline \multicolumn{7}{|l|}{ Disengagement } \\
\hline School Safety & & & $0.427^{* * *}$ & $(0.007)$ & $0.426 * * *$ & $(0.007)$ \\
\hline \multicolumn{7}{|l|}{ Level-2 } \\
\hline Secondary & & & & & -0.089 & $(0.051)$ \\
\hline Adult Availability & & & & & 0.079 & $(0.089)$ \\
\hline Moral Engagement & & & & & 0.357 & $(0.213)$ \\
\hline Moral & & & & & 0.139 & $(0.161)$ \\
\hline Disengagement & & & & & & \\
\hline School Safety & & & & & $0.241 * *$ & $(0.087)$ \\
\hline \multicolumn{7}{|l|}{ Variance } \\
\hline $\begin{array}{l}\text { Between Schools } \\
\left(\mu_{0}\right)\end{array}$ & 0.021 & $(0.004)$ & 0.011 & $(0.002)$ & 0.008 & $(0.002)$ \\
\hline Within Schools $\left(\varepsilon_{0}\right)$ & 0.758 & $(0.008)$ & 0.597 & $(0.007)$ & 0.597 & $(0.007)$ \\
\hline Total Variance & 0.779 & & 0.608 & & 0.605 & \\
\hline$-2 \operatorname{LogL}$ (Deviance) & 43323.86 & & 32350.84 & & 32329.14 & \\
\hline
\end{tabular}

Note. Standard errors are in parentheses.

$* * * p<.001, * * p<.01,{ }^{*} p<.05$. 
availability, moral engagement, moral disengagement, and feeling unsafe at school reduced the between school variance in victimization by $16 \%\left(\mathrm{R}_{2}^{2}=.16\right)$. All predictors at Level-1 remained significant within the Level-2 model with the exception of age. Collective perceptions of feeling unsafe was the only statistically significant predictor of victimization at Level-2.

Bystanding involvement. A hierarchical linear random intercepts model was conducted to examine the individual and school level effects for witnessing involvement. Table 16 displayed the HLM coefficients for witnessing involvement. The investigation of the variance components of the null model revealed that approximately $7 \%$ of the variability in bystanding is associated with differences between schools, and $93 \%$ of the variability in bystanding is associated with differences within schools $(\mathrm{ICC}=.067)$. The null hypothesis that mean levels of witnessing behaviour were identical between schools was rejected, $\chi^{2}(1)=720.27, p<.001$. This indicates that mean levels of witnessing behaviour differed across schools. The bystanding model included:

Bystanding $\mathrm{ij}_{\mathrm{j}}=\beta_{0 j}$ Constant $+\beta 1_{i j}($ Female $)+\beta 2_{i j}($ age $)+\beta 3_{i j}$ (Adult Availability) $+\beta 4_{i j}$ (Moral Engagement $)+\beta 5_{i j}($ Moral Disengagement $)+\beta 6_{i j}($ School safety $)+\gamma_{01 j}($ Secondary $)+\gamma_{02 j}$ (Adult Availability) $+\gamma_{03 j}$ (Moral Disengagement) $+\gamma_{04 j}($ Safety $)$ $\beta_{0 \mathrm{ij}}=+\gamma_{00}+\mu_{0 \mathrm{j}}++\varepsilon_{0}$

At the individual level, being a girl, older, low adult availability, high moral engagement and high moral disengagement, as well as feeling safe in school lead to witnessing involvement. For every one-unit increase in age, moral engagement, moral disengagement, and feeling unsafe, average levels of witnessing bullying increased by $0.10,0.05,0.12$, and 0.26 , respectively. For every one-unit decrease in adult availability, average levels of bullying 
Table 16

Effects of Individual-Level and School-Level Variables on Bystanding

\begin{tabular}{|c|c|c|c|c|c|c|}
\hline & $\begin{array}{l}\text { Null } \\
\text { Model }\end{array}$ & & $\begin{array}{l}\text { Level-1 } \\
\text { Model }\end{array}$ & & $\begin{array}{c}\text { Level-2 } \\
\text { Model } \\
\end{array}$ & \\
\hline \multicolumn{7}{|l|}{ Level-1 } \\
\hline Constant & $1.23 * * *$ & $(0.032)$ & $1.22^{* * *}$ & $(0.023)$ & $1.23 * * *$ & $(0.033)$ \\
\hline Female & & & $0.225^{* * *}$ & $(0.019)$ & $0.225^{* * *}$ & $(0.019)$ \\
\hline Age & & & $0.098 * * *$ & $(0.006)$ & $0.100^{* * *}$ & $(0.007)$ \\
\hline Adult Availability & & & $-0.067 * *$ & $(0.018)$ & $-0.069 * * *$ & $(0.018)$ \\
\hline Moral Engagement & & & $0.047^{*}$ & $(0.019)$ & $0.048 * *$ & $(0.019)$ \\
\hline Moral & & & $0.117 * * *$ & $(0.016)$ & $0.114^{* * *}$ & $(0.016)$ \\
\hline \multicolumn{7}{|l|}{ Disengagement } \\
\hline $\begin{array}{l}\text { School Safety } \\
\text { Level-2 }\end{array}$ & & & $0.262 * * *$ & $(0.010)$ & $0.261 * * *$ & $(0.010)$ \\
\hline Secondary & & & & & -0.046 & $(0.085)$ \\
\hline Adult Availability & & & & & 0.172 & (0.148) \\
\hline Moral Engagement & & & & & 0.130 & $(0.349)$ \\
\hline Moral & & & & & 0.478 & $(0.265)$ \\
\hline \multicolumn{7}{|l|}{ Disengagement } \\
\hline School Safety & & & & & $0.223^{*}$ & $(0.144)$ \\
\hline \multicolumn{7}{|l|}{ Variance } \\
\hline $\begin{array}{l}\text { Between Schools } \\
\left(\mu_{0}\right)\end{array}$ & 0.095 & $(0.015)$ & 0.033 & $(0.006)$ & 0.028 & $(0.007)$ \\
\hline Within Schools $\left(\varepsilon_{0}\right)$ & 1.324 & $(0.015)$ & 1.230 & $(0.015)$ & 1.230 & $(0.030)$ \\
\hline $\begin{array}{l}\text { Total Variance } \\
-2 \text { LogL (Deviance) }\end{array}$ & $\begin{array}{c}1.419 \\
52384.79\end{array}$ & & $\begin{array}{c}1.263 \\
42098.08\end{array}$ & & $\begin{array}{c}1.258 \\
42087.36\end{array}$ & \\
\hline
\end{tabular}

Note. Standard errors are in parentheses.

${ }^{* * *} p<.001,{ }^{* *} p<.01,{ }^{*} p<.05$ 
involvement increased by 0.07 . Individual level variables in Conditional Model 1 explained $11 \%$ of the within school variance in bystanding $\left(\mathrm{R}_{1}^{2}=.109\right)$.

The addition of level-2 variances of collective adult availability, moral engagement, moral disengagement, and school safety accounted for approximately $10 \%$ of the variability between schools for bullying involvement $\left(\mathrm{R}^{2}{ }_{2}=.102\right)$. Overall, collective perceptions of feeling unsafe at school was the only statistically significant predictor of bystanding involvement at Level-2.

\section{Discussion}

The purpose of the present study was to better understand the social factors that support bullying behaviour, by combining ecological systems theory and Bandura's theory of moral disengagement. This was measured by conducting three HLM models to predict bullying, victimization, and bystanding involvement as a function of the individuals' characteristics and the wider school environment.

The overall prevalence rates for victimization and bullying were higher than prevalence rates found by other researchers (Currie et al., 2004; Nansel et al., 2001), due to using more inclusive cut-offs and behavioural descriptors. Using behavioural descriptors to measure bullying and a cut off of "once only in the past three months," it was found that $47 \%$ of youth reported bullying others, $62 \%$ reported being victimized, and $72 \%$ witnessed bullying at least once within the last three months. The overall bullying and victimization prevalence rates are much higher than what has been found in previous research using general Olweus questions (Currie et al., 2004; Nansel et al., 2001). The witnessing prevalence rates are consistent with what have been found by observational and self-report research (Craig \& Pepler, 1997; Trach et al., 2010). 
A challenge of using a cut-off of "only once in the past three months," tends to exclude information about the severity of bullying involvement by collapsing all bullying experiences into either being involved or not. In the present study, children who reported regular bullying perpetration, victimization, and bystanding of "every week or more in the past three months" was a relatively infrequent event around $5-10 \%$ for bullying and victimization, and $20 \%$ for witnessing. This suggests that when using a strict cut-off of "every week or more," there are less children who experience severe bullying involvement on a regular basis. Since children were asked to recall a recent period of time in their lives, and because they were asked about whether they had experienced, witnessed, or participated in specific bullying behaviours, higher and more specific rates of bullying, victimization, and bystanding were obtained. It is not uncommon to find higher rates of bullying when children are asked if they have experienced specific behaviours rather than asking them whether they have been bullied or not (Cook et al., 2010). Clearly, bullying is a serious issue that touches many Canadian children's lives.

Overall, social and verbal forms of bullying and victimization were more commonly reported than physical forms of bullying across all ages, which is consistent with previous Canadian and American studies (Trach et al., 2010; Wang et al., 2009). As expected, a higher proportion of boys reported engaging in more direct physical forms, while a higher proportion of girls reported engaging in more covert forms of social bullying. This is consistent with previous literature (Trach et al., 2010; Wang et al., 2009). This is not surprising given the social relationship issues that have been discussed among girls and boys (Crick \& Grotpeter, 1996; Galen \& Underwood, 1997; Pepler et al., 2010).

We found that a larger proportion of primary students reported being victimized, which is consistent with the literature showing that younger students report being victimized more 
frequently than older students. This has been shown by using both general Olweus measures (Solberg \& Olweus, 2003; Whitney \& Smith, 1993), and more specific behavioural descriptors of bullying (Wang et al., 2009). Moreover, girls were more likely to be witnesses of all forms of bullying behaviour in comparison to boys, which is consistent with previous literature (Salmivalli et al., 1996; 1999; Wang et al., 2009). It may be that since bullying situations are exciting, girls are more cognizant of social situations and maladaptive social relationships.

Consistent with our hypothesis girls were more likely to endorse moral engagement attitudes, and boys were more likely to endorse moral disengagement attitudes. This is explained by their documented empathic experiences to bullying (Espelage et al., 2004; Pozzoli \& Gini, 2007). Younger students were more likely to be morally engaged, while older students were more likely to endorse moral disengagement mechanisms. This finding is consistent with Bandura's theory that children gradually develop higher levels of tolerance for more detrimental behaviours over time (Bandura, 1999; Bandura et al., 2001; Hymel et al., 2005; Trach et al., 2010). Although longitudinal data is needed to determine if children actually become morally disengaged over time or if some children are never morally engaged to begin with, this finding suggests support for the former argument.

The HLM analyses examined individual level factors of sex, age, adult availability, moral disengagement, and moral engagement to predict one's individual role as a bully, victim or bystander. In addition, the school climate characterized by an environment of collective attitudes regarding school safety, adult availability, moral engagement, and moral disengagement was also important to examine in the present study. The individual variables that predicted bullying behaviour were expected. Being highly morally disengaged and low morally engaged, perceiving adults as less available and feeling unsafe at school all predicted 
bullying behaviour at the individual level. This suggests that those who engage in bullying share some common attitudes and perceptions regarding the endorsement of those behaviours.

In examining the role of individual and school level variables in contributing to bullying we found that at the individual level, being an older girl, being highly morally engaged and highly morally disengaged, perceiving adults as less available and feeling less safe at school all predicted to witnessing bullying. The same was true for predicting victimization with the exception of age. What is surprising in these findings is that those who are witnessing and being targeted by high levels of bullying behaviours are both highly morally engaged and disengaged. This has not been reported previously nor does it fit intuitively with Bandura's theory. Gini (2006) found that all roles involved in bullying, including victims, shared some tendency to be morally disengaged, which points to the overall experience to disengage somewhat from being involved in bullying. However, the present study differs from past researchers in that the items that assessed moral attitudes asked specifically about bullying behaviours in contrast to others that have asked about more general attitudes related to conduct.

These findings raise the question as to how an individual can be both morally engaged and disengaged at the same time. It is not surprising that victims and bystanders would be highly morally engaged as the items ask about active intervention in bullying situations (e.g. "It is my responsibility to do something when I see bullying"). These children tended to support statements endorsing pro-social responses to bullying behaviour despite not wanting to intervene themselves. This is consistent with findings that children believe that something should be done about bullying, but feel less responsible since they believe adult's are primarily responsible for intervening in bullying situations (Hymel et al, 2005; Pepler, et al., 2010). 
Perhaps the experience of victimization led victims to empathize and care for others who are victimized (Kasen et al., 2004), which may account for their high levels of moral engagement. These individuals know that bullying behaviour is morally wrong, and may empathize with others who are victimized in similar ways as suggested by the homophily hypothesis (Espelage \& Swearer, 2009). However, victims may also better understand why they are targets of bullying, and thus endorse moral disengagement mechanisms because they have internalized negative perceptions of self from their victimization experiences with the larger peer group that failed to intervene. To this end, high moral engagement and moral disengagement in victims points to conflicted attitudes about victimization, such that they can rationally justify empathy towards a victim, and why bullies target victims as deserving of the behaviour.

Witnesses to bullying may be hypersensitive and empathetic to others who are being harmed, and therefore are more aware of bullying incidents. This confounding finding of both high moral disengagement and moral engagement among witnesses may be explained by Obermann (2011b), in that bystanders who are morally engaged may be similar to the guilty bystander characterized by intention to intervene, but who justified their failure to intervene by endorsing attitudes that support moral disengagement such as "Students who get picked on a lot usually deserve it." Differences in cognitions between active and passive witnesses were not examined in the present study, and may be of future interest to examine the cognitions related to bullying intervention more fully.

Overall, this study expands upon previous literature, confirming that an individual can endorse both moral engagement and moral disengagement mechanisms. This suggests that moral disengagement and moral engagement may not exist on a single continuum as presented 
in the scale by Bandura et al. (2001), such that low moral disengagement yields high moral engagement, but can be conceptualized as two distinct components that are able to be endorsed simultaneously depending upon one's role in bullying situations.

Consistent with previous literature examining school safety (Beran \& Tutty, 2002; Vaillancourt, Brittain et al., 2010), the majority of students often feel safe at school. Secondary school students also reported feeling more safe at school, which may be a function of less reported victimization rates in comparison to primary school students. In contrast with literature on school safety (Brown, Birtch, \& Kancherla, 2005; Varjas et al., 2009), we found that boys were more likely to feel unsafe at school. This may be due to the fact that boys experienced more physical bullying and victimization, which may be perceived as more harmful than other covert types of bullying. Boys also reported adults as less available in bullying situations.

An important finding in the present study was that the majority of variability was at the individual level, which is consistent with other studies using either perceptions aggregated at the school-level (Gendron et al., 2011) or classroom-level (Sapouna, 2010) at Level-2. According to Steele (2008), null model hierarchies that are comprised of individuals at the Level-1 unit will typically have most of the variance at Level-1. Overall, individual factors that are within schools such as cognitions related to the acceptability of bullying, predict involvement in bullying, victimization, and bystanding, This suggests that rather than utilizing a one-size-fitsall approach for mandating similar bullying intervention programs across schools, intervention programs need to be tailored to each individual school.

Collective levels of moral disengagement and moral engagement did not predict to individual involvement in bullying, victimization, or witnessing behaviour. This is in contrast to 
Salmivalli \& Voeten (2004) who report effects beyond the individual, understanding bullying as a classroom phenomenon. Collective levels of moral disengagement may be a function of smaller peer group situations within the classroom, rather than part of the larger school context. Salmivalli \& Voeten (2004) find that bullying behaviour at the individual level is predicted by the attitudes towards bullying at the classroom level. Since individuals are nested within classrooms, and these classrooms are nested within schools, aggregating individuals at the school without taking the classroom level into consideration may account for loss of variability in explaining bullying. Future studies should examine the contextual effects of classrooms in combination with school contexts to gain a more comprehensive understanding of how children's social contexts contribute to bullying.

In conclusion, it was found that individual characteristics were more predictive of bullying involvement than collective school level factors. Collective feelings of being unsafe at school was a consistent predictor across all types of bullying involvement, suggesting that more fearful and less safe environments include more bullying, victimization, and witnessing behaviour. The most surprising finding in the current study included that of witnesses and victims being both morally engaged and morally disengaged. Although individual-level cognitions regarding bullying predicted involvement, the collective moral disengagement and moral engagement variables did not predict bullying involvement, suggesting that individual attitudes regarding endorsement of bullying behaviours should be targeted.

\section{Limitations and Future Research}

Although the present study has a number of strengths, including the large sample and the fact that school context is taken into consideration, there were also several limitations that should be considered. Due to the large sample size, many prevalence rates and mean 
differences were found to be statistically significant, and the differences in these effects were small. These differences must be interpreted with caution, especially since some statistically significant sex and grade level differences were below or close to $10 \%$. It will be beneficial to conduct similar studies with equally large sample sizes, to determine if these findings can be replicated.

One limitation of the present study was that it only included one informant source, solely relying on youths' self-reports of bullying experiences. Including multiple informants (e.g. peer reports, and teacher reports) that could comment on the recent nature of bullying, victimization and witnessing that occurs in schools has been suggested by Swearer, Siebecker, JohnsenFrerichs, and Wang (2010) to obtain a more representative measure of bullying.

Another limitation of the study is that the measure of moral engagement and moral disengagement have been recently developed, and have not undergone extensive psychometric testing. Factor analyses are not available from previous studies and were not reported in this document, since it was beyond the scope of this study. Future research should include a factor analyses to determine the items that are most relevant in measuring the constructs of interest. Furthermore, a single item of general school safety (e.g. "How often do you feel safe in this school?") was used. This question did not take into consideration the contexts in which children can feel safe. Vaillancourt, Brittain et al. (2010) have shown that children are less likely to feel safe in certain places in school that are characterized by low adult availability, such as hallways, bathrooms, transportation to and from school, etc. Future research should use a measure that asks specifically about safety across different school contexts such as the classroom.

Another limitation of this study is that each bullying experience (i.e. witness, perpetrator and target) was assessed separately without taking into consideration the simultaneous roles that 
children may experience. A study by Rivers et al. (2008) showed that there are many roles that individuals can take that can affect one's psychological well-being, even participating in all three - as a bully, victim, and a bystander. Furthermore, this complicated relationship issue of participating in all three roles of bullying has yet to be further explored in the literature. Since bullying involvement occurs on a continuum (Hymel et al., 2005), it would be important to determine the cognitive mechanisms and environmental factors that predict to involvement in all three participant roles. This would be an avenue for future research to examine, particularly since those who experience both bullying and victimization have poor psychosocial health, in comparison to those who are solely targets of bullying, and those who primarily engage in bullying others.

In this study in the HLM analyses the dependent variables were combined into a summary score to predict overall levels of bullying, victimization, and bystanding behaviour across all forms (i.e. physical, social and verbal) of bullying behaviour. Research conducted in the future using Hierarchical Linear Modeling should focus on predicting to each of the different forms of bullying behaviour. It has been shown in previous research (Vaillancourt, Trinh et al., 2010; Wang et al., 2009) that boys and girls engage in various bullying forms at different rates. For example, engaging in behaviour may differ for boys and girls, such that overt physical forms may be less supported by girls and supported more by boys, while more social forms may be endorsed by girls.

Additionally, this study examined whether students had witnessed bullying, and did not differentiate between the different active and passive bystander roles. Since this dataset was collected in 2005 , the measure of witnessing behaviour was included prior to the recent studies that have examined the effect of attitudes and behaviour of individuals who participate in 
different bystander roles (Gini et al., 2008). It has been suggested that in the future researchers differentiate between bystander roles, particularly between active and passive witnesses of bullying behaviour (Rivers et al., 2009; Salmivalli et al., 1996). Since bystanders can actively join in, defend the victim, or passively watch bullying, witnessing bullying without including the possibility of intervention provides limited information about the attitudes and behaviours of witnesses in situations of bullying. Moreover, Obermann (2011) notes the differences between three types of passive bystanders that focus on the cognitions regarding intervention in bullying episodes. The importance of examining the cognitions of these different types of witnesses may provide critical information regarding bystander intervention or inaction.

Another area of future research is to examine how moral disengagement occurs over time at the school level. To date, only one longitudinal study on moral disengagement has been conducted (Paciello et al., 2008). Longitudinal designs would be extremely informative as to how bullying and moral disengagement develop and change over time as a result of the school context. The cross-sectional design chosen for this study only captures a small piece of what it is like to experience bullying at certain point in time, with comparisons made between primary and secondary school students. Since bullying is a group process that occurs repeatedly over time, it would be extremely beneficial to follow children throughout school to determine how their cognitions and the overall school climate with regards to bullying change as a result of the immediate school environment. A cross sectional design is unable to determine whether children become morally disengaged over time which leads to bullying others, or whether the act of bullying over time leads individuals to become more morally disengaged. This points to the importance of longitudinal studies to understand and explain how moral disengagement and bullying behaviour develop over time. 
Only one context of school climate was examined in this study. Across schools, we found that feeling unsafe at school predicted involvement in bullying, victimization, and bystanding. According to the social-ecological models proposed by Espelage \& Swearer (2010), a logical next step would be to include the wider social contexts in which children develop, particularly including how various contexts such as the home, the classroom, and the wider community impacts on bullying experiences and failure to take action in bullying situations. Research has found that healthy development occurs when there are consistent messages delivered across contexts, which promote healthy and constructive relationships among them (Sheridan, Warnes, \& Dowd, 2004). By understanding how school environments perpetuate the notion and acceptability of bullying, this may inform policy development especially for the Ontario Ministry of Education in trying to ensure all schools have similar bullying intervention and prevention plans in place.

\section{Implications for Educational Professionals and Policy Development}

Despite these limitations, this study contributes knowledge to the field of bullying by demonstrating that both individual and school contexts are important in predicting individuals' participation in bullying. Although individual-level variables contributed to more of the explained variability in individuals' experiences of bullying involvement, collective school level perceptions of feeling unsafe were also related to bullying, victimization, and witnessing behaviour over and above individual-level characteristics. The collective attitudes at the school level of feeling unsafe that leads to bullying, victimization and witnessing these behaviours suggests that there is still much to be done in schools within Ontario in order to include successful interventions to make schools safe for all children. This points to the importance of 
such policy developments that have been put in place by the Ontario Ministry of Education committed to ensuring that schools are safe, caring, and inclusive environments for all students. Furthermore, this study showed that individual differences within schools explained more of the variability in bullying involvement than did school contexts. Although all schools in Ontario are mandated to include bullying intervention and prevention plans, not all plans are exactly equal in terms of providing support, and school principals are freely allowed to vary in terms of what intervention is provided and who is targeted. Schools should have intervention programs that address their unique needs, particularly related to adult involvement and attitudes that inhibit or allow bullying. Findings highlight that a one-size fits all policy mandated across school will not be as effective as a more individualized approach.

This research may inform policy pertaining to interventions mandated by the Ontario Ministry of Education, by suggesting interventions targeted at not only individuals who are involved in bullying, victimization and witnessing, but also involving supportive school personnel. Adult support is imperative to decreasing bullying, victimization, and witnessing behaviour, and suggests structurally changing the school environment to make adults more available for children in need. This points to the importance of providing professional training for teachers about how to appropriately support victims and intervene in bullying situations.

Intervention programs should also focus on how to decrease moral disengagement attitudes that allow bullying to occur, and increase moral engagement attitudes that promote moral responsibility to intervene in bullying situations. This study adds to the literature by also examining the cognitions of witnesses, suggesting that the larger audience of bystanders who are involved should be included in intervention programs as well. The implications of this study suggest that ensuring safety within the school is critical. Intervention programs should include 
the school and the wider social contexts in which children live. Interventions should reach out to families, classrooms, and the wider community to get the message across of creating a civil society in which children do not have to fear going to school. Interventions must also include components focusing on attitudes and responsible action in bullying situations for bystanders who are present in the majority of bullying situations.

Dan Olweus (1994), the pioneer in the bullying field, argued that "it is a fundamental democratic right for a child to feel safe in school and to be spared the oppression and repeated, intentional humiliation implied in bullying" (p. 28.). A fundamental problem within Ontario schools is that students feel unsafe. Bullying remains a profound social, educational, and community issue that can be tackled with insights from research informing social policy and intervention programs that target all contexts in which children live. With a constant message being sent throughout families, classrooms, schools and communities that bullying is not tolerated, school administrators should strive to maintain safe and caring school environments where all children feel accepted. 


\section{References}

Alasker, F. D., \& Gutzwiller-Helfenfinger (2010). Social behavior and peer relationships of victims, bully-victims, and bullies in kindergarten. In S. R. Jimerson, S. M. Swearer, \& D. L. Espelage (Eds.), Handbook of bullying in schools: An international perspective (pp. 87-100). New York, NY: Taylor \& Francis.

Almeida, A., Correia, I., \& Marinho, S. (2010). Moral disengagement, normative beliefs of peer group, and attitudes regarding roles in bullying. Journal of School Violence, 9, 23-36. doi: $10.1080 / 15388220903185639$

Bandura, A. (1990). Selective activation and the disengagement of moral control. Journal of Social Issues, 46(1), 27-46.

Bandura, A. (1999). Moral disengagement in the perpetration of inhumanities. Personality and Social Psychology Review, 3(3), 193-209.

Bandura, A. (2002). Selective moral disengagement in the exercise of moral agency. Journal of Moral Education, 31, 101-119. doi: 10.1080/0305724022014322

Bandura, A., Caprara, V., Barbaranelli, C., Pastorelli, C., \& Regalia, C. (2001). Sociocognitive self-regulatory mechanisms governing transgressive behavior. Journal of Personality and Social Psychology, 80, 125-135. doi: 10.10337/0022-3514.80.1.125

Beran, T. N. (2006). A construct validity study of bullying. The Alberta Journal of Educational Research, 52(4), 241-250.

Beran, T. N., \& Tutty, L. (2002). Children's reports of bullying and safety at school. Canadian Journal of School Psychology, 17(2), 1-14.

Bosworth, K., Espelage, D. L., \& Simon, T. (1999). Factors associated with bullying behavior in middle school students. Journal of Early Adolescence, 19, 341-362. 
Boulton, M. J. (1997). Teachers' views on bullying: definitions, attitudes and ability to cope. British Journal of Educational Psychology, 67, 223-233.

Bovaird, J. A. (2010). Scales and surveys: Some problems with measuring bullying behavior. In S. R. Jimerson, S. M. Swearer, \& D. L. Espelage (Eds.), Handbook of bullying in schools: An international perspective (pp. 277-292). New York, NY: Taylor \& Francis.

Bradshaw, C. P., Sawyer, A. L., \& O'Brennan, L. M. (2009). A social disorganization perspective on bullying-related attitudes and behaviors: The influence of school context. American Journal of Community Psychology, 43, 204-220. doi:10.1007/s10464-0099240-1

Bryk, A. S., \& Raudenbush, S. W. (1992). Hierarchical linear models. Newbury Park, CA: Sage.

Bully in suicide boy case may face trial (2011, September). CBC News Online. Retrieved from: http:/www.cbc.ca/news/canada/toronto/story/2011/09/28/toronto-bullied-boy-court.html

Clarke, P., \& Wheaton, B. (2007). Addressing data sparseness in contextual population research using cluster analysis to create synthetic neighbourhoods. Sociological Methods \& Research, 35, 311-351. doi: 10.1177/0049124106292362

Cohen, J. (1992). A power primer. Quantitative Methods in Psychology, 112(1), 155-159.

Cook, C. R., Williams, K. R., Guerra, N. G., \& Kim, T. E. (2010). Variability in the prevalence of bullying and victimization. In S. R. Jimerson, S. M. Swearer, \& D. L. Espelage (Eds.), Handbook of bullying in schools: An international perspective (pp. 265-276). New York, NY: Taylor \& Francis.

Cornell, D. G., \& Bandyopadhyay, S. (2010). The assessment of bullying. In S. R. Jimerson, S. 
M. Swearer, \& D. L. Espelage (Eds.), Handbook of bullying in schools: An international perspective (pp. 265-276). New York, NY: Taylor \& Francis.

Cornell, D. G., Sheras, P. L., \& Cole, J. C. (2006). Assessment of bullying. In S. Jimerson \& M. Furlong (Eds.), Handbook of school violence and school safety (pp. 191-210). Mahwah, NJ: Erlbaum.

Cowie, H. (2000). Bystanding or standing by? Gender issues in coping with bullying in English schools. Aggressive Behavior, 26, 85-97. doi: 10.1002/(SICI)1098-2337

Craig, W. M., \& Harel, Y. (2004). Bullying, physical fighting and victimization. In C. Currie, C. Roberts, A. Morgan, R. Smith, W. Settertobulte, O. Samdal, \& V. Barnekow Rasmussen (Eds.), Young peoples health in context: International report from the HBSC 2001/2002 survey. Copenhagen, Denmark: WHO Regional Office for Europe.

Craig, W. M., Henderson, K., \& Murphy, J. G. (2000). Prospective teachers' attitudes toward bullying and victimization. School Psychology International, 21, 5-21.

Craig, W. M., \& Pepler, D. J. (1997). Observations of bullying and victimization in the school yard. Canadian Journal of School Psychology, 13, 41-59.

Craig, W. M., Pepler, D., \& Atlas, R. (2000). Observations of bullying in the playground and in the classroom. School Psychology International, 21, 22-36.

Crick, N., Bigabee, M. A., \& Howes, C. (1996). Gender differences in children's normative beliefs about aggression: How do I hurt thee? Let me count the ways. Child Development, 67, 1003-1014.

Crick, N. R., \& Grotpeter, J. K. (1996). Children's treatment by peers: Victims of relational and overt aggression. Developmental Psychopathology, 8, 367-380.

Currie, C., Roberts, C., Morgan, A., Smith, R., Settertibulte, W., Samdal, O., \& Barnekow, 
Rasmussen, V. (Eds.). (2004). Young peoples health in context: International report from the HBSC 2001/2002 survey. Copenhagen, Denmark: WHO Regional Office for Europe.

Dedrick, R. F., Ferron, J. M., Hess, M. R., Hogarty, K. Y., Kromrey, J. D., Lang, T. R., . . \& Lee, R. (2009). Multilevel modeling: A review of methodological issues and applications. Review of Educational Research, 79, 69- 102. doi:

$10.3102 / 0034654308325581$

Demeray, M. K. \& Malecki (2011). The role of social support in the lives of students involved in bullying. In D. L. Espelage \& S. M. Swearer (Eds.), Bullying in North American schools ( $2^{\text {nd }}$ ed., pp. 147-158). New York, NY: Routledge.

Dooley, J. J., Pyzalski, J., \& Cross, D. (2009). Cyberbullying versus face-to-face bullying: A theoretical and conceptual review. Journal of Psychology, 217, 182-188. doi:10.1027/0044-3409.217.4.182

Eliot, M., Cornell., D., Gregory, A. \& Fan, X. (2010). Supportive school climate and student willingness to seek help for bullying and threats of violence. Journal of School Psychology, 48, 533-553.

Espelage, D. L., Bosworth, K., \& Simon, T. R. (2000). Examining the social context of bullying behaviors in early adolescence. Journal of Counseling and Development, 78, 326-333.

Espelage, D. L., \& Holt, M . K. (2007). Dating violence and sexual harassment across the bullyvictim continuum among middle and high school students. Journal of Youth \& Adolescence, 36, 799-811. doi: '10.1007s10964-006-9109-7

Espelage, D. L., Mebane, S. E., \& Adams, R. S. (2004). Empathy, caring, and bullying: towards 
an understanding of complex associations. In D. L. Espelage \& S. M. Swearer (Eds.), Bullying in American schools: A social-ecological perspective on prevention and intervention (pp. 1-14). Mahwah, NJ: Lawrence Erlbaum Associates.

Espelage, D. L., \& Swearer, S. M. (2009). Contributions of three social theories to understanding bullying perpetration and victimization among school-aged youth. In $M$. J. Harris (Ed.), Bullying, rejection and peer victimization: A social cognitive neuroscience perspective (pp. 151-170). New York. NY: Springer Publishing Company.

Espelage, D. L., \& Swearer, S. M. (2010). A social-ecological model for bullying prevention and intervention: Understanding the impact of adults in the social ecology of youngsters. In S. R. Jimerson, S. M. Swearer, \& D. L. Espelage (Eds.), Handbook of bullying in schools: An international perspective (pp. 61-72). New York, NY: Taylor \& Francis.

Field, A. (2009). Discovering statistics using SPSS (3rd ed.). Washington, DC: Sage Publications.

Flannery, D. J., Wester, K. L., \& Singer, M. I. (2004). Impact of exposure to violence in school on child and adolescent mental health and behavior. Journal of Community Psychology, 32, 559-573. doi:10.1002/jcop.20019

Frey, K. S., Edstrom, L. V., \& Hirschstein, M. K. (2010). School bullying: A crisis or an opportunity? In S. R. Jimerson, S. M. Swearer, \& D. L. Espelage (Eds.), Handbook of bullying in schools: An international perspective (pp. 403-415). New York, NY: Taylor \& Francis.

Galen, B. R., \& Underwood, M. K. (1997). A developmental investigation of social aggression among children. Developmental Psychology, 33(4), 589-600.

Gasser, L., \& Keller, M. (2009). Are the competent the morally good? Perspective taking 
and moral motivation of children involved in bullying. Social Development, 18,798 816. doi:10.1111/j.1467-9507.2008.00516.x

Gay Ottawa teen who killed himself was bullied. (2011, October). CBC News Online. Retrieved from: http://www.cbc.ca/news/canada/ottawa/story/201 1/10/18/ottawa-teen-suicidefather.html

Gendron, B. P., Williams, K. R., \& Guerra, N. G. (2011). An analysis of bullying among students within schools: Estimating the effects of individual normative beliefs, selfesteem and school climate. Journal of School Violence, 10, 150-164. doi:

$10.1080 / 153888220.2010 .539166$

Gini, G. (2006). Social cognition and moral cognition in bullying: What's wrong? Aggressive Behavior, 32, 528-539. doi:10.1002/ab.20153

Gini, G., Albeiro, P., Benelli, B., \& Altoe, G. (2008). Determinants of adolescents' active and passive bystanding behavior in bullying. Journal of Adolescence, 31, 93-105. doi: $10.1002 / a b .20204$

Gini, G., Pozzoli, T., \& Hauser, M. (2011). Bullies have enhanced moral competence to judge relative to victims, but lack moral compassion. Personality and Individual Differences, 50, 603-608. doi: 10.1016/j.paid.2010.12.002

Glew, G. M., Fan, M., Katon, W., Rivara, F. P., \& Kernic, M. A. (2005). Bullying, psychosocial adjustment and academic performance in elementary school. Archives of Pediatrics \& Adolescent Medicine, 159(1), 1026-1031.

Godfrey, R. (2005). Under the bridge: The true story of the murder of Reena Virk. British Colombia, BC: Simon \& Schuster.

Goldbaum, S., Craig, W. M., Pepler, D., \& Connolly, J. (2007). Developmental trajectories of 
victimization. Identifying risk and protective factors. In: J. E. Zins, M. J. Elias \& C. A. Maher (Eds.). Bullying, victimization and peer harassment: $A$ handbook of prevention and intervention (pp. 143-160). New York, NY: Haworth Press.

Gresham, F. M., MacMillan, D. L., Bocian, K. M., Ward, S. L., \& Forness, S. R. (1998). Comorbidity of hyperactivity-impulsivity-inattention and conduct problems: risk factors in social, affective, and academic domains. Journal of Abnormal Child Psychology. 26, 393-406.

Hawkins, D. L., Pepler, D. J., \& Craig, W. M. (2001). Naturalistic observations of peer interventions in bullying. Social Development, 10, 512-527.

Hawley, P. H., Stump, K. N., \& Ratcliff, J. (2011). Sidestepping the jingle fallacy: Bullying, aggression, and the importance of knowing the difference. In D. L. Espelage \& S. M. Swearer (Eds.), Bullying in North American schools ( $2^{\text {nd }}$ ed., pp. 101-115). New York, NY: Routledge.

Holt, M., \& Keyes, M. A. (2004). Teachers' attitudes towards bullying. In D. L. Espelage \& S. M. Swearer (Eds.), Bullying in American schools: A social-ecological perspective on prevention and intervention (pp.121-139). Mahwah. NJ: Lawrence Erlbaum Associates.

Hoover, J. H., \& Hazler, R. J. (1994). Bullies and victims. Elementary School Guidance and Counselling, 25, 212-220.

Hughes, S. A. (2011). Phoebe Prince suicide: What can be done about bullying? The Washington Post. Retrieved from http://www.washingtonpost.com Hyde, L. W., Shaw, D., \& Moilanen, K. L. (2010). Developmental precursors of moral 
disengagement and the role of moral disengagement in the development of antisocial behavior. Journal of Abnormal Child Psychology, 38, 197-209. doi:10.1007/s10802009-9358-5

Hymel, S., Rocke-Henderson, N., \& Bonanno, R. A. (2005). Moral disengagement: A framework for understanding bullying among adolescents [Special issue]. Journal of Social Sciences, 8, 1-11.

Hymel, S. Schonert-Reichl, K. A., Bonanno, R. A., Vaillancourt, T., \& Rocke Henderson, N. (2010). Bullying and Morality: Understanding how good kids can behave badly. In S. R. Jimerson, S, M, Swearer, \& D. L. Espelage (Eds.), Handbook of bullying in schools: An international perspective (pp. 101-117). New York, NY: Taylor and Francis.

Janosz, M., Archambault, I., Pagani, L. S., Pascal, S., Morin, A. J. S., \& Bowen, F. (2008). Are there detrimental effects of witnessing school violence in early adolescence? Journal of Adolescent Health, 43, 600-608. doi:10.1016/j.jadohealth.2008.04.011

Juvonen, J., Graham, S., \& Shuster, M. A. (2003). Bullying among young adolescents:

The strong, the weak, and the troubled. Pediatrics, 112(6), 1231-1237.

Kaltiala-Heino, R., Rimpela, M., Marttunen, M., Rimpela, A., \& Rantanen, P. (1999).

Bullying, depression, and suicidal ideation in Finnish adolescents: School survey. British Medical Journal, 319, 348-351.

Kasen, S., Berenson, K., Cohen, P., \& Johnson, J. G. (2004). Effects of school climate on changes in aggressive or other behaviors related to bullying. In D. L. Espelage \& S. M. Swearer (Eds.), Bullying in American schools: A social-ecological perspective on prevention and intervention (pp.121-139). Mahwah. NJ: Lawrence Erlbaum Associates Kowalski, R. M., \& Limber, S. P. (2007). Electronic bullying among middle school 
students. Journal of Adolescent Health, 41, 22-30. doi:10.1016/j.jadohealth.2007.08.017

Ladd, G. W., \& Kochenderfer-Ladd, B. (2002). Identifying victims of peer aggression from early to middle childhood: analysis of cross-informant data for concordance, estimation of relational adjustment, prevalence of victimization, and characteristics of identified victims. Psychological Assessment, 14(1), 74-96.

Latane, B., \& Darley, J. M. (1968). Group inhibition of bystander intervention. Journal of Personality and Social Psychology, 10, 215-221.

Latane, B., \& Darley, J. M. (1970). The unresponsive bystander: Why doesn't he help? New York, NY: Appleton-Century-Crofts.

Latane, B., \& Nida, S. (1981). Ten years of research on group size and helping. Psychological Bulletin, 89, 308-324.

Lee, C. (2011). An ecological systems approach to bullying behaviors among middle school students in the United States. Journal of Interpersonal Violence, 26, 1664-1693. doi: $10.1177 / 0886260510370591$

Lee, T. H., Cornell, D. G., \& Cole, J. C. M. (2006, August). Concurrent validity of the Olweus bully/victim questionnaire. Poster session presented at the American Psychological Association conference, Louisiana.

Leff, S. S., Freedman, M. A., Macevoy, J. P., \& Power, T. S. (2011). Considerations when measuring outcomes to assess for the effectiveness of bullying- and aggressionprevention programs in the schools. In D. L. Espelage \& S. M. Swearer (Eds.), Bullying in North American schools ( ${ }^{\text {nd }}$ ed., pp. 205-223). New York, NY: Routledge.

Luke, D. A. (2004). Multilevel modeling (Vol, 143). Thousand Oaks, CA: Sage University Papers. 
Maas, C. J. \& Hox, J. J. (2004). Robustness issues in multilevel regression analysis. Statistics Neerlandica, 58, 127-137.

Maas, C. J. \& Hox, J. J. (2005). Sufficient sample sizes for multilevel modeling. Methodology, 1, 86-92. doi: 10.1027/1614-1881.1.3.86

Ma, X. (2002). Bullying in middle school: Individual and school characteristics of victims and offenders. School Effectiveness and School Improvement, 13, 63-89.

Malecki, C. K., \& Demaray, M. K. (2004). The role of social support in the lives of bullies, victims, and bully-victims. In D. L. Espelage \& S. M. Swearer (Eds.), Bullying in American schools: A social-ecological perspective on prevention and intervention (pp.121-139). Mahwah. NJ: Lawrence Erlbaum Associates.

McConville, D. W., \& Cornell, D. G. (2003). Aggressive attitudes predict aggressive behavior in middle school students. Journal of Emotional and Behavioral Disorders, 11, 179-187.

Menesini, E., Sanchez, V., Fonzi, A., Ortega, R., Costabile, A., \& Lo Feudo, G. (2003). Moral emotions and bullying: A cross national comparison of differences between bullies, victims and outsiders. Aggressive Behavior, 29, 515-530. doi: 10.1002/ab.10060

Nansel, T., Overpeck, M., Pilla,R. S., Ruan, W. J., Simons-Morton, B., \& Scheidt, P. (2001). Bullying behaviors among U.S. youth: Prevalence and association with psychosocial adjustment. Journal of the American Medical Association, 285, 2094-2100.

Nezlek, J. B. (2008). An introduction to multilevel modeling for social and personality psychology. Social and Personality Psychology Compass 2, 842-860. doi:10.1111/j.1751-9004.2007.00059.x

Obermann, M. L. (2011a). Moral disengagement among bystanders to school bullying. 
Journal of School Violence, 10, 239-257. doi: 10.1080/15388220.2011.578276

Obermann, M. L. (2011b). Moral disengagement in self-reported and peer nominated school bullying. Aggressive Behavior, 37, 133-144. doi: 10.1002/ab.20378

O'Connell, P., Pepler, D., \& Craig, W. (1999). Peer involvement in bullying: Insights and Challenges for intervention. Journal of Adolescence, 22, 437-452.

Oliver, R., Hoover, J. H., \& Hazler, R. (1994). The perceived roles of bullying in small-town Midwestern schools. Journal of Counseling and Development, 72(4), 416-419.

Olweus, D. (1978). Aggression in the schools: Bullies and whipping boys. Washington, DC: Hemisphere Press.

Olweus, D. (1993). Bullying at school. What we know and what we can do. Cambridge, UK: Blackwell.

Olweus, D. (1994). Bullying at school: Basic facts and an effective intervention programme. Promotion and Education, 1(4), 27-31.

Olweus, D. (2003). A profile of bullying at school. Educational Leadership, 60, 12-19.

Olweus, D. (2010). Understanding and researching bullying: Some critical issues. In S. R. Jimerson, S. M. Swearer, \& D. L. Espelage (Eds.), Handbook of bullying in schools: An international perspective (pp. 9-33). New York, NY: Taylor \& Francis.

Ontario Ministry of Education (2011, November 2). Safe schools. Retrieved from http://www.edu.gov.on.ca/eng/safeschools/ministry.html

Paciello, M., Fida, R., Tramontano, C., Lupinetti, C., \& Caprara, G. V. (2008). Stability and change of moral disengagement and its impact on aggression and violence in late adolescence. Child Development, 79(5), 1288-1309.

Pallant, J. (2010). SPSS survival manual: A step by step guide to data analysis using SPSS $4^{\text {th }}$ 
ed.). New York, NY: McGraw-Hill Education.

Pellegrini, A. D., Long, J., Solberg, D., Roseth, C., Dupuis, D., Bohn, C., \& Hickey, M. (2010). Bullying and social status during school transitions. In S. R. Jimerson, S. M. Swearer, \& D. L. Espelage (Eds.), Handbook of bullying in schools: An international perspective (pp. 199-209). New York, NY: Taylor \& Francis.

Pellegrini, A. D. \& van Ryzin, M. J. (2011). Part of the problem and part of the solution: The role of peers in bullying, dominance, and victimization during the transition from primary school to secondary school. In D. L. Espelage \& S. M. Swearer (Eds.), Bullying in North American schools (2 ${ }^{\text {nd }}$ ed., pp. 91-100). New York, NY: Routledge.

Pepler, D., Craig, W., \& O’Connell, P. (2010). Peer process in bullying: Informing prevention and intervention strategies. In S. R. Jimerson, S. M. Swearer, \& D. L. Espelage (Eds.), Handbook of bullying in schools: An international perspective (pp. 469-479). New York, NY: Taylor \& Francis.

Peter, T., Roberts, L. W., \& Buzdugan, R. (2008). Suicidal ideation among Canadian youth: A multivariate analysis. Archives of Suicide Research, 12, 1-13. doi: $10.1080 / 13811110802100882$

Pinheiro, P. S. (2006). World report on violence against children. Geneva, Switzerland: United Nations.

Pozzoli, T., \& Gini, G. (2010). Active defending and passive bystanding behavior in bullying: The role of personal characteristics and perceived peer pressure. Journal of Abnormal Child Psychology, 38, 815-827.

Rasbash, J., Browne, W., Goldstein, H., Yang, M., Plewis, I., \& Healy, M. (2009). A users guide to MLwiN (ver. 2.10). London: Centre for Multilevel Modeling 
Rasbash, J., Steele, F., Browne, W. J., \& Goldstein, H. (2009). A users guide to MLwiN (ver. 2.10). London, UK: Centre for Multilevel Modelling, University of Bristol.

Raudenbush, S. W. \& Willms, J. D. (1991). The organisation of schooling and its methodological implications. In S. W. Raudenbush and J. D. Willims (Eds.), Schools, pupils, and classrooms: International studies of schooling from a multilevel perspective (pp. 1-12). San Diego, California: Academic Press.

Reid, P., Monsen, J., \& Rivers, I. (2004). Psychology's contributions to understanding and managing bullying within schools. Educational Psychology in Practice, 20, 241-258. doi: $10.1080 / 026673604200051817$

Rigby, K. (2003). Consequences of bullying in schools. The Canadian Journal of Psychiatry, 48(9), 583-590.

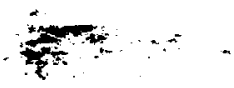

Rigby, K. (2005). Why do some children bully at school? The contributions of negative attitudes towards victims and the perceived expectations of friends, parents, and teachers. School Psychology International, 26, 147-161. doi: $10.1177 / 0143034305052910$

Rigby, K. \& Slee, P. T. (1990). Victims and bullies in school communities. Journal of the Australasian Society of Victimology, 1(2), 23-28.

Rigby, K., \& Slee, P. T. (1992). Bullying among Australian school children: Reported behavior and attitudes toward victims. The Journal of School Psychology, 131, 615-627.

Rivers, I., Poteat, V. P., Noret, N., \& Ashurst, N. (2009). Observing bullying at school: The mental health implications of witness status. School Psychology Quarterly, 24, 211 223. doi:10.1037/a0018164

Rowan, B., Raudenbush, S. W., \& Kang, S. J. (1991). School climate in secondary 
schools. In S. W. Raudenbush \& J. D. Willims (Eds.). Schools, pupils, and classrooms: International studies of schooling from a multilevel perspective (pp. 203-223). San Diego, California: Academic Press, Inc.

Salmivalli, C., Lagerspetz, K., Bjorkqvist, K., Osterman, K., \& Kaukiainen, A. (1996). Bullying as a group process: Participant roles and their relations to social status within the group. Aggressive Behavior, 22, 1-15.

Salmivalli, C., \& Peets, K. (2009). Bullies, victims, and bully-victim relationships in middle childhood and early adolescence. In K. H. Rubin, W. M. Bukowski, \& B. Laursen (Eds). Handbook of peer interactions, relationships, and groups (pp. 322-340). New York, NY: Guilford.

Salmivalli, C. \& Voeten, M. (2004). Connections between attitudes, group norms, and behaviour in bullying situations. International Journal of Behavioural Development, 28, 246-258. doi:10.1080/01650250344000488

Salmon, G., James, A., \& Smith, D. M. (1998). Bullying in schools: Self-reported anxiety, depression and self-esteem in secondary school children. British Medical Journal, 317, 924-925.

Sapouna, M. (2010). Collective effects in the school context: Does it help explain victimization and bullying among Greek primary and secondary school students? Journal of Interpersonal Violence, 25, 1912-1927. doi: 10.1177/0886260509354509

Slee, R. T. (1995). Peer victimization and its relationship to depression among Australian primary school students. Personality and Individual Differences, 18, 57-62.

Smith, P.K., \& Shu, S. (2000). What good schools can do about bullying: Findings from a survey in English schools after a decade of research and action. Childhood, 7, 193-212. 
Snijders, T. A. B, \& Bosker, R. J. (1999). Multilevel analysis: An introduction to basic and advanced multilevel modeling. London, UK: Sage Publications.

Solberg, M. E., \& Olweus, D. (2003). Prevalence estimation of school bullying with the Olweus Bully/Victim Questionnaire. Aggressive Behavior, 29, 239-268.

South, C. R. \& Wood J. (2006). Bullying in prisons: The importance of perceived social status, prisonization, and moral disengagement. Aggressive Behavior, 32, 490-501. doi:10.1002/ab.20149

Statistics Canada. (2006). Ethnocultural portrait of Canada. Retrieved from http://www12.statcan.ca/

Sticks, stones and bullies. (2005, March). CBC News Online. Retrieved from http://www.cbc.ca/news/background/bullying/

Swearer, S. M., \& Doll, B. (2001). Bullying in schools: An ecological framework. Journal of Emotional Abuse, 2, 7-23.

Swearer, S.M., Collins, A., Radcliff, K H., \& Wang, C. (2011). Internalizing problems in students involved in bullying an victimization. In D. L. Espelage \& S. M. Swearer (Eds.), Bullying in North American schools ( $2^{\text {nd }}$ ed., pp. 45-61). New York, NY: Routledge.

Swearer, S. M., \& Espelage, D. L. (2004). Introduction: A social-ecological framework of bullying among youth. In S. M. Swearer \& D. L. Espelage (Eds.), Bullying in American schools: A social-ecological perspective on prevention and intervention (pp. 1-14). Mahwah, NJ: Lawrence Erlbaum Associates.

Swearer, S. M., \& Espelage, D. L. (2011). Expanding the social-ecological framework of 
bullying among youth: Lessons learned from the past and directions for the future. In $D$. L. Espelage \& S. M. Swearer (Eds.), Bullying in North American schools (2 ${ }^{\text {nd }}$ ed., pp. 310). New York, NY: Routledge.

Swearer, S. M., Espelage, D. L., Vaillancourt, T., \& Hymel, S. (2010). What can be done about school bullying? Linking research to educational practice. Educational Researcher, 39, 38-47. doi:10.3102/0013189X09357622

Swearer, S. M., Siebecker, A. B., Johnsen-Frerichs, J., \& Wang, C. (2010). Assessment of bullying/victimization: The problem of comparability across studies and across methodologies. In S. R. Jimerson, S. M. Swearer, \& D. L. Espelage (Eds.), Handbook of bullying in schools: An international perspective (pp. 305-329). New York, NY: Taylor \& Francis.

Tabachnick, B. G., \& Fidell, L. S. (2007). Using multivariate statistics ( $5^{\text {th }}$ ed.). Toronto, ON: Pearson Education.

Trach, J., Hymel, S., Waterhouse, T., \& Neale, K. (2010). Bystander responses to school bullying: A cross-sectional investigation of grade and sex differences. Canadian Journal of School Psychology, 25, 114-130. doi: 10.1177/0829573509357553

Twemlow, S. W., Fonagy, P., \& Sacco, F. C. (2010). The etiological cast to the role of the bystander in the social architecture of bullying and violence in schools and communities. In S. R. Jimerson, S. M. Swearer, \& D. L. Espelage (Eds.), Handbook of bullying in schools: An international perspective (pp. 73-86). New York, NY: Taylor \& Francis.

Vaillancourt, T., Brittain, H., Bennett, L., Arnocky, S., McDougall, P., Hymel, S., . . Cunningham, L. (2010). Places to avoid: Population-based study of student reports of 
unsafe and high bullying areas at school. Canadian Journal of School Psychology, 25, 40-54. doi: $10.1177 / 0829573509358686$

Vaillancourt, T., Hymel, S., \& McDougall, P. (2003). Bullying is power: Implications for school-based intervention strategies. Journal of Applied School Psychology, 19, 157176.

Vaillancourt, T., McDougall, P., Hymel, S., Krygsman, A., Miller, J., Stiver, K., \& Davis, C. (2008). Bullying: Are researchers and children/youth talking about the same thing? International Journal of Behavioral Development, 32, 486-495. doi:

\section{$10.1177 / 0165025408095553$}

Vaillancourt, T., McDougall, P., Hymel., S., \& Sunderani, S. (2010). Respect or fear? The relationship between power and bullying behavior. In S. R. Jimerson, S. M. Swearer, \& D. L. Espelage (Eds.), Handbook of bullying in schools: An international perspective (pp. 211-222). New York, NY: Taylor \& Francis.

Vaillancourt, T., Trinh, V., McDougall, P., Duku, E., Cunningham, L., Cunningham, C., . . \& \& Short, K. (2010). Optimizing population screening of bullying in school-aged children. Journal of School Violence, 9, 233-250. doi:10.1080/15388220.2010.483182

van der Wal, M. F., de Wit, C. A. M., \& Hirasing, R. A. (2003). Psychosocial health among young victims and offenders of direct and indirect bullying. Pediatrics, 111, 1312-1317. doi: $10.1542 /$ peds.1111.6.1312

Varjas, K., Henrich, C. C., \& Meyers, J. (2009). Urban middle school student's perceptions of bullying, cyberbullying and school safety. Journal of School Violence, 8 , 159-176. doi: $10.1080 / 15388220802074165$

Wang, J., Iannotti, R. J., \& Nansel, T. R. (2009). School bullying among adolescents in 
the United States: Physical, verbal, relational and cyber. Journal of Adolescent Health, $45,368-375$.

Werner, N. E., \& Nixon, C. L. (2005). Normative beliefs and relational aggression: An investigation of the cognitive bases of adolescent aggressive behavior. Journal of Youth and Adolescence, 34, 229-243. doi:10.1007/s10964-005-4306-3 


\section{HWDSB Safe Schools Survey}

\section{Create Your Unique Identifier:}

Note: The first 10 questions, with the exception of number 8 , are required.

What colour are your eyes?

$\underset{\bigcirc}{\text { brown blue }} \underset{\bigcirc}{\operatorname{green}} \underset{\bigcirc}{\text { other }}$

What is the first letter of your first name? For example, if your name is Sara, the first letter of your name is $\mathbf{S}$.

\section{A B C D EF G H I JKL M NOPQR ST U VWXYZ \\ OOOOOOO0O0 0000000000000000}

In which month were you born?
January Fe
December
0
o
March Apri

\section{pril May}

What is the first letter of your mother's first name? For example, if your mother's name is Sandra, then you would select S. If you don't have a mother, think of the adult in your life who is most like a parent to you (father, aunt, grandmother).

\section{ABCDEF G H I JKL MNOPQRSTUVWXYZ OOOOOOOOOO 0000000000000000}

Are you:

$$
\underset{0}{\text { female male }}
$$

What is the last letter of your last name? For example, if your last name is Jones, the last letter is $\mathbf{S}$.

\section{ABCDEF G H I J L M NOPQR STUVWXYZ 00000000000000000000000000}

What is the last digit in the day of the month that you were born? For example, if you were born on the 15th day of the month, it would be 5 . If you were born on the $21 \mathrm{st}$, it would be 1. 


\section{Student Information}

Remember, all responses to this questionnaire are anonymous. But we do want to know something about the students who complete this survey, so please answer the following questions.

A. What school do you go to?

(Click here to choose)

What grade are you in?

\section{2 \\ 000}

How old are you?

\section{$8910111213+$ 000000}

People sometimes think about themselves in terms of race or the colour of their skin. If you feel comfortable identifying yourself in this way it may help us to find out if this is one of the reasons students are bullied. You do not have to answer this question if you do not wish to do so. (Check more than one if appropriate.)

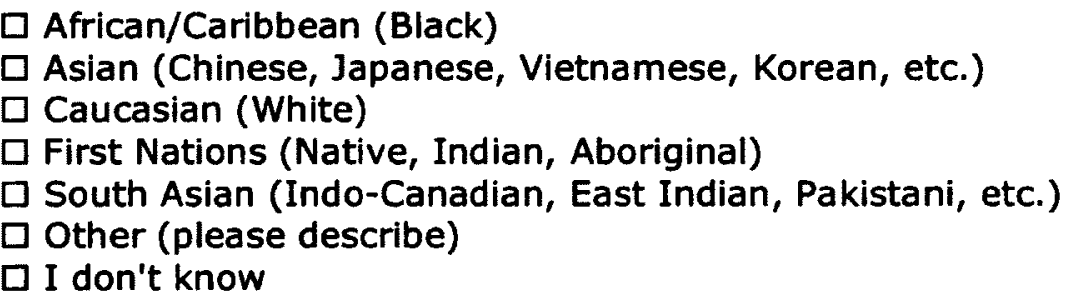

\section{Safe School Questions}

1. During the past 3 months, I have felt safe at this school.

O All of the time $O$ Most of the time $O$ Some of the time $O$ Rarely $O$ Never

2. If you have felt unsafe, please indicate particular places/times during the past 3 months, where you have felt unsafe at this school.
Classroom
$\square$ Lunchroom/cafeteria
$\square$ Washroom
$\square$ Change room
$\square$ Hallway
$\square$ On my way home from school
$\square$ On my way to school
During class 


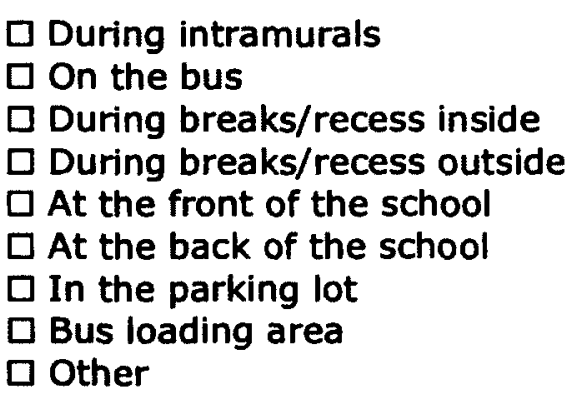

Bullying

Bullying Definition: We say a student is being bullied when another student, or a group of students say nasty and unpleasant things to him or her. It is also bullying when a student is hit, kicked, threatened, locked inside a room, sent nasty notes, when people don't talk to him or her and things like that. These things may take place frequently and it is difficult for the student being bullied to defend him/herself. It is also bullying when a student is teased repeatedly in a negative way.

But it is not bullying when two students of about the same strength quarrel or fight.

\section{Using the definition above please answer the following questions.}

3. How often have you been bullied at this school in the last 3 months?

O Never (It has not happened in the past 3 months)

O A few times (It has happened only a few times in the past 3 months)

$O$ Once in a while (It happened once in a while in the past 3 months)

O Once a week (It happened about once a week in the past 3 months)

O Several times a week (It happened several times a week in the past 3 months)

4. How often have you been bullied at this school by being left out and you end up being alone at recess or lunch in the past 3 months?

O Never (It has not happened in the past 3 months)

O A few times (It has happened only a few times in the past 3 months)

$O$ Once in a while (It happened once in a while in the past 3 months)

O Once a week (It happened about once a week in the past 3 months)

o Several times a week (It happened several times a week in the past 3 months)

5. How often have you bullied other students at this school in the past 3 months?

O Never (It has not happened in the past 3 months)

O A few times (It has happened only a few times in the past 3 months)

O Once in a while (It happened once in a while in the past 3 months)

O Once a week (It happened about once a week in the past 3 months)

O Several times a week (It happened several times a week in the past 3 months)

Bullying Examples: Because bullying takes many forms we are also interested in knowing about your perceptions of how often these different types of bullying occur in your school.

Physical bullying: When someone hits, shoves, kicks, spits, or beats up on others 
Verbal bullying: Name-calling, mocking, hurtful teasing, threatening, etc.

Social bullying: Excluding others from the group, gossiping or spreading rumours about others, setting others up to look foolish, making sure others don't associate with the person

Computer bullying: Using the computer or e-mail messages or pictures to hurt someone's feeling, make someone feel bad, threaten someone, etc.

\section{At school, how often have other studento...}

6A. Physically bullied you? Examples: hit, klcked, pushed, slapped, spat on or otherw/se physically hort you)

ONot at all in the past three months

Oonce only in the past 3 months

OA few times in the past 3 months

OEvery week in the past 3 months

OMany times a week in the past 3 months

6B. Verbally bullied you? Examples: sald mean things to you, teased you, called you names, verbally

threatened you

O Not at all in the past three months

O Once only in the past 3 months

O A few times in the past 3 months

O Every week in the past 3 months

O Many times a week in the past 3 months

6C. Soclally bullled you? Examples, Excluded others from your group, gossiped, spread rumours, or made others look foollsh etc.

O Not at all in the past three months

O Once only in the past 3 months

0 A few times in the past 3 months.

O Every week in the past 3 months

o Many times a week in the past 3 months

60. Bullied you on the computer? Examples: used computer or emall messages or pictures to threaten you or make you look bad

O Not at all in the past three months

O Once only in the past 3 months

$O$ A few times In the past 3 months

$O$ Every week in the past 3 months

O Many times a week in the past 3 months

At school, how often have you taken part in....

A) Physically bullying others? Examples: hitting, kicking, pushing, slapping, spitting on or otherwise physically hurt others

$O$ Not at all in the past three months 
$O$ Once only In the past 3 months

$O$ A few times in the past 3 months

$O$ Every week in the past 3 months

o Many times a week in the past 3 months

B) Verbally bullying others? Examples; saying mean things to others, teasing others, calling others nomes, verbally threatening others

O Not at all in the past three months

O Oricesonly in the past 3 months

O A few times in the past 3 months

O Even week in the past 3 months

0 Many times a week in the past 3 months

C) Socially bullying others? Examples: leaving others out of the group on purpose, refusing to plor hang

out) inth others, saying bad things behind the backs of others (gossiping), getting other

students to not llke someone.

O Not at all in the past three months

$O$ Once only in the past 3 months

O A few times in the past 3 months

O Every week in the past 3 months

0 Many times a week in the past 3 months

D) Bullying others on the computer? Examples: using the computer or email messages or pictures to.

threaten others or make them look bad

O Not at all in the past three months

O Once only in the past 3 months

O A few times in the past 3 months

0 Every week in the past 3 months

- Many times a week in the past 3 months

\section{At school, how often have you seen other students...}

7A physlcally bully others? Examples: hit, klck, push, slap, spit on or otherwise physlcally hurt others

0 Not at all in the past three months

O Once only in the past 3 months.

O A few times in the past 3 months

O Every week in the past 3 months

O Many times a week in the past 3 months

7B. Verbally bully others? Examples: say mean things to others, tease others, call others names, verbally threaten others

O Not at all in the past three months

$O$ Once only in the past 3 months

O A few times in the past 3 months

O Every week in the past 3 months

O Many times a week in the past 3 months 
7C. Socially bully others? Examples: leave others out on purpose, refuse to play (or hang out) with others, say bad things behind the backs of others (gossiping), get other students to not like someone

O Not at all in the past three months

o Once only in the past 3 months

0 A few times in the past 3 months

o Every week in the past 3 months

o Many times a week in the past 3 months

70. Bully others on the computer? Examples, use the computer or emall messages or pletures to threaten atfers or make them look bad

O Not at all in the past three months

O Once only in the past 3 months.

OA fow times in the past 3 months

o Every week in the past 3 months

o Many times a week in the past 3 months

8. Where/when does bullying happen most at this school?

$\square$ Gym

$\square$ Playground

$\square$ Classrooms

$\square$ Lunchroom/cafeteria

$\square$ Hallways

$\square$ Change rooms

$\square$ Washrooms

$\square$ On the way to school

$\square$ On the way home from school

$\square$ During class

$\square$ During intramurals

$\square$ During breaks/recess outside

$\square$ During breaks/recess inside

$\square$ At the front of the school

$\square$ At the back of the school

$\square$ In the parking lot

$\square$ Bus loading area

$\square$ Coatroom/cubbies

$\square$ On the school bus

$\square$ Other places (please describe where):

9. If you have been bullied, whom did you tell?

$O$ I have not been bullied

O No one

O Principal/Vice-Principal

O Teacher

O Parent

O Friend

O Bus Driver

O Relative (brother, sister, cousin, etc.)

O Other

10. What happened when you told?

O I wasn't bullied 
O I was bullied but never told anyone

$O$ Told and things got worse

$O$ Told and nothing changed

$O$ Told and things got better

Note: Although the following questions are optional, we encourage you to take the time to complete them. It will provide further information to assist your school.

11. How often has your mother or father talked with you about bullying?

O Never 0 Sometimes o often O Very often

12. How often do teachers try to put a stop to it when a student is being bullied at this school?

O Never O Sometimes O Often O Very often

13. How often does the Principal/Vice-Principal try to put a stop to it when a student is being bullied at this school?

0 Never $O$ Sometimes $O$ Often $O$ Very often

14. How often do students try to put a stop to it when a student is being bullied at this school?

O Never 0 Sometimes 0 Often $O$ Very often

15. How often can you find an adult at this school when you need help?

0 Never 0 Sometimes 0 Often 0 Very often

16. How often do you think teachers in this school talk with students in class about bullying?

0 Never 0 Sometimes 0 Often 0 Very often

17. How often do you think teachers in this school talk to students about being a bystander (witness) to bullying?

O Never $O$ Sometimes $O$ Often $O$ Very often

18. How often do students in this school use peer mediation to solve problems?

O Never $O$ Sometimes $O$ Often $O$ Very often

19. How often do teachers address conflict resolution during lessons in this school?

O Never O Sometimes O Often O Very often 
20. It is akay to call some students nasty names.

O I Stróngly Agree O I Agree O I Disagree O I Strongly Disagree

21. Students who get picked on a lot usually deserve it.

0 I Strongly Agree O I Agree O I Disagree O I Strongly Disagree

22. Students who are bullied feel sad about it.

O I Strongly Agree O I Agree 0 I Disagree O I Strongly Disagree

23. It is okay to foin in when someone you don't like is being bullied.

O I Strongly Agree O I Agree O I Disagree O I Strongly Disagree

24. Bullying is just a normal part of being a student.

O I Strongly Agree O I Agree O I Disagree O I Strongly Disagree

25. Getting bullied helps to make students tougher.

O I Strongly Agree O I Agree O I Disagree O I Strongly Disagree

26. It is my responsibility to do something to help when I see bullying.

o I Strongly Agree 0 I Agree 0 I Disagree 0 I Strongly Disagree

27. In my group of friends, bullying is okay.

O I Strongly Agree O I Agree O I Disagree O I Strongly Disagree

28. Students who join in bullying are as bad as the bully.

O I Strongly Agree O I Agree 0 I Disagree O I Strongly Disagree

29. I'm upset when another student is being bullied.

O I Strongly Agree O I Agree O I Disagree O I Strongly Disagree

30. If you're angry with someone, it's okay to keep them out of your group of friends.

O I Strongly Agree O I Agree O I Disagree O I Strongly Disagree

31. It is best to avoid repeating stories about others, if you don't know what is true.

O I Strongly Agree O I Agree O I Disagree O I Strongly Disagree

32. It is okay to like students who get bullied.

O I Strongly Agree O I Agree O I Disagree O I Strongly Disagree 
33. Students who get bullied are Just as good as other students.

$$
\text { O I Strongly Agree } O \text { I Agree } O \text { I Disagree O I Strongly Disagree }
$$

34. Students should be punished for teasing.

$$
\text { O I Strongly Agree O I Agree O I Disagree O I Strongly Disagree }
$$

